\title{
A STUDY OF THE JAPANESE TRANSLATION \\ OF
}

HUCKLEBERRY F INN

A Thesis

Presented to

the Faculty of the Graduate School

University of Missouri

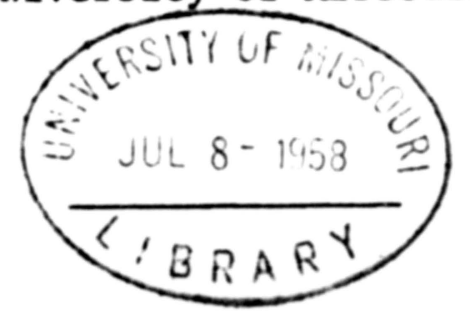

In Partial Fulfillment

of the Requirements for the Degree

Master of Arts

by

Shozo Nakada

June 1958 
The undersigned, appointed by the Dean of the Graduate Faculty, have examined a thesis entitled

A STUDY OF THE JAPANESE TRANSLATION

OF

HUCKLEBERRY F INN

presented by Shozo Nakada

a candidate for the degree of Master of Arts

and hereby certify that in their opinion it is worthy of acceptance.

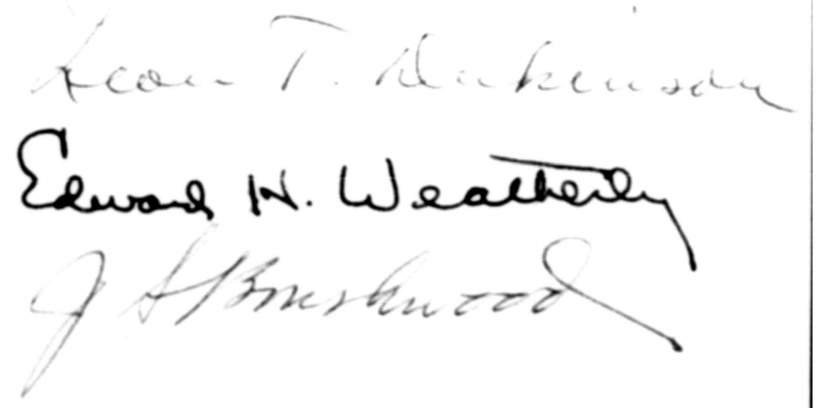




\section{ACKNOWLEDGMENT}

I wish to express my sincere appreciation to Dr. Leon T. Dickinson, my adviser, for his patience and guidance in the preparation of this thesis, and to Dr. Edward H. Weatherly for his suggestions and corrections in the manuscript. Also, I wish to express my sincere gratitude to the Japanese National Diet Library and Professor Masajiro Hamada of Kobe University, for their assistance in providing the Japanese bioliography of Mark Twain.

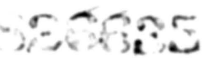




\section{TABLE OF CONTENTS}

CHAPTER

PAGE

INTRODUCTION..$\cdot$. . . . . . . . . . . . . iv

I. THEORY OF TRANSLATION . . . . . . . . . . . 1

II. LANGUAGE . . . . . . . . . . . . . . 26

III. SENTENCES . . . . . . . . . . . . . . 80

IV. STYLE AS INTERPRETATION . • . . . . . . . 112

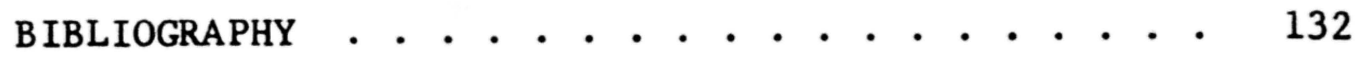

APPENDIX . . . . . . . . . . . . . . . . . 142 


\section{INTRODUCT ION}

\section{Mark Twain in Japan}

With the opening of the country to the Western world in 1867, Japan experienced a sudden breakdown of its long Medieval period and the birth of a new age. A rapidly expanding knowledge of the Western World and an enthusiasm for Western culture led the whole country to an intellectual revival and modernization, and thus developed a new course in world culture. In the field of literature, as one of the movements of the intellectual revival, European literature was immediately introduced to the country and encouraged the creation of new forms of poetry, novel, drama, and literary criticism in Japan. Especially the influence of English, French, German, and Russian literature at that time was so great in every genre of Japanese literature that modern Japanese literature owes its establishment to European literature much more than to traditional Japanese literature.

Although the works of such European writers as Wordsworth, Shakespeare, Baudelaire, Verlaine, Maeterlinck, Flaubert, Zola, Ibsen, Schiller, Goethe, Dostoievsky, Tolstoy, and Turgenev, were introduced into Japan by translators in 1880s, 1890s, and early 1900s, the introduction of American literature was very gradual. 
Poe, Irving, Longfellow, Hawthorne, Thoreau, Whitman and others of the older school of American literature were introduced to Japan as a part of English literature, but the substantial importation of American literature had to wait until the end of World War II.

Mark Twain in his lifetime had visited many foreign countries, but had never made a trip to Asia. As with other American authors, it was a long time before he became well known in Japan. Ten Humorous Stories, a collection of Mark Twain's short stories, appeared for the first time in Japan in 1916. It was edited and translated by Kuni Sasaki, and contained The Jumping Frog, The Esquimau Maiden's Romance, The Stolen White Elephant, and others. In 1919 The Adventures of Tom Sawyer was translated into Japanese, and The Adventures of Huckleberry Finn (abridged) in 1921. The complete translation of Huckleberry Finn appeared in 1936. Besides these titles, seven other translations of Mark Twain's works appeared before World War II: The Prince and the Pauper in 1927, Pudd'nhead Wilson in 1929, and twentyseven other short stories in several translations. A few scholarly articles and books were also published: Mark Twain, a biography, by Eizo Ohashi in 1936; "Mark Twain's Conception of Social Justice," in 1936; "Mark Twain's Literature and His National Character," in 1936; and 
"A Short History of Criticism of Mark Twain," in 1942, by Masajiro Hamada. Above all, one of the greatest contributions to the study of Mark Twain in Japan was the publication of Huckleberry Finn by Eizo Ohashi as one of the Kenkyusha English Classics in 1935. Edited with introduction and notes primarily for the students of English in Japan, this text has become the standard Japanese edition of Huckleberry Finn in English.

The real recognition of Mark Twain's works, however, began in Japan after the end of World War II. A closer relationship and understanding between Japan and the United States after the end of the war has promoted a new cultural exchange between the countries. In order to meet the needs of a rapidly increasing reading public for American literature, Japan has produced a vast amount of translation of American literature covering nearly all the well-known authors in the nineteenth and twentieth centuries. The fame of Mark Twain as the first real American writer of democracy and as the best American humorist has risen higher than that of any other American writer, and his reading public in Japan has come to embrace both children and adults.

The number of translations of Mark Twain and scholarly works about him has increased four or five times during the last ten years: between 1946 and 1956 there 
appeared about twenty-two new translations, twenty-eight translations for children's books, and about twelve scholarly publications. New translations included Life on the Mississippi, Tom Sawyer Abroad, Tom Sawyer Detective, A Connecticut Yankee in King Arthur's Court, The Innocents Abroad, and several collections of Mark Twain's short stories. Huckleberry Finn, Tom Sawyer, and The Prince and the Pauper have been translated and published many times. The only children's books are abridged translations of Huckleberry Finn, Tom Sawyer, and The Prince and the Pauper.

Not only the number of translations of Mark Twain's works but also the large sale of his books in Japan prove his great popularity there. According to the information from the Iwanami Shoten Publisher in 1956, The Prince and the Pauper, one of the Iwanami Library editions, was at that time the twenty-third printing since the first printing in 1934, and had sold a little over one hundred thousand copies. Huckleberry Finn, another Iwanami Library edition in two volumes, was the tenth printing and had sold about forty-eight thousand copies since 1941. The Innocents Abroad, one of the Iwanami Library in three volumes, was published in 1951, and reached the third printing in 1956; and Huckleberry Finn, one of the children's editions published by Kodansha in 1952, had its 
eighth printing in 1956. Such extensive publication and sale suggest how much Mark Twain's works are loved by the Japanese people.

This is also true with the scholarly publications about Mark Twain. At every college and university, the standard Japanese edition of Huckleberry Finn, one of the Kenkyusha English Classics, is used for an English textbook and is studied in the English Department. Since the end of World War II, at least one or two scholarly articles and theses have been written every year, and further development of the study of Mark Twain is expected.

\section{Purpose of This Study}

The purpose of this investigation is to make an exploratory study of certain phases of a Japanese translation of Huckleberry Finn, in order (1) to find the method used in the translation; (2) to determine the qualities of the language in the translation; (3) to determine the stylistic qualities of the sentences; (4) and to form an evaluation of the Japanese translation by considering its context from the point of view of style.

A study of this type is important primarily because the information thus derived can make a definite contribution to an understanding of the quality of Japanese 
translations of Huckleberry Finn. There have been many Japanese translations of Mark Twain's works since 1916, but none of them has ever been introduced to the United States. Although it is a hasty judgment to apply the result of this study to other Japanese translations of Mark Twain's works, the study of the translation of Huckleberry Finn as Mark Twain's most representative work in the original can do much to lead to a better understanding and appreciation of the quality of the Japanese translations.

This evaluation of the quality of the translation, however, is not the sole purpose of the study. This study will also show the differences of language between English and Japanese and hence the difficulties involved in the translation. The language and style of Huckleberry Finn are so peculiar that the reproduction into Japanese is extremely difficult. This study, therefore, deals with the language and style in the original and in the translation. Conceivably it may help improve the quality and method of Japanese translation in the future.

\section{Organization of Chapters}

An exhaustive study of all the elements of the translation is not the purpose of this investigation. Three subjects are selected for detailed study: the 
language, the stylistic qualities of the sentences, and the style as interpretation. Since this is the study of a translation, the general theory of translation is discussed briefly at the beginning. The main body of the investigation is divided into four parts: Chapter I will deal with a study of the theory of translation; Chapter II, with language; Chapter III, with the stylistic qualities of the sentences; and Chapter IV, with style as interpretation.

4. Materials Used and Methods of Procedure

Materials used. Since Huckleberry Finn is the most successful and representative of all Mark Twain's works, the translation of Huckleberry Finn was chosen for the present study. There are three different translations of Huckleberry Finn in Japan. Two of them, however, are abridged translations; the only complete translation is at the present The Adventures of Huckleberry Finn, translated by Tameji Nakamura and published in two volumes in 1936 by Iwanami Shoten, the biggest and the most reputable publishing company in Japan. Mr. Nakamura was graduated from Tokyo (Imperial) University in 1924, and had been formerly a professor of English at Kansai Gakuin University and Tokyo University of Commerce before his retirement. The text used in this study is No. 2644 
and 2645 of the Iwanami Library edition, and the tenth printing of Volume $I$, and the eighth printing of Volume II. The English text used for this study is the Authorized Edition of Huckleberry Finn published by Harper \& Brothers in 1912 .

Methods of procedure. An exploratory study of any Japanese translation of an English work is hitherto unprecedented both in Japan and in the United States. Therefore, it was necessary to devise some new method to divide the materials into units that could be most useful for the study. They are divided into two groups: language and style. In the study of the qualities of language the materials are subdivided into twelve parts: (1) nouns;
(2) verbs;
(3) adjectives;
(4) adverbs;
(5) idiomatic

phrases; (6) peculiarities of spelling, inflection, and grammar; (7) interjections and expletives; (8) figures of speech; (9) river and nautical terms; (10) names of American political and social institutions; (11) names of American dwellings and landscapes; and (12) proper nouns. In the study of language, since the characteristic quality of the original language is informal and colloquial rather than formal and standard, more emphasis is put on informal, colloquial language, and most examples are taken from it. In the study of style the materials are divided into 
the stylistic qualities of the sentence and style as interpretation. The stylistic qualities of the sentence are subdivided into the length of the sentence, the sentence structure, and rhythm. Style as interpretation mainly deals with the interpretation of characters in the translation.

The method used for the present study is comparison. The qualities of the original and of the translation are constantly compared one with another. Although it was essential for this study to use both Japanese and English, the use of the original Japanese of the translation would have been meaningless to English readers. Therefore, the Japanese translation is retranslated into English, in spite of the fact that retranslation cannot exactly reproduce the quality of the original translation. In attempting retranslation, the reproduction of the Japanese translation in English was done as faithfully as possible, and many explanations are given to each Japanese word under discussion. At the end of this thesis, an appendix is supplied, in which more examples are taken from the translation and from the original. In the appendix, for the benefit of possible Japanese readers, the Japanese of the translation is used in footnotes. 
CHAPTER I

\section{THEORY OF TRANSLATION}

\section{Culture and Translation}

In the formation of man's personality three factors are considered the most significant elements: original nature, or individual capacity; social and cultural environment; and personal experience. The second, the social and cultural environmens, however, seems to play the most important role in a man's life. As for the first, an individual capacity could never be fully realized without the aid of social and cultural environment, and the third, the personal experience, is also limited within a particular social and cultural environment. The moment when the human infant is born with original capacity and with potentialities of growth, he becomes a member of a society. Beginning with the family group at first, moving out into the neighborhood, and finally into the community, his mode of thinking and his original capacity are constantly influenced by other people, by his particular social and cultural environment, and by the age he lives in. And through these countless directing influences from outside, his original capacity will be developed and his personality formed within the limitations of his social 
and cultural environment.

So it is with the cultural development of a nation. The culture of a nation can never stand alone, nor advance by itself, but on its cultural heritage in the past, and on the influences from diverse cultures of its neighboring nations. The significance of the diffusion of various cultures among nations is realized in the fact that new ideas and practices are often borrowed rather than invented by the members of any one nation, and that the exchange is the main source of cultural development. The historian Niebuhr asserted that "no single examples can be brought forward of an actually savage people having independently become civilized."1 Therefore, only through the encouragement of a reciprocal influence of peoples upon one another, and at the same time through the maintenance of their cultural heritage in the past, can there be hope for the cultural progress of a nation in the future.

In the exchange of human thought from one country to the other, translators, who hold the key of language, provide the transportation. The work of translation has the utmost significance for an understanding of humanity and for dispelling international misunderstandings and distrust. Moreover, translators are partially responsible

$1_{W}$. D. Babington, Fallacies of Race Theories (London, 1895), p. 172 . 
for the cultural advancement of a nation by introducing thoughts of other nations, and thus influencing the cultural trend of a nation.

For example, one is very certain that if the Greek manuscripts in the library at Alexandria had not been translated into Arabic and preserved in translations when the originals were destroyed by fire, the whole development of European thought could have been quite different. The European Renaissance, that great revival of art, literature, and learning in Europe in the Fourteenth, Fifteenth, and Sixteenth centuries, originated in the rediscovery of ancient Greek and Roman manuscripts, which scholars proceeded to translate into modern languages. Since the opening of Japan to the Western World in 1868, an enormous number of European books have been introduced by translators, and as a result the country has suddenly begun to experience the most extraordinary cultural revival in its history.

Especially in the field of literature is cultural interaction important. Literary art must rely upon reciprocal influence, if it is to remain alive. Each country constantly offers to others new ideas and new materials to work with, and gives a new inspiration to others. Since literary art depends ultimately on a writer's use of words, most readers of books in unfamiliar 
languages must rely on translators. The role of the translator, therefore, however humble it may be, is significant for the development of literature.

\section{Theory of Literature}

"There is no department of literature," said Sir Alexander Fraser Tytler in 1790, "which has been less the object of cultivation than the Art of Translation. "2 Tytler's words could still be repeated at the present time with respect to the theory of translation. ${ }^{3}$ Today, with so many imperfect translations being published, it seems doubtful whether translations can be accepted without challenge. Konrad F. Bieber, on his examination of the English translation of Albert Camus' The Rebel, expresses his pessimistic view on the abuses made by a translator:

The message of this significant book rCamus' The Rebely is actually betrayed by an outrageously bad translation. The shamefully poor English version exposes Camus to the suspicion of ignorance in history and sociology; of a complete lack of common sense; and moreover of being arrogant and

2 Alexander Fraser Tytler, Essays on the Principles of Translation (London, 1790), pp. 1-2.

3 Protasio Maymi, "General Concepts or Laws in Translation," Modern Language Journal, XL (Jan. 1956), 13. "Most contemporary translators take their art for granted and seem to disregard the laying down of specific rules or explaining the techniques followed by them in their work. There is still the same need, as pointed out by Tytler, for unfolding of the laws and principles of translation." 
cynical . . The Rebel is neither the first nor certainly the last good book to suffer such a treatment at the hand of an incapable translator -. . The English-speaking world is missing a good deal by being cheated through a shameful mutilation of thought which must be denounced. 4

The advancement of literary art has been always hastened by translations from foreign literatures; and because of modern highly developed mass communication, the demand is much more strongly felt today than ever before. But because the work of translation has been considered subordinate to creative work, the study of the theory of translation has been less emphasized than any other field of literature. As a result, a complete theory of translation has not yet been formulated, and the practice has not been satisfactorily attained. 5 Although the problems of each translator vary with the character of his original, the further development of the theory and methods of translation should be strongly urged to comply with the present necessity and demands of translation.

Theoretically, translation of literary art is simply impossible. Language is the basic material of the

${ }^{4}$ Konrad F. Bieber, "The Translator--Friend or Foe?" French Review, XXVIII (May, 1955), 493-497.

5 Flora Ross Amos, Early Theories of Translation (New York, 1920), p. xi. "Yoreover, the re has never been uniformity of opinions with regard to the aims and methods of translation." 
literary artist, and every literary work is a selection of words from a given language. A word, however, is not simply an arbitrary symbol for some object or idea.

Beside the conventional meaning fixed by common usage on the part of the community, a word has its sounds when spoken, and the connotations that have clustered around it through social, historical, and literary influences in the course of its history. When a word is spoken, it directly evokes an image in terms of verbal symbol, and it creates the object inseparable from the word used, thus heightening its meaning. A word, therefore, can never be represented exactly by an "equivalent" word, either in the same language or in another one. "No two words are precise equivalents," says a famous translator, Benjamin Jowett, "just as no two leaves of the forest are exactly similar."

In the translation of poetry the difficulty of translation has been generally accepted. "The basic assumptions of modern criticism make it clear," says William Frost in his recently published book, "that, on "a priori grounds, the translation of poetry is a theoretical impossibility. "6 In poetry every word is so

6william Frost, Dryden and Art of Translation (New Haven, 1955), p.'9. 
carefully and exactly selected and arranged in a limited space that it is impossible to be replaced by any other word. It has its exact connotation and sound, and in its arrangement with other words it forms numbers and measures, rhymes, and the varied harmony of the measure. A translation of poetry is not a translation of one language into another, but a translation of poetry into poetry in which all the poetic qualities of the original are preserved. Literary prose, though not the same as poetry in the arrangement and selection of words, is not simply a written or spoken language. An artistic literary prose has its own rhythms and verbal symbols; each word is carefully selected and cannot properly be replaced with another. The prose of certain passages in the English Bible, in De Quincey and Ruskin, in Emerson and in Melville, carries rhythm and sometimes melody, while forcing themselves even on the unattentive reader. Such prose has given way today to a more simple colloquial diction, but the literary prose written in a colloquial diction often has various devices of rhythm, sound, and verbal symbol. Both in poetry and prose, therefore, every word is so carefully and exactly selected and arranged that the reproduction of its exact quality in another word and in another language is theoretically impossible.

Whatever the theoretical impossibility of the exact 
translation of literary work may be, translations do and will appear. It is to be hoped that the further study of the art of translation will make the aims and methods of translation much more orderly and clear so that a literary work may be reproduced in another language with more accuracy.

The purpose of translation is to reproduce the original work in another language as faithfully and accurately as possible. It should reproduce the ideas, and the style or manner, of the original in an accurate, exact manner in another language; it should also produce the same effect on readers that the original work produced on readers of the original language. Alexander Fraser Tytler describes a good translation to be "that in which the merit of the original work is so completely transfused into another language, as to be as distinctly apprehended, and as strongly felt, by a native of the country to which that language belongs, as it is by those who speak the language of the original work." 7

Consequently translations must be faithful to the original work. The words faithful, accurate, exact, and true to the original are very obscure terms, and could be interpreted in many different ways. According to each

$$
\text { 7ytler, pp. 8-9. }
$$


different interpretation of these terms, the methods of translation will vary from one extreme to the other. Flora Ross Amos summarized it as follows:

Again, critics have been hesitant in defining the all-important term "faithfulness." To one writer fidelity may imply a reproduction of his original as nearly as possible word for word and line for line; to another it may mean an attempt to carry over into English the spirit of original, at the sacrifice, where necessary, not only of the exact but of the exact substance of his source. The one extreme is likely to result in an awkward, more or less unintelligible version; the other, as illustrated, for example by Pope's Homer, may give us a work 80 modified by the personality of the translator or by the prevalling taste of his time as to be almost a new creation.8

The differences in interpreting the term faithful may be said to result in three different methods of translation: (1) literal translation, or word-for-word, line-for-line translation; (2) idiomatic translation, according to the idiom peculiar to the language of translators; and (3) paraphrastical translation, in which translators restate the sense of the original in their own thoughts and words.

\section{Literal translation. Literal translation follows} the language patterns of the original work word for word. This theory of translation is based on the assumptions that the languages of both the original and the

$$
{ }^{8} \text { Amos, p. xil. }
$$


translation have exactly the same quality, and that for every word in the original language an equivalent word can be found in the other. Those translators who practice literalness seek to reproduce mere words, phrases, and sentences, simply by replacing each word of the original with the equivalent words according to dictionary meanings. Since a word has its own sound and connotation which expresses more than its conventional meaning, and since each language has its own peculiar idiomatic expressions, it is simply impossible to convey the ideas and the style or manner of the original faithfully in another language. Style of literary language, for example, varies greatly according to each language. A short sentence structure may be an artistically good style in one language and not in another. Brevity of Latin could not be translated into English without sacrificing all the ease and spirit of the original. The Latin and Greek languages admit of inversions which are inconsistent with the nature of English. The method of literal translation, therefore, cannot well succeed in reproducing the meaniing and style of the originat.

Idiomatic Translation. Since each language has its own idiomatic expression and style, idiomatic translation seeks to add to or retrench the language of the 
original in order to conform to the nature of the language into which the translation is made. This method differs

from literal translation in its interpretation of the word faithful, for it seeks to be faithful not to individual words but to the thoughts and concept of the original. As early as the Ninth Century in English literature, King Alfred employed this method in his version of Pope Gregory's Pastoral Care, and his method is distinctly described in the Proem to The Consolations of Philosophy of Boethius: "King Alfred was the interpreter of this book, and turned it from book Latin into English, as it is now done. Now he set forth word by word, now sense from sense, as clearly and intelligently as he was able. 19

Idiomatic translation seems the most satisfactory method at the present. Under this method the translator is free to make additions and omissions of words, gramatical changes, and he tries to find the style equivalent to the original in translation. Under this method, moreover, the translator is willing to amplify or modify the thoughts and concepts of 'the original'. Hilaire Belloc advises translators to "transmute boldly; render

${ }^{9}$ King Alfred Version of the Consolations of Boethius, trans. Sedgefield (ox ford, 1899), p. 1 으 
the sense by corresponding sense without troubling over the verbal difficulty in your way. Where such rendering of sense by corresponding sense involves considerable amplification, do not hesitate to amplify for fear of being verbose." 10

This method of translation, however, has many actual problems. Since the problems of each translator vary with the character of his original, various concrete methods and theories of adaptation in each case must be found out. There would be problems, for example, of how the colloquial expressions of Don Quixote could best be expressed in English; of what kind of idiomatic phrases are best to express the meaning of Tolstoy's War and Peace; of how the language treating the peculiar customs of one country could be translated.

Another problem is that of the translator's subjectivity. In the process of translation a translator inevitably executes his judgment on adding to or deleting from the words and thoughts of the original. Furthermore, translators frequently are not scholars, and their judgment on difficult palsages is próbably not always trustworthy.

${ }^{10}$ Hilaire Belloc, On Translation (Oxford, 1931), p. 34 . 
Paraphrastical Translation. The third method, paraphrastical transiation, is that in which the ideas, and the style and manner, of the original work are completely restated by a translator in his own words and manner. It allows translators to express not only the idiomatic quality of the original, but the style and the thought of the original in their own thought and manner of writing. It is, in other words, a creation of a new literary work by imitation.

This kind of translation, however, contains 80 much of the sentiment and mode of expression of the translator, as well as the taste of his contemporaries, that it can hardly be regarded as a reproduction of an original. It is 80 modified that all sight of the original author is 108t, and those who are inquisitive to know the original author's thoughts will be disappointed. Re-creation of a work by imitating the original is the most advantageous way for a translator to show himself, but also it may do the greatest wrong to the reputation of the original author. Whether the translation of this kind is superior to the original work or not, it is certainly not a faithful reproduction of the original.

From the general survey of these three main methods of translation, the second, the idiomatic translation seems the most suitable method. Word-for-word translation 
can hardly reproduce the language and style of the original in another language without resulting in an awkward, clumsy product. Paraphrastical translation changes too much the quality of the original to be called a faithful reproduction of the original. Also, to succeed at all, this method should be limited to the few translators who have a creative ability equal to the original. The second method, as a result, has more advantages than the other two methods in reproducing the language and ideas of the original, while maintaining the original characteristics at the same time.

Lastly, the qualifications of a translator need to be discussed briefly. A translator should have a perfect knowledge of the language of the original and of the language into which the translation is made. Ideally he should have had some experience in that country where the language of the original is spoken, so that he may be able to understand not only the language but the connotation of each word, and to discern the characteristics of the language and style of the original. And since most translations are likely to be more successfully done from the language of the original into a translator's native language rather than from his native language. into a foreign language, he should have complete command of his native language. The most desirable thing is that a 
translator himself be a writer or a poet.

Another qualification for a translator is that he must have a competent knowledge of the subject of the original in order to convey the original idea faithfully. Any misunderstanding of the meanings of the original, from major themes to the smallest passages and words, could not be tolerated at all. A translator therefore is required to study the original work thoroughly and be able to interpret its major and minor themes correctly. He should become acquainted with the other works of the original author and with the society and ideas he tries to represent. These two requirements for a translator, both of the language and ideas of the original, are inevitable for attempting any work of translation.

\section{Japanese Language}

In the application of the theory of translation, the linguistic difference between languages is the greatest obstacle. Translations between languages within the same language family are easier than between languages from two utterly different language families. The English language belongs to the Teutonic (Germanic) branch of the IndoEuropean family, and in view of many gramatical, structural, and etymological similarities among English, French, German, and Spanish, translations among them are 
much more easily made than between English and Japanese. The Japanese language, like Basque, Manchu, the Papuan, Australian and Amerindian (e.g. Mexican and Greenlandic) vernaculars, is etymologically and structurally entirely unrelated to other languages and stands alone outside any recognized family.

The order of thought, therefore, and the order of words and meanings of words, are so different in Japanese and English that a direct literal translation from English into Japanese and vice versa is impossible. In making any translation, it is absolutely necessary first to understand clearly what idea is conveyed in one language, and then to rearrange its component thoughts for proper presentation in the other. Understanding and translating are, in other words, two different things, and the methods of translation thus applied depend solely upon either the idionatic translation or the paraphrastical translation.

While English, like any other Indo-European language group, has only one way of writing, Japanese has three different kinds of writing? Chinese characters, katalana, and hirakana. Although the structure of Japanese bears no resemblance to that of Chinese at all, with the introduction of Chinese culture into Japan in the Third Century, A.D., the Japanese borrowed a large number of Chinese words to express new ideas which came in with 
the Chinese culture. The Chinese vocabularies thus introduced to Japan, however, have undergone a tremendous change of meanings and connotations in Japan after over one thousand years, and they have become a part of distinct Japanese vocabularies.

Japanese also borrowed the Chinese system of writing, wherein each ideograph represents a monosyllable and expresses a distinct idea. As Chinese words do not have inflections and ideographs for transcribing Japanese particles for case and inflectional endings, Japanese adopted, for purpose of transcription of these particles, ideographs of corresponding sound without reference to the ideas inherent in the ideographs so employed. Two parallel systems of syllabic writing, katakana and hirakana, are derived from abbreviating these Chinese ideographs. While the ideographs represent subordinate particles, such as connectives, case endings, and inflections, the hirakana is very widely used in most writings, whereas the use of the katakana has recently been limited to the transcription of slang and interjections, the pronunciations of some ideographs, foreign words and names, telegrams, and to some formal publications like the Official Gazette.

The katakana and the hirakana have different alphabets made of forty-eight signs and pronounced the 
same in both case. These two different Alphabets are called Japanese Alphabets:

$\begin{array}{lllllllllll}\mathrm{A} & \mathrm{Ka} & \mathrm{Sa} & \mathrm{Ta} & \mathrm{Na} & \mathrm{Ha} & \mathrm{Ma} & \mathrm{Ya} & \mathrm{Ra} & \text { Wa } & \mathrm{N} \\ \mathrm{I} & \mathrm{Ki} & \mathrm{Shi} & \mathrm{Chi} & \mathrm{Ni} & \mathrm{Hi} & \mathrm{Mi} & \ldots & \mathrm{Ri} & \mathrm{I} & \\ \mathrm{U} & \mathrm{Ku} & \mathrm{Su} & \mathrm{Tsu} & \mathrm{Nu} & \mathrm{Fu} & \mathrm{Mu} & \mathrm{Yu} & \mathrm{Ru} & \ldots \\ \mathrm{E} & \mathrm{Ke} & \mathrm{Se} & \mathrm{Te} & \mathrm{Ne} & \mathrm{He} & \mathrm{Me} & \ldots & \mathrm{Re} & \mathrm{E} \\ 0 & \mathrm{Ko} & \mathrm{So} & \mathrm{To} & \mathrm{No} & \mathrm{Ho} & \mathrm{Mo} & \mathrm{Yo} & \mathrm{Ro} & 0\end{array}$

Consonants are:

K sounds Ga Gi Gu Ge Go

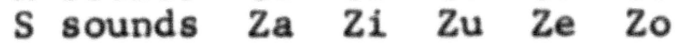

T sounds $\mathrm{Da} \mathrm{Ji} \mathrm{Zu}$ De Do

$\mathrm{H}$ sounds $\mathrm{Ba} \mathrm{Bi}$ Bu $\mathrm{Be}$ Bo

$\mathrm{Pa} \mathrm{Pi} P u$ Pe Po

At the present the basic Chinese characters (ideographs in Japanese) are limited to one thousand and a few hundreds; but through the device of combining two or more ideographs, the Japanese has a system of word building capable of indefinite expansion to meet the need of expressing new ideas. Thus by writing in combination the ideographs pronounced $j \underline{i}$ (self), do (move), and sha (vehicle), there was created the word jidōsha (automobile); by combining bun (letter) and gaku (learning), there was produced the word bungaku (literature).

In the case of words of European origin Japanese has modified them considerably to meet the limitations of Japanese alphabets, and also many have been abbreviated: apāto (apartment), depāto (department stores), bata (butter) kohi (coffee), bōto (boat), garasu (glass), etc.

As English has poetic diction and colloquial 
language, so Japanese has two very distinct languages: the written or literary language and the spoken language.

The written language is the language of classical

literature, which differs very considerably from the spoken language. Since the late Nineteenth Century, however, under the influence of universal education and the growing demands of the modern world for written communication, the written language has given ground to the more familiar everyday speech. Today the written language is used only in legal documents and diplomatic and some business communication, and the spoken language has taken over all the writings. The principal characteristic of the spoken language which distinguishes it from the written is a tendency to blend many inflectional endings of verbs with the stem of the verb, whereas in the written language the verb stem remains invariable.

Since the written language is abundant in rhythm and melody, and is full of poetic dictions, it corresponds, to a certain extent, to English poetic and rhythmical literary language of the "grand style," such as the Bible, Paradise Lost, and even Moby-Dick. In like manner Japanese classics will be best translated into English by the use of English poetic diction, as English classics will be into the written Japanese.

Japanese nouns normally have neither gender nor 
number. Sex can be indicated, if necessary, by the use of such nouns as os (male) and mesu (female), or otoko (man) and onna (woman).

For the most part Japanese leaves numbers unspecified. For example, uma ga imashu may mean either there is a horse, or there are horses. When particularization is necessary, number can be indicated in various ways, such as adding a definite number of one, two, or prefixes such as sho (various), and suffixes designating plurality like tachi, domo, and $\underline{\text { ra }}$. Japanese verbs therefore have no number at all, and plural number of the noun does not affect verbs.

Japanese has neither a definite nor indefinite article.

In translating English into Japanese, it seems better not to indicate the gender, number, and article of English, unless they are specifically emphasized by the original author; otherwise it would seem a very clumsy, awkward Japanese expression. In translating Japanese into English, on the other hand, translators should add number, gender, and articles to the original.

Japanese has three different cases of nouns. The case of a noun is identified by the case particle which follows immediately after the noun. The form of the nour remains invariable. They are wa (nominative) ni (dative), 
no (possessive), and 으 (accusative). For example:

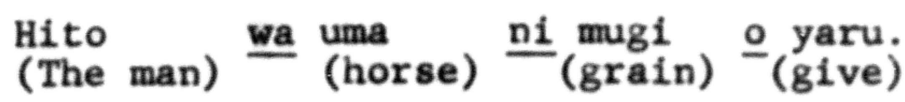

(The man gives grain to the horse.)

In rendering personal pronouns Japanese has a choice of a number of personal pronouns for each of three persons, which distinctly express one's social rank and perscnal relationship. In an ordinary, polite discourse watakushi for I, anata for you, and ano kata (that person) for he. The second and third persons are, however, often addressed by title rather than by personal pronouns. Since Japanese people are very sensitive to the level of social rank, and consequently to each personal pronoun, in translating English into Japanese it is important for translators to interpret the social rank and the personal relationship of each character in English works and accordingly to apply the most proper personal pronouns. A polite, standard personal pronoun does not always fit into English I, you, thou, and he or she.

Quite different from English, all Japanese adjectives and verbs conjugate according to each mood. There are three kinds of regular verbs and adjectives, and five different kinds of irregular verbs and adjectives. The written and spoken languages have different forms of conjugation'. 
Japanese has no relative pronouns or clauses. In place of a relative clause Japanese uses a verb or a verbal clause, the verb taking what is called the attributive form, which in the spoken language is identical with the conclusive form. For example:

Kinō kita hito wa kyō kaetta.
(Yesterday) (came)

(The man who came yesterday returned today.)

Japanese translators who try to translate the English relative pronouns that, which, where, who produce very clumsy Japanese sentences.

Japanese has a habit of frequently omitting words from a sentence. Especially the subject of a sentence and personal pronouns are very often omitted. For example, "Whose hat is it?" "Mr. Brown's,"--not "It is Mr. Brown's hat." If it is were translated, it would be a very bad sentence.

The fundamental rule of Japanese construction is that a modifier always precedes the word it modifies. Thus, adjectives always precede the nouns they modify, and adverbs precede the verbs, adjectives, or other adverbs they modify. Also, the subject precedes the predicate, and the finite verb comes always at the end of a sentence. Explanatory and dependent clauses precede the principal clauses they modify. For example: 
Kono midori no jidōsha wa totemo hayaku hashiru. (This) (green) (of) (car) (very) (fast) (runs)

(This green car runs very fast.)

Kinō Tokyo de watakushi wa nagaiaida

(Yesterday) (in) (I) (long time)

awanakatta tomodachi ni aimashita.

(have not seen) (friend) (met)

(Yesterday in Tokyo I met a friend whom I have not seen for a long time.)

Either from English into Japanese or Japanese into English, translators have a great task completely and accurately to reconstruct each sentence and word in a proper form.

Levels of speech dictated by social situations are very familiar in Japanese. There are three wide levels: the plain level, used to an inferior or by intimates among themselves; the polite level, used to strangers and acquaintances of approximately equal rank; and the honorific level, used to a superior. These classifications have originated in the long Medieval social structure. These levels will be indicated by the changes of various personal pronouns and of inflections of verbs.

In Japan, each part of the country having had little contact with other parts in the past, each region has developed its own dialect. There are about seven major dialects in Japan, Tokyo dialect being standard Japanese at the present. One dialect differs from another mainly in the use of various inflections and accents. 
Translation of dialects is one of the most difficult problems. How could Kansai dialect or Izumo dialect be translated into English? How could New England dialect or West Saxon dialect be presented in Japanese? Each dialect reflects the peculiar character of the locality where it is spoken, and it would be absurd to represent an American Negro in the South speaking in Izumo dialect, which has no similar social structure at all, and also to hear Japanese farmers in Izumo speaking in the Southern accent. The standard English or Japanese, on the other hand, is not proper to represent a dialect. The best method, it seems is to combine several dialects and vulgar languages in the country to make something like a dialect common to all regions, so that it may not reflect and call to mind one particular part of the country.

As has been shown in this general outline of Japanese language, the differences between English and Japanese are very wide, and there is no linguistic similarity between two languages. In addition to the differences of language, moreover, the Japanese language has developed in a social structure entirely different from those of Europe. As a result, the connotation of each Japanese word makes it much different from its English equivalent.

In the work of translation from English into 
Japanese and from Japanese into English, the only possible way is to understand the ideas of the original and to reproduce them in the style and manner of another language as closely as possible. In the rearrangement of the thoughts conveyed in the original and in the style, translation has to depend upon the ability of translators, and the subjectivity of translation will be inevitable. 


\section{CHAPTER II}

\section{LANGUAGE}

On the fly leaf of The Adventures of Huckleberry Finn one finds the following introductory note as to the nature of the language used in the book:

In this book a number of dialects are used, to wit: the Missouri negro dialect; the extremest form of the backwoods Southwestern dialect; the ordinary "Pike County" dialect; and four modified varieties of this last. The shadings have not been done in a haphazard fashion, or by guess work; but painstakingly, and with the trustworthy guidance and support of personal familiarity with these several forms of speech.

I make this explanation for the reason that without it many readers would suppose that all these characters were trying to talk alike and not succeeding.

THE AUTHOR ${ }^{1}$

The language used in Huckleberry Finn is American colloquial speech, and the story is told by Huck Finn, a western boy, in his own idiom. It is not the formal standard English found in the spelling book with which Miss Watson "took a set at him,"2 but the American colloquial language in the Mississippi Valley that he hears

${ }^{1}$ Samuel Clemens, The Adventures of Huckleberry Finn (New York: Harper' Brothers, 19I2), pp. v. Here after page references are always to this Authorized Edition of Huckleberry Finn.)

$$
2 \text { Ibid., p. } 17 .
$$


at home. It is an "informal colloquial speech, locally established by a slight addition of local practices in speech." 3 "It derives," says H. L. Mencken, "not from the subtle logic of learned and stupid men, but from the rough-and-ready logic of every day. It has a vocabulary of its own. Its verbs are conjugated in a way that defies all the injunctions of the grammar books . . . it repudiates all the finer distinctions between the parts of speech. 14

It proves nothing, however, to say that Huckleberry Finn is great because it is written in the native idiom. In spite of Mark Twain's assertion that "the shadings have not been done in a haphazard fashion, or by guesswork; but painstakingly, and with the trustworthy guidance and support of personal familiarity," the novel does not

${ }^{3}$ George Philip Krapp, The English Language in America (New York, 1925), p. 243. He adds that "A person who speaks a low colloquial English in plantation surroundings is readily interpreted to be a Southerner of some degree, but essentially the same language spoken on the range would establish the speaker as a cowboy, or in the gold region as a miner. The statement quoted earlier in this chapter, that there are no true dialects in America, is thus seen to be in the main defensible, so far as dialects have been utilized for literary purposes. One may say that there have been only two forms of speech in America, the more or less formal standard and the more or less informal colloquial."

${ }^{4}$ H. L. Mencken, The American Language (New York, 1923), pp. 269-270. 
exhaust scientifically all the details of dialect speech in the Mississippi Valley. ${ }^{5}$ The most remarkable achievement of American colloquial language in the novel is that it is best utilized for a special literary purpose. The vivid, colorful, and straightforward language of Huckleberry Finn deeply penetrates into the core of life in the Valley, and, "perceived with a sensitiveness and used with a skill nowhere else equalled, is proved competent for all the effects of fiction." 6

Formal English, says H. W. Fowler, is "not the plain English for what is meant, not the form that the mind uses in its private debates to convey to itself what it is talking about, but translation of these into language that is held more suitable for public exhibition."7 Informal, colloquial English, as distinguished from formal English, means "the typical

5 Katherine Buxbaum, "Mark Twain and American Dialect," American Speech, II (Feb. 1927), 236. "An annotation in a bibliography of books containing American dialects, published in 1914 by the St. Louis Public Library, discredits Mark Twain's explanatory note thus summarily: 'This statement is not to be taken seriously; it is humor;' and adds rather drastically, 'He does not stand high as a dialect writer, although some of the dialect in these two works Huckleberry Finn and Tom Sawyer is quite good." "

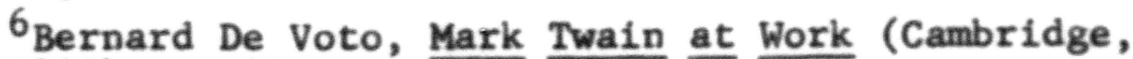
Mass., 1942), p. 95 .

${ }^{7}$ H. w. Fowler, Dictionary of Modern English Usage (Oxford, 1927), p. 189. 
language of an educated person going about his everyday affairs." 8 It is above all the language which is still warm with human association, and which stands closer to experience. Being the language of daily affairs, American colloquial speech is very rich in local color, and has its nuances, subtleties, and infinite varieties. It is the most direct and colorful language.

Mark Twain once wrote that "Expression--expression is the thing in art. I do not care what it expresses, and I cannot tell, generally, but expression is what I worship, it is what I glory in, with all my impetuous nature." 9 Being extremely language-conscious, he was very sensitive to the color and exact meaning of language. In "Fenimore Cooper's Literary Offenses" he says, "Use the right word, not its second cousin."10 In many other places in his writings, he shows how he abhorred lack of clarity and poor choice of words. One of these examples displays his love of the precise word:

8 Porter G. Perrin, Writer's Guide and Index to English (New York, 1942), p. 613.

9 John B. Hoben, "Mark Twain: On the Writer's Use of Language," American Speech, XXXI (Oct. 1956), p. 136, fn. 4. "From 'An English Notebook' (De Voto check list, item 70, Mark Twain Papers, University of California, Berkeley). Copyright 1956 by the Mark Twain Company."

10 "Fenimore Cooper's Literary offenses," p. 81. 
Now here's something else I remember. It's about the first time I ever stole a watermelon. 'Stole' is a strong word. Stole? Stole? No, I don't mean that. It was the first time I ever withdrew a watermelon. It was the first time I ever extracted a watermelon. That is exactly the word I want--'extracted.' It is definite. It is precise. It perfectly conveys my shade of meaning I am looking for. You know we never extract our own teeth. 19

His love of the exact word naturally led him to the more familiar and expressive American colloquial speech.

"He selects his words with care," says Miss Frances Emberson, "for 'local color',--for accuracy in transcribing the idiom of a peculiar locality or American idiom in general."12 "'Pretty much' may not be elegant English," he comments on formal English, "but it is high time it was. There is no elegant word or phrase which means just what it means."13 And he exults in the rich and colorful slang of Nevada:

As all the people of the earth had representative adventures in the Silverland, and as each adventurer had brought the slang of his nation or his locality with him, the combination made the slang of Nevada the richest and the most infinitely varied and copious ${ }_{14}$ that had ever existed anywere in the world

1 Mark Twain's Speeches, pp. 287-288.

12 Frances Guthrie Emberson, Mark Twain's Vocabulary: A General Survey (University of Missouri, 1935), p. 13.

13 A Tramp Abroad, II, p. 130.

${ }^{14}$ Roughing It, I, p. 60 . 
The American colloquial language of Huckleberry Finn is developed fully by Mark Twain's skill in using the language at the level of genius, and it achieved all the effectiveness of its expression--the greatest simplicity, directness, lucidity, vigor, and grace.

This chapter deals with the language of Huckleberry Finn in Japanese translation. One of the most difficult problems of translating it into Japanese is posed by the informal, colloquial language used in the book. Colloquialisms, dialects, slang, archaisms, and Americanisms pervade the book. In "A Vocabulary Study of Huckleberry Finn" Miss Emberson lists 456 Americanisms. She also lists 743 nineteenth century coinages (archaisms and obsolete words), the majority of which are first cited in Huckleberry Finn after $1800 .{ }^{15}$ These words will not easily find their equivalents in the Japanese language, whose social and cultural backgrounds are utterly different from those of America. Moreover, since they tend to be more vivid, concrete, and local, and create more definite images than formal, standard language, if one cannot translate the colloquial language, he loses much of these original qualities.

15"A Vocabulary Study of Huckleberry Finn," an unpublished Master's Thesis by Frances Guthrie Emberson, (Missouri, 1930), pp. 52-57. 
The purpose of this chapter is to examine the qualities of the language in the Japanese translation of Huckleberry Finn, and the method used in the translation. The method used in this study is comparison between the qualities of the original and those of the translation. The method of the Japanese translation is examined by three general methods of translation: (1) literal translation; (2) idiomatic translation; and (3) paraphrastical translation. Literal translation is translating the language of the original word for word and representing it by the Japanese equivalent according to dictionary meaning. Idiomatic translation is adapting the original language to the peculiar nature of the Japanese language, and includes adaptation and expansion.

The materials in this chapter are arranged in the following order: (1) nouns; (2) verbs; (3) adjectives; (4) adverbs; (5) idiomatic phrases; (6) peculiarities of spelling, inflection, and grammar; (7) interjections and expletives; (8) figures of speech; (9) river and nautical terms; (10) names of American political and social institutions; (11) names of American dwellings and landscapes; and (12) proper nouns. Since the characteristic quality of the original language is informal and colloquial rather than formal and standard, most of the examples used in this chapter are taken from colloquialisms, dialects, 
slang, and archaisms. For further reference, the additional study of the language of the Japanese translation is supplied in the Appendix.

\section{Nouns}

A noun is defined as "the name of a person, place, thing, quality, action, or idea . . . 16 In this section, however, proper nouns and names of distinctly American objects are excluded, and treated later in each separate section.

In Huckleberry Finn both concrete and abstract nouns are used together, and made very effective, producing the concrete images of objects and of emotion, thought, and action. In translating these concrete and abstract nouns of the original standard English, the Japanese translation literally follows them, replacing them with Japanese equivalent nouns. For example:

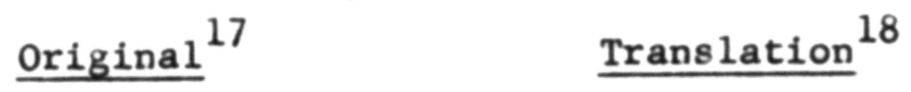

He jumped up yelling, and the first thing the light showed was the varmint curled up and ready for

He jumped up yelling "Wah." And the first thing the light showed was the varmint curled up and

${ }^{16}$ Perrin, p. 570.

17 Hereafter the original will be always listed on the left side, and the translation on the right.

${ }^{18}$ The original language of the translation is retranslated into English in order to make it intelligible to English readers. 
another spring. I laid him out in a second with a stick, and Jim grabbed pap's whiskyjug and begun to pour it down.

$$
(\mathrm{x}, 81)^{19}
$$

ready for another spring. I killed the snake in a second with a stick. And Jim grabbed pap's whisky jug, and began to pour it down.

In the above example every noun, concrete and abstract, is represented by the equivalent Japanese noun, and adapted to Japanese successfully. Most standard English terms generally find Japanese equivalents, and their original qualities and meanings are well represented in Japanese without sacrificing the original too much.

Difficult problems, however, arise in translating the informal, colloquial nouns. Huckleberry Finn is full of colloquialisms, dialects, slang, and archaisms, whose meanings are not always found in an ordinary dictionary and easily understood. Besides, they are rich in the local color and connotation, qualities which cannot easily find Japanese equivalents without being adapted to Japanese.

In the translation American colloquial nouns are represented by formal, standard nouns, and often their original meanings are expanded. For example:

"You think you're a good deal of big-bug, don't you?" $(\mathrm{V}, 39)$
"You think you became quite a man of eminence, don 't you?"

Big-bug is a colloquialism for great, which means "a

19 The Roman numerals indicate the chapter, and the Arabic the page number of the Authorized Edition. 
person of wealth, eminence, or social importance (OED)." It is a terse, eloquent, and picturesque word to describe a person of such a high position. It gives a concrete and vivid picture of his self-important, pompous character and social standing. In the translation it is represented by the formal and polite phrase, a man of eminence. When it is replaced by standard Japanese, it loses a great deal of its vivid and picturesque quality.

She had the grit to pray for Judus if she took the notion--there warn't no backdown to her, I judge. You may say what you want to, but in my opinion she had more sand in her than any girl I ever see. . .

(XXVIII, 250)

She had the courage to pray for Judas, if she took the notion--there was no back-down to her, I think. Whatever you may say, in my opinion she had more courage than any girl I have ever seen

Grit, U.S. slang, means "firmness or solidity of character (OED)," and "unyielding courage (W)." It is represented by a standard Japanese, courage, which is general and abstract. Also, sand, another U.S. slang term, whose meaning is "firmness of intention (OED)" and "courage $(W), "$ is represented by the same abstract standard Japanese, courage. Grit originally means rough, hard particles of sand, and being applied to a person who sticks firmly to his intention, both $\underline{\text { grit }}$ and sand give him a concrete and vivid image of hardness of his character. When they are replaced by a general, abstract noun, their original connotation and picturesqueness are utterly lost. 
Most of these American colloquial nouns, like bigbug and sand, are represented by formal, standard Japanese. The rich, local connotations are lost in translation, and the flat and monotonous language lacks vitality. Other terms exhibiting this are: lunkhead $>$ fool, old pie $>$ hospitality, jake $>$ country folks, and body > everybody or people.

Besides the method of literal translation, idiomatic translation is used to expand the original meaning in the translation. For example:

When we got home Aunt Sally was that glad to see me she laughed and cried both, and hugged me, and give me one of them lickings of hern that don't amount to shucks . . . (X́) $\dot{\mathrm{I}}, 3 \dot{5} 7)$
When we got home, Aunt Sally was so glad that she laughed and cried, and hugged me and gave me a kicking in her own fashion that doesn't amount to any hurting or itching at all.

Hern, a dialect of hers, is represented by standard Japanese, and its meaning is expanded into in her own fashion. In dialect the old feminine form of an absolute possessive pronoun, hern, like yourn, is still retained. Although the translation cannot reproduce its exact connotation, its original meaning is expanded and emphasized. In this sentence, however, licking is carelessly mistaken for kicking, and consequently the whole meaning of the following sentence is misunderstood. Shucks, colloq., whose meaning is "something worthless 
Most of these American colloquial nouns, like bigbug and sand, are represented by formal, standard Japanese. The rich, local connotations are lost in translation, and the flat and monotonous language lacks vitality. Other terms exhibiting this are: lunkhead $>$ fool, old pie $>$ hospitality, jake $>$ country folks, and body $>$ everybody or people.

Besides the method of literal translation, idiomatic translation is used to expand the original meaning in the translation. For example:

When we got home Aunt Sally was that glad to see me she laughed and cried both, and hugged me, and give me one of them lickings of hern that don't amount to shucks . . . (Xi) $\dot{\mathrm{X}}, 37)$
When we got home, Aunt Sally was so glad that she laughed and cried, and hugged me and gave me a kieking in her own fashion that doesn't amount to any hurting or itching at all.

Hern, a dialect of hers, is represented by standard Japanese, and its meaning is expanded into in her own fashion. In dialect the old feminine form of an absolute possessive pronoun, hern, like yourn, is still retained. Although the translation cannot reproduce its exact connotation, its original meaning is expanded and emphasized. In this sentence, however, licking is carelessly mistaken for kicking, and consequently the whole meaning of the following sentence is misunderstood. Shucks, colloq., whose meaning is "something worthless 
(OED)" like corn husks, or any outer covering, is

faultily expanded into neither hurting nor itching.

This method of expansion is often applied when Japanese has no equivalent word at all. For example:

. . and there was nigger boys in every tree, and bucks and wenches looking over every fence. $\cdot$. (XXII, 195)
There were nigger boys in every tree. And nigger men and nigger women were looking over every fence.

Since there is no Negro in Japan, both buck, U.S. colloq., and wench, local U.S., have no equivalent words in Japanese. These are therefore expanded into nigger men and nigger women. The methods of adaptation could reproduce the original meanings to a certain extent, but often fail in reproducing their original quality of American colloquial language.

In the Japanese translation sometimes misinterpretations or obscure passages are noted. For example: . . because rapscallions and dead beats is the kind the widow and good people takes the most interest in

$$
\text { (XIII, 108) }
$$

Because rascals and big frauds are the kind of people the widow and good people are most interested in.

Dead beat, U.S. slang, means "a worthless idler who sponges on his friends (OED)." It is translated into Japanese colloquialism, big fraud, which is not a correct interpretation of the original. Also, rapscallions here is translated into standard Japanese, rascals or bad 
people, which weakens the original word a great deal.

The law takes a man worth six thousand dollars and up'ards, and jams him into an old trap of a cabin like this

$$
(V I, 48)
$$

That is, the law takes six thousand dollars and more away from a man, and jams him into a cabin like this trap... .

Trap, a slang term, is "a contemptuous term applied to anything old or worn out (W)." It is translated into standard Japanese trap, which means any stratagem designed to trick a person. This is obviously a misinterpretation. In some cases, however, the translation is happily made, and the original colloquial nouns are well adapted to equivalent colloquial nouns. For example:

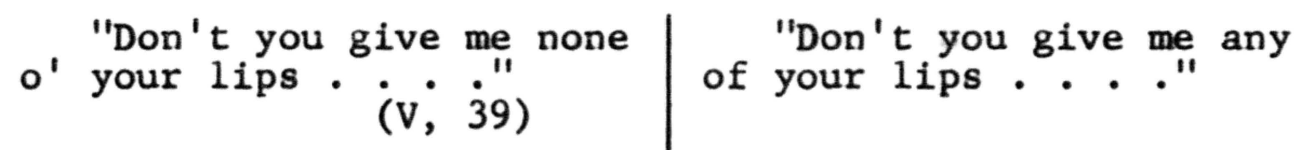

Lip, slang, means "a saucy talk, impudence (OED)," and this is exactly translated into Japanese slang, lip, whose meaning and connotation can precisely convey the original. It is a very difficult thing to do, and actually is very seldom successful.

\section{Verbs}

The verbs in Huckleberry Finn have many varieties, and are usually quite vivid. Especially in the passages of action they are exact and vivid enough to enable the reader to recxeate the action in the book. For example, 
variations of "walk," "run," or "go," are: break for, clear out, clip, dig out, heal, hump (oneself), light out, mosey along, pile in, put, scoot, shine above, shove, skaddle, slide out, spin down, take out, trapse, and use around. Such varied and vivid verbs increase the concrete, picturesque quality of Huckleberry Finn. Also some other verbs are used to make subjects and objects vivid and alive, as in "mist curl up," "river softened up," and "east reddens up." The Japanese translation must reproduce these various qualities of the original verbs, if ever it tries to maintain the original qualities of Huckleberry Finn.

Standard English verbs are represented either by equivalent Japanese verbs or by expansion. For example:

They all smoked and talked, and I eat and talked... They all asked me questions and I told them how pap and me and all the family was living on a little farm down at the bottom of Arkansaw, and my sister Mary Ann run off and got married and never was heard of no more, and Bill went to hunt them . (XViI, 139)
They all talked while smoking. And I talked while eating . . . They all asked me questions. And I told them that pap, I, and all the family were living on a little farm down at the bottom of Arkansaw, and my sister Mary Ann ran off and got married and was never heard of afterward, and Bill went to hunt them ... .

All of the standard English verbs in the above example, smoked, talked, eat, asked, told, living, got married, heard, and hunt, are reproduced by standard Japanese 
equivalents. In the case of smoked and eat, their meanings are expanded into while smoking and while eating. However, these expansions in translation weaken the vivid and rapid actions described by a simple sentence of smoked and talked, and I eat and talked. Huck's solecisms, eat for ate, was for were, and ran for run, are all corrected into standard Japanese.

In Huckleberry Finn, however, actions and modes of thinking in active passages depend upon the varieties of expressions accomplished by American colloquial verbs rather than by standard English verbs. They are concrete, vigorous, picturesque, and rich in connotation. Most of them are translated by means of expansion and pretty accurately reproduced. For example:

Then I jumped in the canoe and dug out for our place, a mile and a half below, as hard as I could go. I landed, slopped through the timber and up the ridge and into the cavern. There Jim laid, sound asleep on the ground. I roused him out and says:

"Git up and hump your-

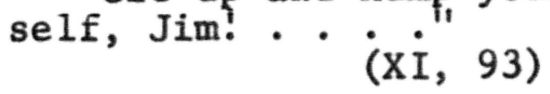

Then I jumped in the canoe and rowed it desperately for our place as hard as I could. It was a mile and half below. I landed, slopped through the timber and up the ridge, and jumped into the cavern. Jim was laying there, sound asleep on the ground. I roused him out and says:

"Get up and hump your-

Dig out, U.S. colloq., means "to depart, elope (OED)," and its meaning is expanded into to row desperately for. Slop, obs., means "to walk or travel through a place in 
mud or slush," and it is exactly translated into Japanese. Also, hump oneself (yourself), U.S. slang, whose meaning is to "bend or gather together for strenuous effort; to exert $(W), "$ is reproduced by equivalent Japanese colloquial expression, work hard or hump oneself. And into the cavern is expanded into jumped into the cavern in the translation. These examples are all successfully translated into Japanese either by substitution or expansion. Some American colloquial verbs, however, are not so successfully rendered. Some are, for example, represented by formal Japanese verbs, sacrificing their original qualities.

I borrowed three dollars from Judge Thatcher, and pap took it and got drunk, and went a-blowing around and cussing.

$$
(\dot{\mathrm{V}}, \dot{4})
$$

I borrowed three dollars from Judge Thatcher, and pap took it and got drunk, and went blowing and cursing

The use of the prefix a in front of a gerund, blowing, is an archaic usage surviving only in dialects. This word is replaced by standard Japanese, blowing, and its original archaic and dialect connotation of a-blowing is entirely lost. Some of the other similar examples are: a-bothering $>$ bothering, a-hunting $>$ hunting, and a-visiting visiting.

Another example of representing dialects by standard Japanese is: 
"Miss What-you-may-callher--I disremember her name--"
". . Miss So-and-so, I forgot her name...."

Disremember is a dialect of to forget, and it is represented by standard Japanese, forget. Japanese has no exact equivalent word, except forget, and in this case it is very difficult to do otherwise.

Sometimes vivid, colorful words are translated into abstract, flat Japanese verbs. For example:

There was things which he stretched, but mainly he told the truth.

$$
(I, 15)
$$

There are things he exaggerated, but mostly they are true.

Stretch, colloq., is "to strain (things) beyond the legitimate length (OED)"; it is concrete and full of vivid image. Being replaced by an abstract word, exaggeration, it cannot convey any original connotation.

Some verbs have meanings very close to one another, and yet slightly different. Most of them are represented by approximate words in the translation. For example, allow has two meanings, one "to declare," and the other "to intend." In both cases the translation has say without making any discrimination between the two at all.

". . Why, Biljy, it beats the Nonesuch, don't it?"

The duke allowed it did. (XXV, 220)

\section{"Why, Biljy (Mr.} Bilgewater), it beats the Monster Play, doesn't it?" The duke said it did.

Allow here means "to declare, to affirm (OED)," and it is 
translated into say, which is not exactly correct and which loses the original colloquial connotation at the same time. Some other examples are reckon and judge, both translated into standard Japanese, think.

Misinterpretations are sometimes noted, too.

I fetched the shore a half a mile above the village, and then went scooting along the bluff bank in the easy water. (XXIV, 211)
I got to the shore half a mile above the village. And then I went scouting along the bluff bank in the easy water.

Scooting, either slang or colloq., means "going suddenly and swiftly." It is carelessly mistaken for scoutirg in the translation, and then completely misunderstood.

\section{Adjectives}

The adjectives in Huckleberry Finn make a significant contribution to the vividness and concreteness of the language. To describe an object, Mark Twain preferred the exact word to the approximate word. "As to the adjective," he agreed with Pudd'nhead Wilson, "when in doubt, strike it out." 20

An adjective modifies a noun or pronoun, to make its meaning more exact. Descriptive adjectives modify the noun by naming a quality or condition of the object it

${ }^{20}$ Pudd'nhead Wilson, p. 96. 
names, thus adding to the exactness of a writer's statement or to the definiteness of his picture. A great number of Mark Twain's adjectives in Huckleberry Finn have exactness and freshness, and make an object so vivid and concrete that the reader can almost create its visual image in his mind. Some of them are: the pale underside of the leaves, spiderwebby, the bluest and blackest, ripping rate, hifalut'n foolishness, brash, ratty old fiddle-bow, raspy, fidgety, solid white, and so $\underline{\text { cool }}$ and fresh and sweet to smell.

Standard adjectives are translated into Japanese by Japanese equivalent adjectives, or by expansion. For example:

Col. Grangerford was very tall and very slim, and had a darkish-paly complexion, not a sign of red in it anywheres; he was clean shaved every morning all over his face, and he had the thinnest kind of lips, and the thinnest kind of nostrils, and a high nose, and heavy eye-brows, and the blackest kind of eyes . . . . (XVIII, 46)
Col. Grangerford was very tall, and slim. He had a pale-darkish complexion. There was no sign of red in it anywhere. He was cleanly shaved every morning. And his lips were inexpressibly thin. His nostrils were inexpressibly small. His nose was high. His eye-brows were heavy. His eyes were the blackest.

In the above the adjectives, tall, slim, high, heavy, and blackest are replaced by equivalent Japanese adjectives. Darkish-paly is adapted to Japanese expression, paledarkish. Thinnest is expanded into inexpressibly thin or 
so thin as to be inexpressible in case of "lips," and inexpressibly small in case of "nostrils." These expansions are very appropriate in Japanese expression, and so far in the above example every adjective is well translated.

The main difficulty, however, arises in translating American colloquial adjectives. Most of them are represented by standard Japanese adjectives without seeking for more vivid and accurate Japanese equivalents. The result is the flat, monotonous adjectives which cannot create vivid and fresh objects in a reader's mind. For example :

Making them pens was a Making pens was a very distressed tough job $\left.{ }_{\text {(XXXVIII, }} \dot{3}^{\circ}\right)^{\cdot} \cdot$ hard job.

Tough means "extremely difficult to cope with (W)," and it is translated into a very common adjective, hard, which cannot express the strong emphasis of the original. This is especially so when the word is modified by the adverb, distressed (originally adjective), which means "extremely, plaguely (OED)."

"Now you're talking!" I says; "your head gets leveler and leveler all the time, Tom Sawyer," I says. (XXXVI, 318)
"Now you are talking!" I say. "Your head is getting better and better all the time, Tom Sawyer," I say.

Leve1, colloq., is said of "the head or mental make up, that is well balanced (OED)." Here it means "smarter and 
smarter," or "cleverer and cleverer." This is replaced by standard Japanese, better and better, or literally "your head can see things better and better." The meaning of the translation is very close to the original, but this standard Japanese fails in the subtle colloquial connotation of level.

"I knew the first house would keep mum and let the rest of the town get roped in...."

(XXIII, 204)

"I knew the customers on the first day would keep it secret strictly, and let the rest of the town get
roped in..."

Mum, colloq., is "being strictly silent or not saying a word (OED)," and it is somewhat archaic except dialect. In the translation its original meaning is expanded into standard Japsnese, to keep the secret strictly. Some other examples of translating these colloquial adjectives into standard Japanese are: dangersome >dangerous; low-down $>$ mean, degraded; fool > foolish; hifalutin > extravagant; ripping > excellent; rough $>$ hard; and smart $>$ clever.

But a few adjectives find their way into Japanese, and are happily reproduced in the translation. For example:

"You hain't done a thing from the start that had any sense in it, except coming out so cool and cheeky with that imaginary blue-arrow mark." $(x x x, 269)$

"You haven't done anything from the start that had any sense in it. The only exception was coming out so cool and cheeky with that imaginary bluearrow mark."

Cheeky, colloq., is characterized by "cheek," and means 
here "being coolly impudent or presuming." This is exactly translated into Japanese colloq., cheeky.

Adjectives like swell and brash are also accurately reproduced into Japanese colloquial expressions.

Some adjectives, however, can hardly be translated directly into Japanese without some expansion, and they are sometimes excellently reproduced by Japanese idiomatic expression. For example:

"... for I ain't got no disposition to throw anything in the way of a fair, open, out-and-out investigation $o^{\prime}$ this miserable business . . . ." (XXIX, 259)
"Because I do not have any disposition to be in the way of a fair, open, roots-and-leaves investigation of this miserable business."

Out-and-out means "complete, thorough-going (OED)," and this is expanded to Japanese idiomatic phrase, diggingroots-and-leaves, whose meaning is "thorough-going."

My new clothes was all greased up and clayey, and I was dog-tired. (II, 27)
My new clothes were all greased up and clayey. And I was cotton-tired.

Dog-tired means "as tired as a dog after a long chase; extremely tired (OED)." It is well translated into Japanese colloquial expression, cotton-tired, which means "the body is so tired out that it is soft like cotton."

\section{Adverbs}

It is obvious that many of Mark Twain's verbs and adjectives contribute to the vividness and exactness of 
his language. The adverbs in Huckleberry Finn, modifying verbs, adjectives, and other adverbs, also heighten greatly the language of the book with an added degree of accuracy and vitality. Some of these examples are: dismal regular and decent, monstrous easy time, ever sorry, painfully white, dead quiet, mighty red, most always, pretty much, ever so, tight, and worked regular. Since most of the adverbs in the book are short, simple, vivid, and precise, it is difficult to translate them. The shorter forms in informal, colloquial writings are often much more vigorous and emphatic than the formal, longer ones.

In the Japanese translation most of these adverbs are represented by weak and formal standard Japanese. For example :

I felt so lonesome I most wished I was dead. The star were shining, and the leaves rustled in the woods ever so mournful; and I heard an owl, away off. -. (I, 17-18)
I was so lonesome that I almost wished I were dead. The stars were shining. And the leaves rustled in the woods very sorrowfully. And I heard an owl, away off... .

The adverbs, both ever so and mournful, are colloquial words. Ever so modifies mournful, another adverb, and both intensify the rustling sound of leaves in the midnight, and nature is personified by mournful. In the translation, however, ever so is represented by standard Japanese, very, which is too weak to reproduce the 
original quality, and mournful by sadly or sorrowfully. Many colloquial adverbs are represented by standard Japanese, and their original vitality is lost. For example :

"You've put on consider- "You've put on many able many frills since I been away."

$$
(\mathrm{V}, 39)
$$
frills since I've been away."

Considerable, dialect form of considerably, is used for emphasizing qualities and quantities as applied to men and things, meaning "considerably," "great deal (OED)." In the translation it is omitted because of many, and not emphasized as in the original at all. Usually in other cases like "a considerable long time," it is represented by standard Japanese, very, a weak general adverb, which cannot convey the exact color of the original. A few other examples are: nation, very, mostly, and almost. Some other examples of representing the original by weak, standard Japanese adverbs are shown in the following examples :

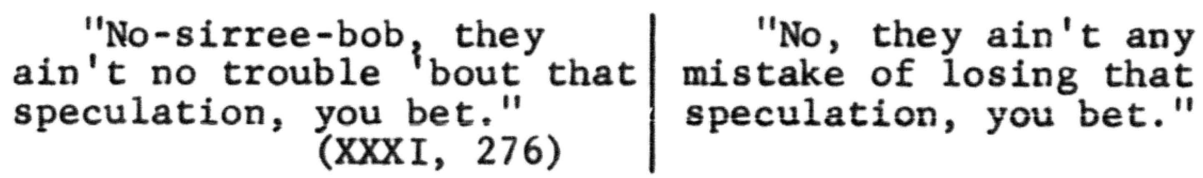

No-sirree-bob, dial., is a very emphatic negative, and much stronger than an ordinary no. It is, however, represented by weak, ordinary standard Japanese, no. 
It was most pesky tedious hard work and slow, and didn't give my hands no show to get well of the sores.. -
It was extremely tedious, hard, slow work. And it did not give any time to get well of the sores.

(XXXVIII, 334)

Pesky, U.S. colloq., means "disagreeably, hatefully (OED)." It is represented by standard Japanese, extremely, and its strong original meaning of "disagreeably" is much weakened.

Just as I was passing a place where a kind of a cowpath crossed the crick, here comes a couple of men tearing up the path as tight as they could foot it. (XIX, 164)
Just when I was passing a place where a kind of a cowpath crossed the creek, a couple of men come tearing up the cowpath with a full speed.

Tight, dial., means "quickly (W)," and it is represented by standard Japanese, with a full speed. A few other examples are: rotten very, slick cleverly.

Some adverbs, sometimes, are expanded. For example :

Then she grabbed up the basket, and slammed it across the house and knocked the cat galleywest...

\section{(XXXVII, 329)}

Then she grabbed up the basket and slammed it to the opposite wall, and knocked it to the cat, making it feel dizzy.

Galley-west, U.S. slang, means "into confusion; all to pieces, and to give a finishing or knockout blow (W)." It is expanded into standard Japanese, making the cat feel dizzy. 
5. Colloquial Phrases and Idioms

"The flavor of Mark Twain's style," the authors of A Mark Twain Lexicon agree, "is always racy of the American soil; and it owes this quality largely to the prodigious store of native phrases and idioms which he employs."21 Huckleberry Finn has a number of expressive colloquial phrases and idioms, such as like to, freeze to, dig out, fix up, carry on, let the cat out of the bag, up to the hub, like all get-out, and bug out. These picturesque and specific colloquial phrases and idioms are difficult to translate into Japanese. Literal translation of these colloquial phrases and idioms will not make any sense at all, and consequently a translator has to rely upon the method of idiomatic translation.

Some colloquial idioms like lay off and bug out find the same equivalent Japanese colloquial idioms, but often they are adapted to Japanese colloquial idioms and phrases, whose meanings are the same as the original, but whose expressions are different. An awful sight of money is, for example, adapted to a big mountain of money, Japanese colloquial expression. Another example is:

$21_{\text {Robert L. Ramsay and Frances G. Emberson, } A}$ Mark Twain Lexicon (University of Missouri, 1938), $\bar{p}$. xIv. 
. . because as long as I was in, and in for good, I might as well go to the whole hog.

$$
\text { (XXXI, 279) }
$$

Because $I$ was in and in for eternity, and I am in such a state that I might as well vomit blood if I had to vomit poison.

To go the whole hog, slang term, means "to go all the way (OED)," and this is well adapted to Japanese idiomatic expression, "might as well vomit blood if I had to vomit poison." In the above example, however, there is a misinterpretation of the idiomatic phrase, for good. It means "fully and completely (W)," and it is misinterpreted as eternity.

Most of these colloquial phrases and idioms, however, are rather represented by standard Japanese than by Japanese idiomatic expressions, and as a result the original expressive and colorful idioms are made flat and awkward. For example:

What are we going to do?--lay around then till he lets the cat out of bag?

$$
\text { (XLI, 356) }
$$

What are we going to do?--Should we lay around there till the doctor discloses the secret?

Let the cat out of bag is "to disclose a guarded secret (W)," and it is represented by standard Japanese, to disclose the secret. This expressive idiom of the original loses completely its colorful expression in the translation.

"We ain't got no time to bother over that," he says; "we got to dig in
'We haven't got time to bother over that," says he. "We have to dig as 
like all git-out."

(XXXVIII, 333)

hard as possible.

Like all get out means "very earnestly; swiftly (OED)."

It is represented by standard Japanese, as hard as

possible, which does not convey the original expression

exactly. Some other similar examples are: to draw a bead

on > take aim at; to get shut of them > forget; to foot the

bill > pay the bill; and go for > attack.

Sometimes misinterpretations occur:

He give me down the banks for not coming and telling him I see niggers come out of his room acting that way--said any fool would $a$ ' knowed something was up. (XXVII, 243)
He scolded me for not going to tell him that I saw niggers sneaking out of his room that way-said any fool would have thought something was up

Down the banks, colloq., means "to call to account (DN)."

It is somewhat misinterpreted because of its too extensive interpretation.

He said he would like to see the widow get me. He said he would watch out, and if they tried to come any such game on him he knowed of a place six or seven miles off to stow me in. (VI, 47)

He said he would like to see the widow take me away. He said he would watch out all the time, and if they tried to do such a thing, he knew a place six or seven miles away to stow me in.

To come game on, slang and colloq., is "to play or practice (a dodge or trick), esp. over any one (OED)." It is translated into standard Japanese, to do things like that, which is not exact and very flat. Original meaning 
and expression are totally lost in the translation. The similar examples are seen in the following: keel over $>$ lie prostrate; by the back (all through) $>$ by a glimpse of the back; come out flatfooted $>$ flee openly; and freeze to $>$ as if frozen.

When these colloquial phrases and idioms are used just for the sake of emphasis, they are sometimes omitted in the translation. For example:

"Till I ask you! Well, I never see the beat of it in my born days!" (XXXIII, 297)

"Till I ask you! Well, I'm struck dumb by your stupidity."

(One's) born days, colloq., means "one's life time (OED)," and it emphasizes the whole sentence. In the translation in my own born days is omitted, and the whole sentence is expanded into struck dumb by your stupidity and it is weakened.

6. Peculiarities of Spelling, Inflections. and Grammar

Mark Twain's opinion on the grammatical incorrectness is shown in the following passage of Life on the Mississippi:

The country gentleman who told me these things had been reared in ease and comfort, was a man of good parts, and was college bred. His loose grammar was the fruit of careless habit, not ignorance. This habit among educated men in the West is not universal, but it is prevalent--prevalent in the 
towns, certainly, if not in the cities; and to a degree which one cannot help noticing, and marveling at. I heard a Westerner, who could be accounted a highly educated man in any country, say, 'Never mind, it don't make no difference, anyway.' A life-1ong resident who was present heard it, but it made no impression upon her .... No one in the world speaks blemishless grammar; no one has ever written it--no one, either in this world or out of it (taking the Scriptures for evidence on the latter point); therefore it would not be fair to exact grammatical perfection from the people of the Valley; but they and all other people may justly be required from kngwingly and purposely debauching their grammar.22

In every sentence of Huckleberry Finn colloquial and dialect peculiarities of spelling, inflection, and grammar are fully displayed by Huck Finn and all the rest of the characters in the book. These colloquial and dialect peculiarities reflect a particular locality, and lend local color to the characteristic quality of American colloquial language in the book.

Miss Frances G. Emberson lists seventy-three of these peculiarities of spelling, inflection, and grammar found in Huckleberry Finn. ${ }^{23}$ It is very difficult to reproduce them in Japanese. Japanese has several major dialects throughout the country, with their peculiarities of spelling, inflection, and grammar, but how to apply them to American colloquial language is a very difficult

$$
\begin{aligned}
& { }^{22} \text { Life on the Mississippi, p. } 210 . \\
& 23_{\text {Emberson, p. } 58 .}
\end{aligned}
$$


problem. In the Japanese translation, however, most of the original peculiarities are represented by standard Japanese, except certain verbal inflections, thus utterly losing the original local color.

Pronunciations of words in Huckleberry Finn are indicated by Mark Twain's admirable usage of phonetic spellings. In the translation they are all corrected into standard Japanese pronunciations, such as sk'yers becomes scarce, biler-factory becomes boiler-factory. Some of the other examples are: druther $>$ rather, chimbly $>$ chimney, seegar $>$ cigar, creture $>$ creature, yellocute $>$ elocute, galluses $>$ gallows, meedyevil $>$ Medieval, labboard $>$ larboard, nuther $>$ neither, ruputation $>$ reputation, sejest $>$ suggest, ketched > catched, vittles > victuals, and yaller $>$ yellow. These colloquial American pronunciations are very rich in local color, and being represented by standard Japanese, the original work loses the richness of colloquial language.

Most of the peculiarities of inflections are also represented by standard Japanese; for instance, warn't becomes wasn't, hain't becomes have not, or haven't; and hearn becomes hear. Other examples are: chaw $>$ chew, brung $>$ brought, bust $>$ burst, cuss $>$ curse, et $>$ eat, gap $>$ gape, looky-here $>$ look, spile $>$ spoil, hove $>$ heave, heril $>$ hers, his'n > his, knowed $>$ known, drownded $>$ drowned, 
yourn $>$ yours. The Japanese translation shows some effort to indicate these peculiarities of inflections by adapting them to Japanese colloquialisms, and applied to some of the low characters like Jim and Huck's father, but these changes of inflections appear very slightly at the last inflection of Japanese verbs, which cannot reproduce any similar effect as the original does. However, all other peculiarities of inflections used by Huck Finn, Tom Sawyer, Aunt Sally, and others are not reproduced at all except by standard Japanese.

Grammatical incorrectness is another feature of colloquial peculiarities. Among these are double negatives, split infinitives, reperitions of names, disagreements of numbers between subject and verb, past participles for past tense and vice versa, adverbs for adjectives, misuse of comparisons, and incorrect abbreviations of words. All of these grammatical peculiarities are represented by standard Japanese in the translation, and on the part of the translator there is no indication of effort to reproduce them in Japanese.

In the original, for example, double negatives are used throughout the book, and they are all represented by standard Japanese, like no--no by no. The split infinitive of to just take is rendered in just to take. Repetitions of names, characteristic of dialect, like Jim he and Judge 
Thatcher he are all avoided in the translation, as Jim and Judge Thatcher. In the disagreement of numbers it is rendered by standard Japanese, as I says becomes I say, and

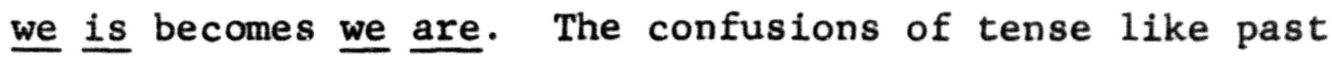
participles for past tense and vice versa often occur, and they are represented by standard Japanese, as I done becomes I did, it begun becomes $\underline{\text { it }}$ began, and $\underline{I}$ run becomes I ran. In the use of simple adjectives for adverbs they are also corrected in the translation, as dismal is rendered by dismally, mournful by mournfully, and considerable by considerably. Incorrect comparisons, such as blessedest, carelessest, worsest, and foolishest are rendered by most blessed, most careless, worst, and most foolish. The abbreviations that occur in the book are also typical of dialect and colloquial language, and in the translation they are used without any abbreviation and contraction, as 'low rendered by think, 'bout by about, $\underline{i n}$ by $\underline{i n g}$, and $\mathrm{p}^{\prime}$ simmons by persimmons. Also, inconsistencies of spellings, like crick and creek, gathered and gethered, and yellow and yallar, are all corrected and rendered consistently.

In the Japanese translation, as seen already in the above, there is no peculiarity of spelling, inflection, and grammar, and the language used there is standard Japanese. Peculiarities of spelling, inflection, and 
grammar are one of the most typical qualities of dialect and colloquial language, and their original local color is entirely lost in the translation because of being represented by standard Japanese.

\section{Expletives}

In Huckleberry Finn, beside the conventional expletives like Confound! For Goodness' sake! My God! and $\underline{0}$ Lord! there are many colloquial expletives, and these infinite varieties of expletives add to the vividness and vitality of the colloquial speech of the book. It seems difficult to find equivalent expletives in the Japanese language, and the Japanese translation repeatedly uses only a few conventional Japanese expletives. As a result, the effect is weak and flat, and the translation loses much of the conversational quality of the original colloquial speech.

Most of the colloquial expletives are replaced by conventional Japanese expletives. For example: goodness and I wish to
alone, dad fetch the whole
business!
(XXVII, 240) God damn! I wish I had just let it be alone.

Dad fetched is an oath akin to dadbinged, but it is represented by a much stronger conventional Japanese expletive, God Damn, which in Buddhism 1iterally means 
"Be a beast in hell after death!" Dog my cat! is also translated into God damn it!

But many times these strong colloquial expletives are represented by weaker Japanese interjections: ish.

Confound it, it is fool- Why, it is foolish.

$$
(\mathrm{XXXV}, 314)
$$

Confound is usually considered a milder form of imprecation, but translated into why, an interjection, which cannot be called an imprecation at all. Other examples are: I be dingbusted! becomes I am struck dumb! and Drot (Hang it)! becomes simply What?

Some expletives are not rendered as expletives, but expanded into an ordinary speech. For example:

. . and by Jimminy, away down through the texas-hall we see a light! (XII, 99)
And, to my surprise, away down through the texas-hall we see a light!

By Gemini (Jimminy) is a mild imprecation or an oath, and its meaning is expanded into to my surprise.

$$
\begin{aligned}
& \text { "Oh, dang it now, } \\
& \text { don't take on so }{\text { (XII, } 106)^{\prime}}^{\prime \prime}
\end{aligned}
$$

Dang, an imprecation, is an emphatic substitute for damn, but it is rendered in an ordinary speech, what happened to you?, rather than by an imprecation.

In the Japanese translation the use of strong colloquial expletives is avoided as much as possible, and 
the repetitions of a few conventional expletives only weakens the characteristic local color and vitality of colloquial language in the original.

Exclamations like Good Land! For the land's sake! are also translated into much weaker conventional Japanese exclamations like Oh! My! and Dear me! For example:

"Good land, duke, lemme hug you!"

$$
(\mathrm{XXV}, 221)
$$

"Indeed, duke let me hug you!"

Good 1and, an exclamation, is represented by a polite, standard Japanese exclamation, indeed.

\section{Figures of Speech}

One of the most outstanding qualities of the language of Huckleberry Finn is the effective use of figures of speech. Properly used, they make "a genuine contribution to understanding or to the appeal of the passage,"24 and they make the writing more concrete, and hence more alive and interesting. Figures of speech in Huckleberry Finn are vivid and picturesque, and drawn from familiar things found in the lives of most people.

Metaphors and similes are the figures of speech most often used in the book. Most of the metaphors are translated 1iterally, following the original use of

$$
24 \text { Perrin, p. } 231 .
$$


metaphors, and successfully represented in Japanese. For example:

. . it was white; not like another man's white, but a white to make a body sick, a white to make a body's flesh craw1--a treetoad white, a fish-belly white.

$$
(\mathrm{V}, 38)
$$

It was white. But it was not like other men's white. It was a white to make a person feel sick. It was a white to make a person's flesh crawl-a rainy toad's white. It was a fish-belly white.

Whiteness of pap's face is rendered in a very vivid and concrete image by the use of two metaphors, tree-toad white and fish-belly white. Both are faithfully translated into rainy toad white and fish-belly white. Treetoad, one of the family Hylidae, is adapted to Japanese rainy toad, which lives on the tree.

. . I lit out and shook the reefs out of my hind legs, and spun down the river road like a deer.

$$
\text { (XXXI, 275) }
$$

. . I ran away, and spread the reefs out of my hind legs, and spun down the river road like a deer.

$\underline{\text { Reef }}$ is one of the horizontal portions of a sail, and shook the reefs out of my hind legs is a metaphor for speeding up an activity. It is very well translated into Japanese without losing any original meaning.

Everybody loved to have him around, too; he was sunshine most always--I mean he made it seem like good weather. When he turned into a cloudbank it was awful dark for half a minute, and that was enough . . .
Everybody loved to have him around, too. He was sunshine almost always--I mean he made it seem like good weather. When he turned into a cloudbank, it was awfully dark for half a minute. And that was enough. 
Col. Grangerford's temper is vividly described by a comparison of sunshine and cloudbank. Especially vivid is the expression of "when he turned into a cloudbank it was awful dark for half a minute." These metaphors are literally translated into Japanese word for word, but very successfully represented.

A few metaphors, however, are occasionally not well translated. They are sometimes represented by abstract phrases, and not expressed as metaphors. For example:

And when they come to look at that spare room they had to take soundings before they could navigate it.

$$
(V, 42-43)
$$

And when they came to look at that spare ruom, it was all in disorder and had no space to step in.

The condition of the room is described by a picturesque steamboating term, to take soundings, and made it vivid and concrete. It gives an image of a ship carefully taking soundings to ascertain the depth of water and moving very slowly close to the shore. It is rendered not by a metaphor but by an ordinary phrase, it was all in disorder and had no space to step in. The original picturesque quality of the metaphor is utterly lost. to do but just hold still, and try and be ready to stand under when the lightning struck.

(XXXII, 289)
There was nothing to do but just hold still. And I must be ready to jump out from the underneath in case of emergency.

A metaphor of when the lightning struck is represented by 
an abstract, general phrase, in case of emergency. A concrete visual image is lost in the translation. In this sentence, stand under ("withstand or undergo") is misunderstood.

Many excellent metaphors in Huckleberry Finn are often comprised in one word--a verb, a noun, and an adjective. They are a concentration of meaning and an easy, rapid transfer of thought, and create a vivid, visual image. Since this kind of metaphor depends upon the concentration of one word, it is difficult to reproduce it in translation. Most of them are represented by general, abstract words. For example, "He was drunk, and weaving about in his saddle," is represented by "swaying on the saddle"; "they both fired off questions," by "asked questions one after another"; "Then Susan she waltzed in," by "she followed in"; "we snaked her out," by "drew out secretly"; "So she took and dusted us both," by "she beat us"; "When she come she was hot and red and cross," by "angry"; "wool-gathering memory," by "dull memory"; "our sailing order," by "our retreating order"; "the shovelfuls of dirt sailing up," by "throwing up"; "dark as sin," by "very dark"; and "one-horse log church," by "a small log church." Represented by abstract, general words in this way, the vivid images of the original are mostly lost in the translation. 
Similes also contribute greatly to the ease and clarity of meanings, and they produce a concrete and vigorous quality in the language of the book. Most of these similes are exactly rendered, and the original qualities maintained in the translation. For example:

. . . and a hard piece of corn-crust started down my throat after it and got met on the road with a cough, and was shot across the table, and took one of the children in the eye and curled him like a fishingworm, and let a cry out of him the size of a warwhoop $\cdot \cdot \cdot$ (XXXVII, 324-325)
And a hard piece of corn-crust started down my throat after it. And it met with a cough on the way, and was shot across the table, and took one of the children in the eye, and curled him like a fishing worm, and he made a cry like a warwhoop.

A simile, "curled him like a fishing-worm," describes the scene accurately and vigorously, and is excellently translated into Japanese. In the above example, among several metaphors used, one of them, the size of a warwhoop, is changed into a simile, like a warwhoop, in the translation.

hear the thunder let go
with an awful crash, and
then go rumbling, grumbling,
tumbling, down the sky
towards the underside of
the world, like rolling
empty barrels down stairs--
where it's long stairs they
bounce a great deal, you
know.

$$
\text { (IX, 76) }
$$

And next you'd hear the thunder go down with an awful crash. And then it goes rumbling, grumbling。 tumbling, down towards the underside of the world, like rolling barrels down stairs, they bounce a great deal, you know.

A simile, like rolling empty barrels down stairs, is an 
exact image of thunder; it adds to the understanding of the previous description of thunder through more familiar image of "empty barrels." Following every word of the original, the translation creates the same vivid image as the original.

. . and the blackest kind of eyes, sunk so deep back that they seemed like they was looking out of caverns at you, as you may say.

$$
\text { (XVIII, 146) }
$$

The eyes were very black. They sank so deep back that they seemed as if they were looking out of caverns at you, as you may say.

This description of Col. Grangerford's eyes by a simile, like they was looking out of caverns at you, conveys an accurate feeling of his eyes to the reader. It is well reproduced in the translation.

. . and she was coming in a hurry, too, looking like a black cloud with rows of glow-worms around it... .

$$
\text { (XVII, 133) }
$$

Moreover, it comes in a hurry. It looked like a black cloud with rows of glow-worms around it.

The above description of a steamboat in the night is vividly visualized by the use of a simile, looking like a black cloud with rows of glow-worms around it. The translation succeeds in reproducing the original quality. As metaphors and similes do, personifications also give inanimate things lively, active expression, and contribute to the vigorous, concrete, and specific quality of the language of Huckleberry Finn. Most of them are 
well represented by means of literal translation. Some of the examples of personifications are: "the leaves rustled in the woods ever so mournful" is represented by sadly in the translation; "the wind was trying to whisper something to me," exactly by trying to whisper; "a steamboat coughing along," by "coughing"; "I might say they [days and nights] swum by, they slid along so quiet and smooth and lovely," by swum by quietly, smoothly, and lovely, except slid by which is represented by gone by; and "cbreeze J comes fanning you," by fanning. Sometimes, however, they are represented by abstract, general words, as in "set the branches to tossing their arms as if they were wild," by shaking them [branches], and "breeze springs up" by starts blowing.

As seen in the above examples, figures of speech are well translated into Japanese. An appropriate use of metaphors, similes, and personifications contributes to strengthen the vitality of the language, and to make the book concrete and alive. The Japanese translation succeeds in representing their original quality of the language through literal translation.

Although different from figures of speech, onomatopoetic words could also be treated here together, because they are a useful form of intensification of meaning and sharpen the images of writings like any other 
figure of speech. Huckleberry Finn has a number of these onomatopoetic words, and they are very effectively used. Most of them are excellently translated into Japanese, and the original quality is immensely heightened. The method used in the translation is idiomatic translation, adapting to Japanese onomatopoetic words. For example, "an owl. . who-whooing" is adapted to Japanese onomatopoetic word, "an ow1. . . crying whoo-whoo"; "the leaves rustled," to "the leaves moved gasa-gasa," gasa-gasa being rubbing sounds of leaves, papers, or hard cloth; "a spider went crawling up my shoulder," to "shook my body mozo-mozo," mozo-mozo being a sensual sound of worms crawling on the skin; shriveled up to curled up zi-zi-zi, which is an audible sound of insects and wool shriveling up; boom (sounds of clock), to the exact Japanese expression, boom; "I heard a twig snap down," to "I heard the sound of a twig break pokin," pokin being a sound of a twig break; "rattled off poetry," to "wrote poetry pera-pera," pera-pera being a sound of rapid, fluent talk; "go rumbling, grumbling, tumbling," to "go goro-goro, goro-goro," goro-goro being a sound of rolling empty barrels in Japanese; and "the buzzing of the rain," to "the rain falling zah-zah," zah-zah being a sound of heavy raining. 
figure of speech. Huckleberry Finn has a number of these onomatopoetic words, and they are very effectively used. Most of them are excellently translated into Japanese, and the original quality is immensely heightened. The method used in the translation is idiomatic translation, adapting to Japanese onomatopoetic words. For example, "an owl. . who-whooing" is adapted to Japanese onomatopoetic word, "an ow1. . . crying whoo-whoo"; "the leaves rustled," to "the leaves moved gasa-gasa," gasa-gasa being rubbing sounds of leaves, papers, or hard cloth; "a spider went crawling up my shoulder," to "shook my body mozo-mozo," mozo-mozo being a sensual sound of worms crawling on the skin; shriveled up to curled up zi-zi-zi, which is an audible sound of insects and wool shriveling up; boom (sounds of clock), to the exact Japanese expression, boom; "I heard a twig snap down," to "I heard the sound of a twig break pokin," pokin being a sound of a twig break; "rattled off poetry," to "wrote poetry pera-pera," pera-pera being a sound of rapid, fluent talk; "go rumbling, grumbling, tumbling," to "go goro-goro, goro-goro," goro-goro being a sound of rolling empty barrels in Japanese; and "the buzzing of the rain," to "the rain falling zah-zah," zah-zah being a sound of heavy raining. 


\section{River and Nautical Terms}

In any study of Mark Twain's works river and steamboating terms have a special interest. American rivers and steamboats have very different features from those of Japanese rivers and steamboats. A mere literal translation therefore would not make Japanese readers fully understand these peculiar Americanisms and appreciate the book, unless they find equivalent terms in Japanese or are supplied with some explanations of the original terms.

Most American river and nautical terms are successfully represented in the translation by replacing them with Japanese equivalents and by expanding their meanings into Japanese. For example, texas is translated into upper deck cabins by adaptation. Texas is "the upper-most structure of a river-steamer, and contains the pilot house and officers' quarters (W)," and upper deck cabins in the translation is exact. Trading-scow, a typical American river boat, is translated into a flat-bottomed lighter, whose meaning is exactly the same as the original. Wharfboat, a boat supporting a platform and moored at a bank as a wharf, is adapted into floating wharf, which is also an exact translation of the original. Cord wood is expanded into cutwoods sold by the cord for fuel correctly. When some of these river and nautical terms, 
however, are literally translated into Japanese, the translation obviously fails in conveying the original meaning and leads to misunderstanding. Cylinder-head, a metal plate or cover closing the end of cylinder, is translated into the head of cylinder, which is neither clear nor precise. Deck passage means a conveyance of a passenger on the deck of a vessel. It is literaliy translated into a modern shipping term, deck passenger, which means the first or second class passengers on a big ship, and the original meaning is lost. Drift-canoe is, like drift boat, a boat for fishing with a drift net, and it is literally translated into drifting canoe, a misinterpretation. Drift-canoe is different from drifting canoe, and cannot be translated literally. But lumberraft, on the other hand, can be translated literally and yet still correctly. A verb like to saddle-bag ("to catch on an obstruction and double around it") is very hard to understand, and it is simply translated into to strike on the side, which does not make the original meaning clear.

\section{American Social and Political Terms}

In Huckleberry Finn there are many Americanisms associated with American political and social institutions, which have originated in American history and society. In translating these terms, the method of 
adaptation and expansion is inevitable to make the meaning clear to a Japanese reader.

In the Japanese translation these terms, social and political, are usually rendered by expansions. For example, abolitionist, a typical American term for the persons seeking the abolition of Negro slavery, is expanded into abolitionist of Negro slavery, whose original meaning is accurately reproduced. Since there is no Negro in Japan, Japanese has a word, black people, used for Negroes, African natives, and any other black-colored people in the world. Nigger, an American colloquial name of Negro with a connotation of contempt, has no equivalent in Japanese. Japanese colloquialism, nigger (a vulgarized form for Negro), has no relationship with slavery, and has no connotation of contempt at all. Japanese colloquial nigger is used in the translation for American nigger. Niggerhead and nigger-trader are translated into Japanese with a slight difference of meaning from the original. Indians is specified as American Indians in the translation, in order to distinguish them from people in India. To tar and feather (to smear with tar and then cover with feathers) originated in American Indians, and it is exactly translated into Japanese by means of expansion. When these Americanisms are translated literally, however, they will not make the original meaning clear. For 
example, free state is literally translated into free state without any expansion, and it cannot explain the original meaning fully to a person who is ignorant of American history.

Among religious terms the method of expansion is also used. Most Japanese people are not Christians, and consequently it is necessary to explain the original meaning. For example, good place Huck talks about is expanded into the Heaven, and bad place into the Hell. To get religion, U.S. vulgar, is expanded into to be converted. But camp-meeting is literally transleted into outdoormeeting without any expansion, and one cannot tell what kind of an outdoor-meeting it is.

\section{American Dwelling and Landscape Terms}

Names of American dwellings and landscapes are some of the most typical Americanisms inseparable from American life. The method of translation is, as in the previous section, idiomatic translation, and the original is expanded to be understandable.

Most Americanisms of American landscapes are well translated into Japanese. For example, bottom is a valley or a low-1ying land, and it is correctly represented by the Japanese equivalent, low-lying land. Towhead is a sand bar made by the silting up of mud around sunken trees 
and through other causes, and it is in the continual process of formation. In the translation it is exactly rendered by an equivalent word, sand bar. Creek and slough are also exactly represented by Japanese equivalents.

In translating American plants and animals, the translation uses either expansion or adaptation of idiomatic translation. A moccasin (water-moccasin) is expanded into a venomous snake living in the water, and the kind of snake is well explained. Whippoorwill (whippowill) is represented by night hawk, which is not exactly the same kind of bird, but which flies in the night like the whippoorwill. Tree-toad is a toad of arboreal habits, especially that of the family Hylidae found chiefly in tropical America. It is represented by rainy toad, which lives on the tree, and whose color, originally green, is quite changeable. Among plants, for example, corn-shuck is exactly represented by corn-husk. Cottonwood is also well represented by the equivalent, white poplar. Hickory is translated according to its original pronunciation in katakana spellings, hikkori. Greens is adapted into vegetable, and corn-pone into corn bread.

Americanisms of dwellings and clothings are also successfully translated into Japanese by means of idiomatic 


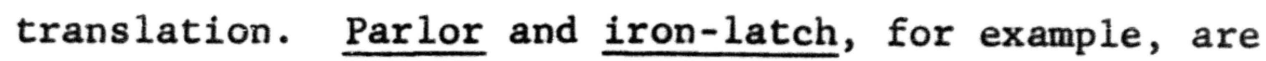
exactly translated by the equivalent words, guest room and iron-latch. Split-bottom chair, a chair having the bottom or seat made of interwoven splints, is replaced by a wisteria chair, whose outward appearance is similar to the original. Among some Americanisms relating to clothes, calico is expanded into cotton cloth; gallows (galluse) into suspenders for trousers; jeans into cotton cloth; roundabout into short jacket; scoop-shovel bonnet is expanded into a bonnet with a shape like a black scoop for digging the soil; and store clothes into the clothes purchased at the store.

\section{Proper Nouns}

The usual practice of rendering European proper nouns into Japanese is accomplished by means of katakana spellings. Having forty-eight characters, katakana can spell out any word according to the original pronunciation, and it is the only Japanese system capable of rendering European proper names into Japanese. In translating the criginal proper nouns, the translation succeeds in reproducing them.

A person's name is generally translated into Japanese faithfully without changing the original spellings. Widow Douglas is translated into Widow Douglas, 
Buck into Buck, Moses into Moses, Huck into Huck, Tom Sawyer into Tom Sawyer, Grangerford into Grangerford, and Sally into Sally. Such spellings as $\underline{\mathrm{R}-0-0-m e o}$ and G-e-o-r-g-e J-a-c-k-s-o-n of the original are faithfully translated in the translation. Some incorrect spellings of names found in the original, however, are mostly corrected in the translation, as Sollermun into Solomon, $\underline{A-r a b s}$ into Arabs, Jawge into George, and Looy into Louis. Titles are also rendered faithfully, as Aunt Polly into Aunt Polly, Judge Thatcher into Judge Thatcher, Miss Watson into Miss Watson, Widow Douglas into Widow Douglas, and Aunt Sally into Aunt Sally. The steamboat, the Walter Scott, is exactly rendered by the Walter Scott. Mars Jawge and Mars Tom are adapted to the $\underline{M r}$. George and $\underline{M r}$. Tom that a servant calls his master in Japan. Certain inconsistencies, however, are noted: Miss is added to Mary, but not to Emmeline and Mary Jane. Harvey and William, though respectable persons, are not called $\underline{\text { Mr}}$.

Place names are translated according to the original spellings, as Arkansaw into Arkansaw, Cairo into Cairo, St. Petersburg into St. Petersburg, Hookerville into Hookerville, and (New) Orleans into Orleans. Some proper names are expanded, too, as Birnam Wood into the wood of Birnam, Pudding Lane into Pudding lane, Bulum's Ass into Bulum's ass, and Drury Lane into Drury Lane. Booth's 
Landing, the name of a town, is mistaken for the name of a ferry landing, Booth's landing.

Summary. This study of the language used in the Japanese translation of Huckleberry Finn leads to a number of important conclusions in regard to the methods employed and the qualities of the language thus achieved in the translation.

The basic method used in the Japanese translation used in this study is that of literal translation. Throughout the book the Japanese translation follows the language of the original work word for word, and attempts to translate every word as closely as possible. The method of idiomatic translation is applied to the words whose meanings need to be clarified either by adaptation or by expansion. The method of paraphrastical translation is not used in the translation at all.

The method of literal translation is employed generally all through the book, and especially in translating standard English into Japanese. Nearly all the standard English of the original is represented in the iranslation by standard Japanese. The result of this method applied to standard English is successful. The Japanese translation reproduces the quality of the original faithfully and keeps the translated meanings very close to 
the original. This is seen in most standard nouns, verbs, adjectives, idiomatic phrases, some figures of speech, and Americanisms. Occasionally, however, misinterpretations and the representation of the original simply according to dictionary meaning are noticed, but the extent is rather small.

The most characteristic feature of the language of Huckleberry Finn is the American informal, colloquial language. American colloquialisms, dialects, slang, and archaisms are extensively used in the book, and they have concreteness, vitality, and rich, local connotation. The effective use of this American informal, colloquial language contributes to the informal and conversational quality of the language of the book. In translating them, the methods used in the translation are literal translation and idiomatic translation. The method of literal translation is mainly used to represent the informal, colloquial la:auage of the original by standard Japanese, and the method of adaptation is used to adapt the original to the Japanese colloquial language.

Idiomatic translation is the only method capable of reproducing the informal, colloquial language of the original. Adaptation and expansion are most helpful. Its effectiveness is successfully illustrated in translating figures of speech and Americanisms. Metaphors, similes, 
personifications, and onomatopoetic words are vividly translated into Japanese. Americanisms relating to rivers and steamboating, to political and social institutions, to dwellings and landscapes, and proper nouns, are also successfully translated by means of idiomatic translation. They are either adapted to the Japanese equivalent, or their original meanings are expanded so as to make them understandable.

In the Japanese translation, however, the method of literal translation is more frequently used than that of adaptation. Most of the informal, colloquial language is represented by formal, standard Japanese. The translation, as a result, loses the informal and conversational quality of the original language. Concreteness, vitality, and the rich, local connotations of the American informal, colloquial language are represented by abstract, general, standard Japanese. This is illustrated in the translation of nouns, verbs, adjectives, adverbs, phrases and idioms, and expletives of the colloquial language, and also in the peculiarities of spelling, inflection, and grammar. The Japanese translation, therefore, fails to reproduce the original quality of the language by literal translation. Misinterpretations and obscure passages are sometimes noticed in the translation. Chiefly they come from the difficulty of understanding the colloquial language of 
the original, and from carelessness on the part of the translator. These misinterpretations and obscure passages are small in number, but they mar the quality of the original language. 


\section{CHAPTER III}

\section{SENTENCES}

The sentence is a unit of expression in prose, and it plays, as well as the word, an important role in determining the qualities of style. Style is "a quality of language which communicates precisely emotions or thoughts, or a system of emotions or thought, peculiar to the author, $" 1$ and in the composition of sentences a writer can have his own characteristic manner of expression different from others. The variations of his expression in the sentence include length, structure, and rhythm.

It is the purpose of this chapter first to discuss the qualities of the sentences of Huckleberry Finn in the original, and then to compare it with those of the Japanese translation, in order to discover the qualities of the sentences of the translation in relation to those of the original. The study is made in terms of length, structure, and rhythm, and their stylistic qualities.

\section{Length}

Variation in the length of sentences in Huckleberry Finn contributes significantly to the stylistic quality of

$1_{J}$. Middleton Murry, The Problem of Style (Oxford, 1925), P. 71. 
the book. The sentences range from short, pithy ones of a few words to long, rambling sentences of over two hundred words. Long sentences are mostly found in the descriptive passages of nature, people, and objects, and in some reflective passages. They are used for the purpose of reproducing the conversational movement of speech as a series of clauses added one after another, as in ordinary conversation, and they produce a smooth, fluent conversational effect. Short sentences, on the other hand, are usually found in active and emotional passages in order to convey an impression of speed. Some of them are, however, very short: pithy sentences of three or four words coming between or after long sentences, and serve as what Mark Twain calls "snappers."2 They are used to produce very effectively a sudden shift in the sentence movement, and give variety to the length of sentence. Consequently, both long sentences and short sentences contribute to the variety of the sentence length and to the vitality of the stylistic quality of the book.

In the Japanese translation, however, there is very little variation in sentence length. Every long, rambling sentence is shortened into several sentences of average sentence length, and every short, pithy sentence is

2 "How to Te11 a Story," How to Te11 a Story and Other Essays (New York, 1897), p. 9 . 
enlarged into a sentence of average length. The sentence length in the translation, in other words, is average; and the translation has very little variation of the sentence length. It does not, therefore, reproduce the vitality of the style attained in the original by the variety of sentence length. For example:

We1l, there was a big out-landish parrot on each side of the clock, made out of something like chalk, and painted up gaudy. By one of the parrots was a cat made of crockery, and a crockery dog by the other; and when you pressed down on them they squeaked, but didn't open their mouth nor look different nor interested. They squeaked through underneath. There was a couple of big wildturkey-wing fans spread out behind those things. On the table in the middle of the room was a kind of a lovely crockery basket that had apples and oranges and peaches and grapes piled up in it, which was much redder and yellower and prettier than real ones is, but they warn't real because you could see where pieces had got chipped off and showed the white chalk, or whatever it was, underneath.

(XVII, 140-141)
We11, there was a big outlandish parrot on each side of the clock. They were made of something like chalk, and painted up ostentatiously. By one of the parrots was a crockery cat. By the other was a crockery dog. And when you pressed down on them, they squeaked. But they didn' $t$ open their mouths, nor look different nor interested. They squeaked through the underneath. And behind these things there was a couple of fans made of big wild turkey wing spread out. On the middle of the room there was a lovely crockery basket. In it apples and oranges and grapes were piled up. They were much redder, yellower, and prettier than real ones. But they were not real. Because ycu could see where pieces had been chipped off and showed the white chalk or something underneath.

In the original paragraph only five sentences are used, and in the translation, on the other hand, fourteen sentences 
are used for the same paragraph. Nearly every comma and semi-colon is replaced by a period. In the original a short, pithy sentence of four words, "They squeaked through underneath," is inserted in the midst of four long sentences averaging thirty-four words. This sudden shift of the sentence length is not found in the translation because it has shortened every long sentence into the average sentence length throughout the paragraph.

Once or twice of a night we would see a steamboat slipping along in the dark, and now and then she would belch a whole world of sparks up out of her chimbleys, and they would rain down in the river and look awful pretty; then she would turn a corner and her lights would wink out and her powwow shut off and leave the river still again; and by and by her waves would get to us, a long time after she was gone, and joggle the raft a bit, and after that you wouldn't hear nothing for you couldn't tell how long, except maybe a frog or something.

$$
\text { (X IX, 163-164) }
$$

Once or twice a night we would see a steamboat slipping along in the dark. And now and then the steamboat would belch a great deal of sparks out of the chimney. And these sparks would fall down in the river like rain, and look awfully pretty. Then the steamboat would turn a corner, and its lights would wink out, its noise shut off, and leave the river still again. By and by, along time after it was gone, the steamboat's waves would get to us, and joggle the raft a bit. And after that you wouldn't hear nothing for so long time that you couldn't tell how long. If there is any sound, it would be frogs or something.

In the above description of a steamboat on the river, the whole paragraph consists of a single sentence of one hundred and ten words. The translation breaks it up at 
almost every comma and semi-colon, making seven sentences out of the original one. Since the conversational quality of a long, rambling sentence is hindered by many flat sentences of average length, the variety and vitality of the description in the original are greatly diminished in the translation.

The person coming was Mary Jane. She went to the coffin, very soft, and kneeled down and looked in; then she put up her handkerchief, and I see she begun to cry, though I couldn't hear her, and her back was to me. I slid out, and as I passed the dining-room I thought I'd make sure them watchers hadn't seen me; so I looked through the crack, and everything was all right. They hadn't stirred.

(XXVII, 236)
The person who came down was Mary Jane. She went to the coffin very quietly, and kneeled down and looked in. Then she took out her handkerchief, and I saw her started crying. Though I couldn't hear her. And her back was toward me. I slid out, and as I passed the dining-room, I thought I'd make sure that watchers didn't see me. So I looked through the crack. Everything was all right. They hadn't stirred.

This paragraph has two very short sentences and two very long sentences. The paragraph starts with a six-word sentence and ends with a three-word sentence. The average length of the two long sentences between these two very short sentences is thirty-three and half words. Two short, pithy sentences at the beginning and at the end give variety to the sentence movement; the last, three-word sentence especially gives an effective conclusion to the paragraph as a snapper. The Japanese translation, however, 
almost every comma and semi-colon, making seven sentences out of the original one. Since the conversational quality of a long, rambling sentence is hindered by many flat sentences of average length, the variety and vitality of the description in the original are greatly diminished in the translation.

The person coming was Mary Jane. She went to the coffin, very soft, and kneeled down and looked in; then she put up her handkerchief, and I see she begun to cry, though I couldn't hear her, and her back was to me. I slid out, and as I passed the dining-room I thought I'd make sure them watchers hadn't seen me; so I looked through the crack, and everything was all right. They hadn't stirred.

(XXVII, 236)
The person who came down was Mary Jane. She went to the coffin very quietly, and kneeled down and looked in. Then she took out her handkerchief, and I saw her started crying. Though I couldn't hear her. And her back was toward me. I slid out, and as I passed the dining-room, I thought I'd make sure that watchers didn't see me. So I looked through the crack. Everything was all right. They hadn't stirred.

This paragraph has two very short sentences and two very long sentences. The paragraph starts with a six-word sentence and ends with a three-word sentence. The average length of the two long sentences between these two very short sentences is thirty-three and half words. Two short, pithy sentences at the beginning and at the end give variety to the sentence movement; the last, three-word sentence especially gives an effective conclusion to the paragraph as a snapper. The Japanese translation, however, 
has nine sentences in the same paragraph, which are composed of average sentences. The variety and vitality arising from two very short sentences of the original therefore are not reproduced in the translation.

The short, vigorous sentences frequently found in active passages produce the rapid movement of action or thought very effectively in the original. In translating these sentences of action, the translation retains the length of the original sentences, thus successfully reproducing the vigorous stylistic quality of short sentences and the actual impression of speed. For example:

It made me shiver. And I about made up my mind to pray, and see if I couldn't try to quit being the kind of a boy $I$ was and be better. So I kneeled down. But the words wouldn't come. Why wouldn't they? It warn't no use to try and hide it from Him. Nor from me, neither. I knowed very welil why they wouldn't come.

$$
\text { (XXXI, 277) }
$$

The thought made me shiver. And I had almost made up my mind to pray and see if I couldn't try to quit being the kind of a boy I was and be better. So I kneeled down. But the word wouldn't come. Why wouldn't come? It was no use to try and hide it from God. No use to try and hide it from me, neither. I knew very well why they wouldn't come.

In the original there are many very short sentences used to describe Huck Finn's emotional struggle in determining whether to be good or bad. His action and emotional reaction are vigorously expressed by short, vivid sentences. The translation succeeds in conveying this feeling by means of the same short, vivid sentences as in 
the original.

\section{Sentence Structure}

The sentence structure of Huckleberry Finn makes an important contribution to the stylistic quality of the book. As to the significance of the virtues of American vernacular in the prose of Huckleberry Finn, Lionel Trilling says, "Most of all it [ the style of the book] has to do with the structure of the sentence, which is simple, direct, and fluent, maintaining the rhythm of the wordgroups of speech and the intonations of the speaking voice. 13

Sentences in their variety run from simplicity to complexity, and some sentences, regardless of their length, can be very complex in structure. It is the simplicity of sentence structure rather than the sentence length that makes the long, rambling sentence of Huckleberry Finn very readable and easily comprehensible. It is also this quality of simple sentence structure that gives the conversational quality and the smooth, fluent flow of actual speech to the style of the book. There are, however, considerable variations in the types of sentences. Variety in the sentence structure, which is necessary if a book is

${ }^{3}$ Lionet Trilling, The Liberal Imagination (Garden City, N.Y., 1953), p. 117 . 
to be readable and vivid, is reflected in sentences varying in length and kind, the occasional use of inverted sentence order and incomplete sentence structure, and the variations in the initial element of the sentence. Both the simplicity and the variety of the sentence structure contribute to the conversational quality and vitality of the style of the sentence in Huckleberry Finn.

In the sentence structure of Huckleberry Finn simple, compound, complex, and compound-complex sentences are employed to give variety to the style of the book. In short, pithy sentences and in sentences of ordinary length the simple and compound sentences predominate. But in long, rambling sentences the complex and the compoundcomplex sentences are frequently used together with the simple and compound sentences, thus producing variety of sentence structure.

As has been seen above, the Japanese translation tends to use short, simple sentences, and the number of simple sentences in the translation far surpasses that of the original. Consequently, the Japanese translation is much simpler in sentence structure and easier to read than the original; but in gaining simplicity, it sacrifices variety. Having too many simple sentences with little variation, it lacks the variety and vitality of the original sentence structure. For example: 
But by and by pap got too handy with his hick'ry, and I couldn't stand it. I was all over welts. He got to going away so much, too, and locking me in. Once he locked me in and was gone three days. It was dreadful lonesome. I judged he had got drowned, and I wasn't ever going to get out any more. I was scared. I made up my mind I would fix up some way to leave there. I had tried to get out of that cabin many a time, but I couldn't find no way. There warn't a window to it big enough for a dog to get through. I couldn't get up the chimbly; it was too narrow. The door was thick, solid oak slabs.

$$
\text { (VI, 45-46) }
$$

But soon pap got too handy with his hickory stick. And I couldn't stand it. I was all over welts. Pap got to going away frequently, too, and locking me in. Once he locked me in and was gone three days. It was dreadfully lonesome. I thought he had been drowned. And I thought I could ever get out of the cabin no more. I became scared. I made up my mind to device some way to leave there. I had tried to get out of that cabin many a time, but it was impossible There was no window big enough for a dog tu go through. I couldn't get up the chimney. It was too narrow. The door was thick, solid oak slabs.

In the above the original has seven simple sentences, three compound sentences, and two complex sentences. The translation, on the other hand, has twelve simple sentences and three compound sentences. The translation has much simpler sentence structure than the original, but it has very little variety in sentence structure because of the use of too many simple sentences in the same paragraph.

About an hour after dinner everybody was dozing around, some in their chairs and some in their rooms, and it got to be pretty dull. Buck and a dog was stretched out on
About an hour after dinner everybody was taking a nap. Some in their chairs, some in their rooms. And it got pretty dull. Buck and a dog were stretched out on the grass 
But by and by pap got too handy with his hick'ry, and I couldn't stand it. I was all over welts. He got to going away so much, too, and locking me in. Once he locked me in and was gone three days. It was dreadful lonesome. I judged he had got drowned, and I wasn $t$ ever going to get out any more. I was scared. I made up my mind I would fix up some way to leave there. I had tried to get out of that cabin many a time, but I couldn't find no way. There warn't a window to it big enough for a dog to get through. I couldn't get up the chimbly; it was too narrow. The door was thick, solid oak slabs.

$$
\text { (VI, 45-46) }
$$

But soon pap got too handy with his hickory stick. And I couldn't stand it. I was all over welts. Pap got to going away frequently, too, and locking me in. Once he locked me in and was gone three days. It was dreadfully lonesome. I thought he had been drowned. And I thought I could ever get out of the cabin no more. I became scared. I made up my mind to device some way to leave there. I had tried to get out of that cabin many a time, but it was impossible There was no window big enough for a dog to go through. I couldn't get up the chimney. It was too narrow. The door was thick, solid oak slabs.

In the above the original has seven simple sentences, three compound sentences, and two complex sentences. The translation, on the other hand, has twelve simple sentences and three compound sentences. The translation has much simpler sentence structure than the original, but it has very little variety in sentence structure because of the use of too many simple sentences in the same paragraph.

About an hour after dinner everybody was dozing around, some in their chairs and some in their rooms, and it got to be pretty dull. Buck and a dog was stretched out on
About an hour after dinner everybody was taking a nap. Some in their chairs, some in their rooms. And it got pretty dull. Buck and a dog were stretched out on the grass 
the grass in the sun sound asleep. I went up to our room, and judged I would take a nap myself. I found that sweet Miss Sophia standing in her door, which was next to ours, and she took me in her room and shut the door very soft, and asked me if I liked her, and I said I did; and she asked me if I would do something for her and not tell anybody, and I said I would. Then she said she'd forgot her Testament, and left it in the seat at church between two other books, and would I slip out quiet and go there and fetch it to her, and not say nothing to nobody. I said I would. So I slid out and slipped off up the road, and there warn't anybody at the church, except may be a hog or two, for there warn't any lock on the door, and hogs likes a puncheon floor in summertime because it's cool. If you notice, most folks don't go to church only when they've got to; but a hog is different.

(XVIII, 152) in the sun and sound asleep. I went up to our room. And I thought to take a nap myself. I found sweet Miss Sophia standing in her door. It was next to ours. And she took me in her room, and shut the door very softly. And she asked me if I liked her. And I said I did. And she asked if I would do something for her and not tell anybody. And I said I would. Then she said she had forgotten her Testament. Left it in the seat at church between two other books. Would I slip out quiet, and 80 to the church, and fetch it to her, not say anything to anybody. So, when I slipped out to the church, there was nobody there. There were only a hog or two.

Because the door wasn't locked. And hogs like a puncheon floor in summer time. Because it is cool. If you notice, most folks don' $t$ go to church only when they have to go. But a hog is different from them.

In the above paragraph the original has eight sentences composed of one simple sentence, one compound sentence, two complex sentences, and four compound-complex sentences The Japanese translation has twenty-three sentences in the same paragraph, having seventeen simple sentences, six compound sentences, and no complex, compound-complex 
sentence at all. While the original has sentences of various types, the majority of the sentences in the translation are simple ones; although they are simple and readable, the effect is flat and monotonous.

Another feature of the sentence structure of Huckleberry Finn is loose sentences. Generally used in long, rambling sentences, loose sentences are characteristic of conversation, and contribute to the conversational quality of the book. The repetitions of unnecessary words being carefully avoided in the book, the loose sentences become more alive, vigorous, and also rhythmical in the sentence movement.

In the translation, however, loose sentences are mostly represented by simple sentences, which are less conversational and rhythmical. Also the unnecessary repetitions of unemphatic words make the translation verbose and weak. For example:

After breakfast I wanted to talk about the dead man and guess out how he come to be killed, but Jim didn't want to. He said he would fetch bad luck; said a man that warn't buried was more likely to go a-hunting around than one that was planted and comfortable. That sounded pretty reasonable, so I didn't say no more; but I couldn't keep from studying over it and wishing I knowed who shot
After breakfast I wanted to talk about the dead man and guess how he came to be killed. But Jim didn't want it. He said it would fetch bad luck. He said moreover that a man who wasn' $t$ buried is more likely to go hunting around than the one that wasn't buried and comfortable. That sounded very reasonable. So I didn't say any more. But I couldn't keep from 
the man, and what they done it for.

$$
(\mathrm{X}, 80)
$$

thinking over it. And I wished I knew who shot the man and what they did it for.

In the above the main statement and subordinate statements in the original sentence are put together one after another in one sentence, and they achieve a rambling, but smooth, conversational quality of the sentence. The translation, on the other hand, separates the main statement from the subordinate, and making it an independent sentence, robs it of the informal and conversational quality of the original loose sentence structure.

As a short, pithy sentence adds variety to a long, rambling sentence, so does the inverted sentence: a departure from the usual order of sentence elements adds variety to the ordinary pattern of sentences. In Huckleberry Finn the inverted sentence sounds natural when, for instance, one wants to express his deep emotion and stress a certain word or thought in conversation; without being a mannerism it contributes to the variety and vitality of the stylistic qualities of the book. This inverted sentence structure is very difficult to reproduce in Japanese because of the nature of the Japanese language; and without it, the translation loses some of the variety and vitality of the original. For example:

Every night we passed towns, some of them away up towns. Some of them were 
black hillsides, nothing but just a shiny bed of lights; not a house could you see. away up black hillside. And they looked just like a shiny bed of lights. You could see not one house.

The inversion, not a house could you see, emphasizes not a house by inverting the normal sentence order and maintains the heightened descriptive passage preceding it. It also adds to the variety of sentence structure along with the previous sentence, which disregards all unnecessary words and is composed of emphatic phrases. In the translation, on the other hand, the original sentence is divided into three sentences, each being rendered in a complete and normal sentence structure and order. As a result, much of the stylistic interest of the original sentence is lost in the translation.

It was the raft, and mighty glad was we to get aboard of it again. (XIII, 105)
It was the raft. And we were very glad to get aboard on it again.

The inversion of mighty glad was we is used to emphasize the adverbial phrase, mighty glad, which very naturally expresses the feeling of being relieved from a dangerous adventure. The translation, however, expresses it in a normal sentence order without any special emphasis, and fails to convey the vitality of the original expression. Although the inverted sentence structure is not found in the Japanese language, Japanese has other ways to express 
black hillsides, nothing but just a shiny bed of lights; not a house could you see.

$$
\text { (XII, 96) }
$$

away up black hillside. And they looked just like a shiny bed of lights. You could see not one house.

The inversion, not a house could you see, emphasizes not $\underline{\text { a }}$ house by inverting the normal sentence order and maintains the heightened descriptive passage preceding it. It also adds to the variety of sentence structure along with the previous sentence, which disregards all unnecessary words and is composed of emphatics phrases. In the translation, on the other hand, the original sentence is divided into three sentences, each being rendered in a complete and normal sentence structure and order. As a result, much of the stylistic interest of the original sentence is lost in the translation.

It was the raft, and mighty glad was we to get aboard of it again. (XIII, 105)
It was the raft. And we were very glad to get aboard on it again.

The inversion of mighty glad was we is used to emphasize the adverbial phrase, mighty glad, which very naturally expresses the feeling of being relieved from a dangerous adventure. The translation, however, expresses it in a normal sentence order without any special emphasis, and fails to convey the vitality of the original expression. Although the inverted sentence structure is not found in the Japanese language, Japanese has other ways to express 
the same quality of the inverted sentence, such as by abbreviating the adjective and verb inflections, by putting down only emphatic words, and so on. But these characteristic manners of Japanese are very seldom used in the translation.

The use of incomplete sentences is another feature of the sentence structure of Huckleberry Finn. Frequently subjects and verbs are left out of the sentence, but the statements are nevertheless complete and independent, and can easily be understood from the context. Omitting unstressed words tends to emphasize the words included, making the expression direct and straightforward. These incomplete sentences are commonly used in conversation and in informal, familiar writings, and they tend to be conversational and informal. In addition, these incomplete sentences give rhythmical and heightened quality to the style.

In the Japanese translation these incomplete sentences of the original are all rendered by complete sentences, and the result is that the sentences in the translation are less conversational and informal, less direct and straightforward, and much less vital than the original sentences. Especially in translating a long sentence, the translation breaks the original sentence into several short sentences. Whenever these several short 
sentences are reproduced by complete sentences, the repetitions of unnecessary and unemphatic words make the sentence movement clumsy and awkward. For example:

But I didn't do it straight off, but laid the paper down and set there thinking--thinking how good it was all this happened so, and how near I come to being lost and going to hell. And went on thinking. And got to thinking over our trip down the river; and I see Jim before me all the time: in the day and in the nighttime, sometimes moonlight, sometimes storms, and we a-floating along talking and singing and laughing. (XXXI, 278)
But, instead of praying at once, I laid the paper down and sat there thinking--how good it was all this happened so, and how close I was to be lost and gone to hell. And went on thinking. And began to think over our trip down the river. I could see Jim before me all the time. I could see him before me in the day and in the night. Sometimes it was moonlight, sometimes it was storms. And talking, singing, and laughing we were floating along.

In the above example there are two sentences without subjects. As often happens in conversation, $\underline{I}$ is omitted because of its frequent use, and it is understood from the context. Japanese has the same habit of omitting personal pronouns both in formal and informal writings, and these two subjectless sentences are reproduced into Japanese without any change of Japanese sentence structure. In the original, however, there are two clauses without verbs after a colon, "in the day and in the night-time, sometimes moonlight, sometimes storms, and we a-floating . . . " In the translation subjects and verbs are added to them, and they are rendered in a complete sentence form 
as "I could see him before me in the day or in the night. Sometimes it was moonlight, storms. And . . we were floating along." Verbs and subjects being supplied in a complete form, the translation does not maintain the conversational and rhythmical quality of the original sentence and the vitality it attains by economy, and it besomes very verbose and flat.

Not a sound anywhere-perfectly still--just like the whole world was asleep, only sometimes the bullfrogs a-chuttering, maybe. The first thing to see, looking away over the water, was a kind of dull line--that was the woods on $t$ 'other side; you couldn't make nothing else out; then a pale place in the sky; then more paleness spreading around; then the river softened up away off, and warn't black any more, but gray; you could see little dark spots drifting along ever so far away-trading scows, and such things; and long black streaks--rafts; sometimes you could hear a sweep screaking; or jumbled up voices, it was so still, and sounds comes so far. .

$$
\text { (X IX, 161) }
$$

There was not a sound anywhere--perfectly still-it was as if the whole world were asleep. Only the bullfrogs clutter sometimes. Looking away over the water, the first thing to see was a kind of dull line--that was the woods on the other side. You can't make anything else out. Then a spot in the sky begins to pale. Then it spreads around more and more. Then the river softens up away off. And it is no more black but gray. You can see little dark spots drifting along very far away--they are trading scows and others. And then you can see long black streaks--they are rafts. Sometimes you can bear a sweep screaking. Or, you can hear jumbled up voices. It is so still, and sounds come so far away.

In the above the selection begins with an incomplete sentence, and repetitions of subjects and verbs are avoided throughout the paragraph: semi-colons, commas, and 
dashes are used to indicate the omission of these unnecessary words. The sentence does not in the least lose meaning. The important words being emphasized, the meaning is actually clarified and the sentence moves smoothly and rhythmically, attaining a heightened quality of style. The translation, on the other hand, has complete sentences, and the repetitions of unnecessary words make the descriptive passages very clumsy and awkward. The variety and the conversational rhythm of the original sentence are not successfully reproduced in the translation.

An appropriate use of conjunctions and connective adverbs is another factor to determine the conversational quality and the smooth, easy flow of the sentence. Instead of the conjunctions and connective adverbs used in the formal writings such as however, in spite of, either . . or, nevertheless, accordingly, in order that, and consequently, the book uses the conjunctions and connective adverbs most commonly used in ordinary conversations and in informal writings, such as and, but, or, so . . (that), then, and so. They are simple and straightforward conjunctions and connective adverbs, and contribute a good deal to the informal, conversational quality, and hence the readability, of the book. Besides, in a long, rambling sentence, they contribute to the 
smooth, easy flow of the sentence.

In translating these informal conjunctions and connective adverbs, the Japanese translation follows every word of the original very faithfully, and most of them are well reproduced in Japanese. The reproduction of every word, however, does not necessarily succeed in reproducing the original style exactly in Japanese. And, for instance, one of the most common conjunctions, is translated into Japanese every time, but the frequent use of and is not natural to Japanese, and produces a clumsy translational effect. Especially when and stands at the beginning of every short sentence, does it produce a rather clumsy sentence movement instead of the smooth, conversational movement and readability of a long, rambling sentence in the original. Because, for, then, and so, are also very often used in the book, but in the Japanese translation they stand most frequently at the beginning of the sentence, instead of that of the subordinate clause. Consequently, their translation results in a very poor sentence structure in Japanese, where subordinate clauses or modifiers always stand before the main clause or word. The literal translation of conjunctions makes the sentence sometimes unnatural. For example:

When him and the old lady When he and the old lady come down in the morning ali came down from the upstairs the family got up out of in the morning, all the 
their chairs and give them good-day, and didn't set down again till they had set down. Then Tom and Bob went to the sideboard where the decanter was, and mixed a glass of bitters and handed it to him, and he held it in his hand and waited till Tom's and Bob's was mixed, and then they bowed and said, "Our duty to you, sir, and madam;" and they bowed the least bit in the world and said thank you, and so they drank, all three, and Bob and Tom poured a spoosiful of water on the sugar and the mite of whisky or apple brandy in the bottom of their tumblers, and give it to me and Buck, and we drank to the old people, too.

$$
\text { (XVIII, 147) }
$$

family got up from their chairs and gave them goodday, and didn't sit down till they had sat down. Then Tom and Bob went to the sideboard where the decanter was, and mixed a glass of bitters and handed it to him. And he held it in his hand and waited till Tom and Bob mixed theirs. And Tom and Bob bowed and said, "Our children's duty to you, sir and madam." And they bowed very little and said thank you. And then all three drank it. And Bob and Tom poured a spoonful of water on the sugar and the mite of whisky or apple brandy in the bottom of their tumblers, and gave it to me and Buck, and we drank it to the old people, too.

The above paragraph has twenty-five conjunctions and connective adverbs in the original, and every one of them is reproduced in the translation. The sentences in the original are only two, and those of the translation are seven. In the translation five sentences out of seven begin with and, and only one with then. Although the conjunctions in the translation are informal and conversational, the frequent repetition of and at the beginning of sentences diminishes the original quality of style and flattens the sentence movement.

Little Tommy Barnes was asleep now, and when they
Little Tommy Barnes was asleep now. And when they 
waked him up he was scared, and cried, and said he wanted to go home to his ma, and didn't want to be $a$ robber any more.

So they all made fun of him, and called him crybaby, and that made him mad, and said he would go straight and tell all the secrets. But Tom give him five cents to keep quiet, and said we would all go home and meet next week, and rob somebody and kill some people.

Ben Rogers said he couldn't get out much, only Sundays, and so he wanted to begin next Sunday; but all the boys said it would be wicked to do it on Sunday, and that settled the thing. They agreed to get together and fix a day as soon as they could, and then we elected Tom Sawyer first captain and Jo Harper second Captain of the Gang, and so started home.

$$
\text { (II, 26-27) }
$$

woke him up, he was scared and cried. And he said he wanted to go home to his ma, and didn't want to be a robber any more.

So they all made fun of him, and called him a crybaby. That made him very mad, and said he would go and tell all the secrets. But Tom gave him a five cent silver to keep quiet, and said we would all go home and meet next week, and rob somebody and kili some people.

Ben Rogers said he couldn't go out often, could go out only Sunday, and so he wanted to begin next Sunday. But all the boys said it wouldn't be right to do it on Sunday. And that settled it. They agreed to get together and $\mathrm{fix}$ a day as soon as possible. And then we elected Tom Sawyer the first Captain and Jo Harper the second captain of the Gang. And we started home.

In the above the original has twenty-five conjunctions, of which eighteen are and. The translation has twenty-two conjunctions, which indicates nearly the complete reproduction of the original conjunctions. The use of conjunctions in the translation, however, is very different from that in the original. The original has five sentences, five conjunctions per sentence, and only two conjunctions used at the beginning of the sentences. The 
translation has twelve sentences, two conjunctions per sentence, and eight conjunctions used at the beginning of the sentences. In a long sentence the use of a simple conjunction and gives a smooth and conversational flow to the sentence, but when it is used constantly in a very short sentence, especially at the beginning of nearly every sentence, it makes the writing clumsy, and does not produce conversational ease and readability.

Punctuation also ands to the effect of the sentence structure. In a long, rambling sentence the appropriate use of comma, semi-colon, colon, and dash contributes to the conversational quality of style, by facilitating the movement from one statement to another with a minimum of interruption. The abundant use of commas, semi-colons, and dashes is especially useful in conveying the feeling of an actual speech to the writing.

In the translation commas, colons, and semi-colons are used less frequently than in the original. Since Japanese does not have either the colon or semi-colon, periods or phrases like in other words and that is to say replace them. Dashes and commas are replaced by periods because of the short length of sentence in the translation. The result is that the translation becomes more formal and less conversational than the original. For example : 
We11, the first I knowed the king got a-going, and you could hear him over everybody; and next he went a-charging up on the platform, and the preacher he begged him to speak to the people, and he done it. He told them he was a pirate-been a pirate for thirty years out in the Indian Ocean--and his crew was thinned out considerable last spring in a fight and he was home now to take out some fresh men, and thanks to goodness he'd been robbed last night and put ashore off of a steamboat without a cent, and he was glad of it; it was the blessedest thing that ever happened to him, because he was a changed man now, and happy for the first time in his life; and, poor as he was, he was going to start right off and ....

$$
(\mathrm{XX}, 179)
$$

We11, the first I knew the king going forward. And the king was crying louder than anybody else. And next he went charging up on to the platform. And the preacher begged him to speak to the people. And he started talking. He told them that he was a pirate--said he had been a pirate for thirty years in the Indian Ocean--and that my crew was thinned out considerably last spring in a fight. And I came home to collect some new men. And thanks to goodness he had been robbed last night and put ashore from a steamboat without a penny. And I am very glad of 1t. This was the most blessed thing ever happened to me. Because I am a changed man now. And I am happy for the first time in my 1 ife. And, poor as I am, I am going to start right away now and ....

In the above example almost every comma and semi-colon is replaced by a period, and every short clause becomes an independent sentence. The translation consequently does not convey the easy, conversational movement of the sentence. Dashes, another device used in familiar writings and in speech, however, are retained in the translation.

He was very sorry he was so pushed, and so was every body; they wished he could stay longer, but they said they could see it couldn't be done. And he said of
He was very sorry he was so much in a hurry. Everybody was sorry, too. They wished they could stay longer. But they said they could see it couldn't be 
course him and William would take the girls home with them; and that pleased everybody too, because then the girls would be well fixed and amongst their own relations; and it pleased the girls, too--tickled them so they clean forgot they ever had a trouble in the world; and told him to sell out as quick as he wanted to they would be ready. (XXVII, 240) done. And he said that he and William would of course take the girls home with them. That pleased everybody, too. Because then the girls would be well off among their own relatives. And it pleased girls, too--it tickled them so much that they forgot entirely about their uncle's death. And they told him to sell the property as quickly as possible, and they would be ready... .

In the above, four semi-colons are used. A semi-colon indicates a relation between two statements not so close as a comma but not so entirely unrelated as a period, and it helps contribute to the conversational quality of style. In the translation these semi-colons have been replaced by the periods, and the conversational effect of the passage is lost.

In the Japanese translation of Huckleberry Finn there are many sentences which do not sound like good Japanese because of their translational words and sentence structure. Each language has its own idioms and sentence structure peculiar to its nature, and when these sentences and idioms are literally translated into another language, they produce very poor sentences and idiom.

One of these examples frequently used in the translation is the use of participles as coordinate verbs. The use of a coordinate verb is a way of making the verb 
less conspicuous and the movement more rapid. Participles in this sentence construction serve as a second verb, and are mostly used in informal and colloquial English. In Japanese sentence structure, however, the main verb always comes at the end of the sentence, and a coordinate verb does not exist in Japanese at all. In the Japanese translation the English coordinate verbs are always carried over to Japanese sentences, and instead of improving Japanese in the translation the sentences become clumsy, translational Japanese. For example:

We11, before long here comes the wreck, dim and dusky, sliding along down! (XIII, 108)

Then, before long, that wreck comes floating down. Dim and dusky, sliding down!

In the translation the original sentence is cut into two pieces, and the second sentence is used to modify the preceding sentence. This coordinate sentence should come at the beginning of the main sentence in Japanese, but the translation makes the clause an independent sentence following after the main sentence, which makes the original meaning vague and clumsy.

It was kind of 1 azy and jolly, laying off comfortable all day, smoking and fishing, and no books nor study.

$$
\text { (VI, 45) }
$$

It was a kind of lazy and jolly life. I was laying off comfortably all day. Smoking and fishing. And there are neither books nor study.

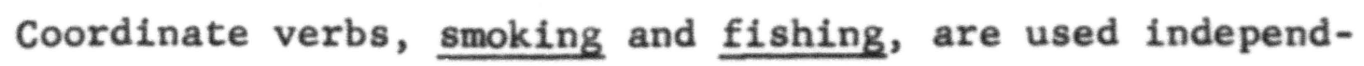
ently after the main statement in the translation, but the 
use of participles at the end results in a poor sentence and never happens in Japanese. Also the sentence is incomplete without a subject. This is the result of literal translation of English sentence structure.

I laid there, and had a good rest and a smoke out of my pipe, looking into the sky . . . .

$$
\text { (VII, 59) }
$$

I laid there, and had a good rest and smoked my pipe, looking into the sky.

The coordinate verb, looking, in the translation does not well agree with Japanese sentence structure and sounds clumsy and translational.

In Japanese all the modifiers have to stand before the words or sentences they modify. Just as a coordinate verb does not exist in Japanese sentence structure, neither does the practice of placing the adverbial phrase after the word or phrase it modifies. In the translation, on the contrary, many adverbial phrases are used after the words or phrases they modify, as in the original English, and they become poor Japanese sentences. For example:

I peeped out through the willow branches, and there it was--a skiff, away across the water.

$$
\text { (VII, 58) }
$$

I peeped out through the willow branches. There it was--a skiff coming away across the river.

In the Japanese translation an adverbial phrase, away across the river, is put after the main sentence. This is hardly regarded as proper Japanese at all. 
I dropped pap's whetstone there too, so as to look like it had been done by accident.

$$
\text { (VII, 57) }
$$

I dropped pap's whetstone there, too. So as to look like it had been dropped by accident.

The adverbial phrase, "so as to look . . . ," is used after the main sentence instead of preceding it. Moreover, the phrase is broken up by the period. This kind of sentence structure is not really used in Japanese, and it is a poor, clumsy sentence.

The frequent use of the conjunctions because and for is another conspicuous feature of the sentences of the translation which hinders their smooth flow and the stylistic quality of the original. The frequent literal translation of because does not make a good Japanese sentence, and the effect is clumsy and unnatural. For example :

The duke done it, and Jim and me was pretty glad to see it. It took away all the uncomfortableness and we felt mighty good over it, because it would a been a miserable business to have any unfriendliness on the raft; for what you want, above all things, on a raft, is for everybody to be satisfied, and feel right and kind toward the others.

$$
\text { (XIX, 170) }
$$

The duke shook hands with him. And Jim and me were very glad to see it. It took away all the unpleasantness. And we felt very good about it. Because it would have been a miserable business to have any unfriendliness on the raft. Because what you want on the raft is above all for everybody to be satisfied and feel right and kind to the others.

In the above the repetitions of because make the writing clumsy and translational, and not smooth Japanese. 
In translating one language into another, the original sentence structure must adapt to that of the language into which it is translated, and the Japanese translation of Huckleberry Finn does not successfully adapt to the nature of Japanese. The consequence is a translational, clumsy sentence structure which impoverishes the stylistic quality of the original.

\section{Rhythm}

Although prose does not have sound and rhythm as precisely and regularly as poetry does, good prose has a certain sound and rhythm pattern created by words, phrases, and sentences. To make writing effective and vigorous, not only descriptive precision but also pleasant sound and rhythm are required. In Huckleberry Finn varieties of the sentence length, the sentence constructions, and punctuations build up its peculiar quality of sound and rhythm--the conversational, easy fluent rhythm and intonations of the speaking voice. The following descriptive passage is particularly rhythmical and smooth:

Two or three days and nights went by; I reckon I might say they swum by, they slid along so quiet and smooth and lovely. Here is the way we put in the time. It was a monstrous big river down there --sometimes a mile and a half wide; we run nights, and laid up and hid daytimes; soon as night was most gone we stopped navigating and tied up-nearly always in the dead water under a towhead; and then cut young cotton-woods and willows, and 
hid the raft with them. Then we set out the lines. Next we slid into the river and had a swim, so as to freshen up and cool off; then we set down on the sandy bottom where the water was about knee deep, and watched the daylight come. Not a sound anywheres--perfectly still--just like the whole world was asleep, only sometimes the bullfrogs a-cluttering, maybe. The first thing to see, looking away over the water, was a kind of dull line--that was the woods on $t$ 'other side; you couldn't make nothing else out; then a pale place in the sky; then more paleness spreading around; then the river softened up away off, and warn't black any more, but gray; you could see little dark spots drifting along ever so far away-trading scows, and such things; and long black streaks--rafts... .

$$
\text { (X IX, 161) }
$$

Here rhythm is effectively produced by the quality of the words used and by the variety of sentence length and structure. Many solecisms and colloquialisms like reckon, quiet, smooth, monstrous, most, anywheres, a-cluttering, and ever so, produce smooth and fluent conversational rhythm to the passage. The variety of sentence length from short, pithy sentences of "Then we set out the lines" to a long, rambling sentence of "Next we slid into the river. . . ," gives the sentences a variety of rhythm from the short, flat sentence to the rhythmical fluent sentence. Above all, the sentence construction includes both long, rambling sentences and short, emphatic sentences. The use of commas, semi-colons, and dashes also contributes to the conversational rhythm of the passage. Sometimes euphony contributes to the rhythm, as 
in "it was so still, and sounds come so far...."

The colloquial, informal sentences, amply varied, give an easy, conversational rhythm to the prose of Huckleberry Finn.

But also some passages are rhythmical because of the effective use of euphony and figures of sound. For example :

It would get so dark that it looked all blueblack outside, and lovely; and the rain would thrash along by so thick that the trees off a little ways looked dim and spider-webby; and here would come a blast of wind that would bend the trees down and turn up the pale underside of the leaves; and then a perfect ripper of a gust would follow along and set the branches to tossing their arms as if they was just wild; and next, when it was just about the bluest and blackest--fst! it was as bright as glory, and you'd have a little glimpse of tree-tops a-plunging about away off yonder in the storm, hundreds of yards further than you could see before; dark as sin again in a second, and now you'd hear the thunder let go with an awful crash, and then go rumbling, grumbling, tumbling, down the sky toward the under side of the world, like rolling empty barrels down stairs--where it's long stairs and they bounce a good deal, you know.

$$
(\mathrm{IX}, 76)
$$

The sound and rhythm in the passage quoted above are produced by the euphony of blue-black, bluest and blackest, thrash along by so thick, and by figures of sound like go grumbling, tumbling, and tree-tops a-plunging.

The Japanese translation, on the other hand, apparently fails to reproduce the rhythm and sound of the 
original work. As observed above, the lack of variety in sentence length and sentence structure, and the translational words and sentence hinder the fluent conversational rhythm and the intonations of the speaking voice. Also euphony and other literary devices to produce rhythm are not used in the translation. The sentences in the translation therefore do not have effective rhythm and sound. For example:

Two or three days, two or three nights have gone by. I think I might say they swam by. They passed away very quietly, smoothly, and pleasantly. We spent our time in the following manner. It was a tremendously big river down there--sometimes a mile and half wide. We ran in the night, and stopped and hid in the day time. When the night was almost gone, we stopped running and tied up the raft--nearly always in the dead water under a towhead. And then we cut young cottonwoods and willows, and hid the raft with them. And then we set out the lines. And then we got into the river and had a swim. So as to feel good and cool. Then we sat down on the sandy bottom about knee deep, and watched the sun rise. There was not a sound anywhere--perfectly still--it was as if the whole world were asleep. Only the bullfrogs clutter sometimes. Looking away over the water, the first thing to see was a kind of dull line--that was the woods on the other side. You can't make anything else out. Then a spot in the sky begins to pale. Then it spreads more and more. Then the river softens up away off. And it is no more black but gray. You can see little dark spots drifting along, very far away--they are trading scows and others. And then you can see long black streaks--they are rafts.

Summary. This study of the stylistic qualities of the sentence in the Japanese translation of Huckleberry 
Finn leads to the following important conclusions:

The length of the sentence is one of the important factors determiling the stylistic qualities of the sentence. In the original work there is a wide range extending from long, rambling sentences to short, pithy sentences. A long, rambling sentence contributes to the conversational quality, and the variations of the sentence length contribute to the variety and vitality of the style. In the Japanese translation most sentences are of average length, without much variation. Neither very short, pithy sentences nor very long, rambling sentences are found in the translation, and it lacks the conversational quality and the variety and vitality of the original. The length of the sentences in the translation therefore does not succeed in reproducing the original stylistic quality resulting from sentence length.

The structure of the sentence makes an important contribution to the stylistic quality of the original. The structure of the sentence is simple and straightforward, and adds to the fluent, conversational quality and the readability of the style. The simple loose sentence, the inverted sentence, and the incomplete sentence give vitality and conversational quality to the style. The appropriate use of simple conjunctions and connective adverbs and punctuation also contributes to the 
conversational quality and readability. In the translation the sentence structure is simple, but its frequent use of periods, its repetitions of unnecessary conjunctions and connective adverbs in a short sentence interrupt the smooth, conversational flow of the sentence and become clumsy. The variety and vitality of style attained by the variations of sentence structure and sentence order are not reproduced in the translation. In particular, certain translational senterce structures and words make the sentence clumsy and unnatural, and weaken the stylistic quality of the translation. The stylistic quality of the original sentence structure is not reproduced successfully in the translation.

In the original the rhythm and sound of the sentence are produced by simple, fluent sentence structure and by some rhythmical devices. The long, rambling sentence, the inverted sentence, the incomplete sentence, the proper use of punctuation, contribute to the rhythmical movement of the sentence and the sound pattern. Some rhythmical devices of euphony and figures of sound are used to produce the rhythm effectively. In the translation the lack of the variety in sentence structure and in rhythmical devices makes the writing flat and monotonous. Thus, the translation fails to reproduce the rhythm and sound of the original. 


\section{CHAPTER IV}

\section{STYLE AS INTERPRETATION}

A work of translation inevitably involves interpretation of both the theme and style of the original work. Besides his perfect knowledge of the language of the original, a translator should have a correct interpretation of the theme and the nature of the original style in order to convey the original work faithfully. An evaluation of a work of translation, therefore, involves the central conceptions which the translation is trying to express by language, and the interpretation of style is ultimately inseparable from that of the theme.

The Japanese translation of Huckleberry Finn is a literal reproduction of the original work: it follows every word and phrase of the original with a negligible number of additions to and deletions from the original. A literal translation of every word of the original by the equivalent Japanese succeeds in reproducing every detail and a series of passages of the original individually--for example, details of descriptive passages, conversations, expressions of ideas and even of feeling. Fidelity entails, however, much more than literalness, and the fidelity of the Japanese translation must be examined not only in the details of passages and expressions, but also in the 
context of the whole translation and the interpretation which animates it. It is therefore the purpose of this chapter to give a final evaluation of the Japanese translation by examining its interpretation of Huckleberry Finn.

Bernard De Voto, speaking about the achievement of

the vernacular of the book, says:

Earlier still, in The Jumping Frog, Mark had anticipated the triumph of Huck Finn's vernacular. Simon Wheeler is formally introduced to tell his story, as in the convention of Thompson and Harris, but his language, once he begins to speak, is an integral part of the effect which the immortal conte produces: you cannot separate the man from his speech nor his story from the personality which his speech expresses. Exactly that, on a much higher level, is the achievement of Huckleberry Finn.

In a translation the style should adapt itself to each character in the book, and it becomes inseparable from his personality and social status. Huck Finn, Nigger Jim, Huck Finn's father, and the Duke and the King, Uncle Silas and Aunt Sally, and other figures have different personalities, and their language and speech reflect both their personalities and social status. The evaluation of a translation, consequently, has to treat the interpretation of characters in the translation.

The narrator of Huckleberry Finn is Huck Finn. His

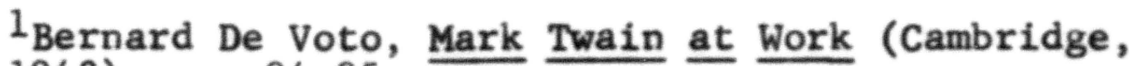
Mass., 1942), pp. 94-95. 
language is that of the American vernacular, "the extremest form of backwoods Southwestern dialect and the ordinary 'Pike County' dialect," ${ }^{2}$ which is comprised of American colloquialisms, dialects, slang, archaisms, and Americanisms prevalent in mid-nineteenth century America. It is the language which comes from the spoken words of the uneducated people and not from the printed words of the spelling book.

Huck Finn, being brought up in his "old rags and sugar hogshead," 3 can write only in this vernacular language. Moreover, he cannot spell words correctly and consistently more than his vernacular permits; this is especially so with unfamiliar English words and foreign names, such as meedyevil, Looy, yellocute; skiff and skift, yaller and yellow. His grammar and sentence structure follow his vernacular, permitting all kinds of solecisms and colloquial constructions. His style, the mode of expression, is fundamentally that of American vernacular, as for example, the opening passage of Chapter I, "That book was made by Mr. Mark Twain, and he told the truth, mainly. There was things which he stretched, but mainly he told the truth." Although his vernacular is sometimes

$$
\frac{2 \text { Huckleberry Finn, p. v. }}{{ }^{3} \text { Ibid., p. } 15 .}
$$


elevated to the literary level and in many passages even to concentrated poetry with its straightforwardness and poetic vitality, his language is ultimately that of an uneducated Southwestern boy, and agrees with his character. Huck Finn's language in the Japanese translation, on the other hand, does not show that he is an uneducated Southwestern boy. Instead of speaking a backwoods Southwestern dialect, he speaks and writes in formal standard Japanese. As was discussed in Chapter II, his language is standard Japanese--not the traditional literary language exclusively used in writings before--which is used among people in the cities and at school throughout the country, and most of Huck's colloquialisms, dialects, slang, and solecism are represented by more formal standard Japanese. In the translation Huck's misspellings and bad grammer, for example, are all corrected, and his peculiar expressions and sentence structures are rendered in standard Japanese expressions, as warn't by wasn't, we $\underline{\text { ws }}$ by we are, meedyevil by Medieval, the carelessest and foolishest things by the most careless and foolish things, that ain't no matter by that does not matter, that book was made by that book was written, I hain't seen no fog by $\underline{I}$ haven't seen any fog, and so on. Not only speaking and writing correctly, Huck uses more abstract, formal language, such as exception for without it, exaggeration for stretcher, 
courage for sand, hospitality for old pie, improve for coming along, preventive method for watch-out, invite for fetch, and confession for making a clean breast.

The Japanese language has several forms for each personal pronoun which will clearly express one's social position and his relationship with others. In his address to Aunt Polly, Mary, Judge Thatcher, Widow Douglas, Miss Watson, the Duke and the King, Uncle Silas and Aunt Sally, who are all regarded higher than himself, Huck always uses a very polite form of address, which indicates his social position as lower than theirs. In his address to Tom, Buck, or Ben Rogers, he uses a form of address equal to his social position and age. In addressing himself, however, he uses two different kinds of personal pronouns: watakushi (or, watashi) in the narration and boku in conversation. Watakushi is a formal, polite personal pronoun used by well-educated men and women both in writing and conversation, and boku is a polite personal pronoun used by young school boys and sometimes by welleducated men only in their conversation. Thus, both watakushi and boku show that Huck is well-educated and that his social position is as good as that of Tom Sawyer and Buck, and it distinguishes him from those uneducated boys who would use much lower personal pronouns like ore, or $\bar{a}$, and boka (a vulgarized form of boku). 
Both in the original and in the translation Huck says that he cannot stand being civilized and that he likes his old way best: "It was kind of lazy and jolly, laying off comfortable all day, smoking and fishing, and no books nor study. Two months or more run along, and my clothes got to be all rags and dirt, and I didn't see how I'd ever got to like it so well at the widow's, where you had to wash, and eat on a plate, and comb up, and go to bed and get up regular, and be forever bothering over a book, and have old Miss Watson pecking at you all the time." 4 In the original his language is adapted to his character and agrees with what he says very well, but in the translation it does not. Huck's language in the translation gives an impression that he is brought up with a good education and that he can write and speak good standard Japanese. His language and manner of expression do not conform to his humble character. Thus, the style of the Japanese translation misrepresents him.

Nigger Jim is the heroic character Mark Twain created. "Jim has all the virtues Mark Twain admired," says De Voto. "He is kind, staunch, and faithful, a brave man, a friend who risks his life and sacrifices his

\footnotetext{
${ }^{4}$ Huckleberry Finn, p. 45.
} 
freedom for a friend . . . $"^{5}$ As an illiterate Negro, Jim speaks "the Missouri negro dialect," 6 which is one of the lowest of American dialects, admitting all the possible kinds of misspellings, pronunciations, bad grammar, colloquialisms, and dialect. His dialect is recorded as he speaks, and it becomes a true kind of literary technique to characterize Jim's personality and express his thought. It is not only a phonetic approximation of Negro dialect, but also a live speech that is very flexible and effective in carrying the rhythms and shadings of thought. His dialect is an expression inseparable from his personality, and it can express his humble Negro folk mind and his true dignity. For example:

'What do dey stan' for? I'se gwyne to tell you. When I got all wore out wid work, en wid de callin' for you, en went to sleep, my heart wuz mos' broke bekase you wuz los', en I didn' $k$ 'yer no mo' what become er me en de raf'. En when I wake up en fine you back agin, all safe en soun', de tears come, en I could a got down on my knees en kiss you' foot, I's so thankful. En all you wuz thinkin' 'bout wuz how you could make a fool uv ole Jim wid a lie. Dat truck dah is trash; en trash is what people is dat puts dirt on de head er dey fren's en makes 'em ashamed."7

In the Japanese translation Jim speaks standard

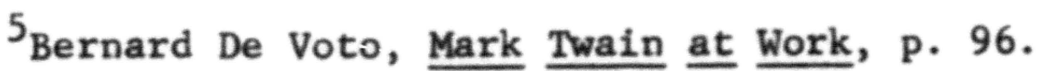

6 Huckleberry Finn, p. v.

${ }^{7}$ Ibid., p. 122. 
Japanese except for a slight variation of verb inflection and use of personal pronouns. His mispronunciations, misspellings, bad grammar, colloquialisms, and dialect are rendered by correct pronunciations, spellings, and grammar of standard Japanese. The dialect used in Jim's speech is his verb inflection da and his personal pronoun ora. The verb inflection da is often used among uneducated people who speak generally a little lower form of standard Japanese than the educated, but it does not belong to any particular dialect form. Any of the major dialects in Japan has as much variation as English does, but Jim's dialect in the translation has nothing to do with these dialects, except da, which makes his speech slightly vulgar. His language is therefore almost the same as Huck's and is basically standard Japanese.

Jim also uses a personal pronoun ora, a dialect form used among the uneducated people, which makes him appear low in the social scale. Jim also uses a very polite form of address to Huck, as in the original, such as Master, Mr., and bochan (applied to the sons of a wealthy family), which shows his social position as much inferior to Huck's. In the Japanese translation Jim does not speak dialect except for a slight variation of his verb inflections and his use of personal pronouns, and his good standard Japanese fails to reproduce the original quality 
of Jim's speech. Therefore, his style in the translation does not conform to his humble character as a Negro and does not express his Negro folk mind and the intensity of his emotion and thought as vigorously and effectively as the original language does.

Inadaptability of the style in the Japanese translation is also true to other minor characters. The Duke, the King, Uncle Silas, Aunt Sally, Aunt Polly, Huck's father, and others all speak alike, and their individuality expressed through their speech and language is greatly diminished in the translation. They all speak standard Japanese--old Mrs. Hotchkiss, and the frauds, the Duke and the King, in the Royal Nonesuch and at the Peters', and good natured Uncle Silas and humorous and kind Aunt Sally. They all appear alike, and in a way they are dead characters without individuality and vitality.

Italics are another stylistic device which affects the interpretation. In the original, italics are often used in conversation and in statement. Both in conversation and statement, they emphasize words and phrases, and give a conversational quality to the style. Sometimes they indicate not only emphasis but irony by stressing certain words and phrases, thus making the writing very vivid and interesting. For example:

"Dry up! I don't want to hear no more out of 
you!" says the duke. "And now you see what you got by it. They've got all of their own money back, and all of ourn but a shekel or two besides. $G$ 'long to bed, and don't you geffersit me no more deffersits, long's you live."

. . and undertaker stretched his neck out towards the preacher, over the people's heads, and says, in a kind of a coarse whisper, "He had a rat.

. because I begun to get it through my head that he was pgst free--and who was to blame for it? Why, me.

These italics indicate the word emphasis of speech, and make the original meaning clear and vivid. In the translation italics are not used at all, though they could be expressed in Japanese, and the emphasis and the meanings expressed by the original italics are not reproduced in the translation.

The meaning of Huckleberry Finn is very closely rendered by literal translation, but not always reproduced by style. In the original work the quality of the style in the descriptive passages of landscapes and in the passages of action is elevated from the ordinary passages. In the descriptive passages of nature, the style is elevated to the rhythmical and poetic level, and produces

$$
\begin{aligned}
& { }^{8} \text { Huckleberry Finn, p. } 271 . \\
& { }^{9} \text { Ibid., p. } 239 . \\
& { }^{10} \text { Ibid., p. } 125 .
\end{aligned}
$$


the quiet, solemn feeling of nature, as seen in Chapter III. In the passages of action the sentence moves very fast to reflect the rapid movement of action and the emotional response to the incident. In both the descriptive passages and the passages of action, the Japanese translation neither elevates the style of the passage to the poetic level, nor does it move rapidly. The style of the Japanese translation, in other words, fails not only in reproducing the original quality of the style, but also in making the style inseparable from the context of the book.

\section{CONCLUSIONS}

This investigation of a Japanese translation of Huckleberry Finn has produced a number of important results. From the information derived from this study it has been possible (1) to find the method of the translation used; (2) to determine the quality of the language in the translation; (3) to determine the stylistic quality of the sentence in the translation; (4) to form an evaluation of the translation from the interpretation of the style in relation to the context of the book; and (5) to propose some suggestions for the improvement of a Japanese translation of Huckleberry Finn. 
The Method of Translation. The basic method of the Japanese translation studied is literal translation. It attempts to translate every word of the original work according to the dictionary meaning of the equivalent Japanese. An idiomatic translation is applied to a few idioms, most figures of speech, and Americanisms, but no paraphrastical translation is used in the work. Very few additions and omissions by the translator are found throughout the book.

Language. The Japanese translation succeeds in translating faithfully and literally almost every word of the original, but the quality of the words thus produced is not always the same as that of the original. Most of the ordinary standard English words find their Japanese counterparts, and their quality is successfully reproduced in the translation. This is seen in most standard nouns, verbs, adjectives, and some idiomatic phrases. Also, figures of speech and Americanisms are represented successfully in Japanese by means of idiomatic translation. The greatest difficulty is translating the informal, colloquial quality of the English, which is perhaps the most notable characteristic of the original work. The American vernacular has concreteness, vitality, and rich local connotations, which cannot easily be reproduced exactly in any other language. In the Japanese translation 
most informal, colloquial English terms are replaced by formal, standard Japanese ones, and they become abstract and general. This is seen in the translation of colloquialisms, dialects, slang, and also in the peculiarities of spellings, inflections, and grammar. The American vernacular, thus represented by the abstract and general standard Japanese, loses its informal, conversational quality and the rich local connotations.

\section{Stylistic Quality of the Sentence. The Japanese} translation is hardly able to reproduce the stylistic quality of the sentence in Huckleberry Finn. The length of the sentence of the original ranges from long, rambling sentences to short, pithy sentences, and contributes to the conversational quality and the variety and vitality of the style. In the Japanese translation each long sentence of the original is broken up into several short sentences of average length, and all the short, pithy sentences expanded to the average length. Without variety of sentence length the translation fails to reproduce the conversational quality and the vitality of the original style.

The sentence structure of the original makes an important contribution to its stylistic quality. The simple, straightforward sentence structure and the use of conjugations, connective adverbs, and punctuation 
contribute to the fluent conversational quality and readability of the style. The variety of sentence structure, the inverted sentence order, and the incomplete sentence add vitality and conversational quality. In the translation the sentence structure is simple, but the smooth, conversational quality and readability are weakened by its frequent use of periods and its unnecessary conjunctions and connective adverbs. The variety and vitality of the original style tend to be lost in the flat, monotonous sentence structure. Also, many translational sentence structures and words make the sentences very unnatural and clumsy, and mar their stylistic quality.

The original has a rhythm and sound pattern produced by the sentence structure and some rhythmical devices. The variety of sentence length, inverted sentences, incomplete sentences, and punctuation contribute to suggest the rhythm and the intonation of the speaking voice. Euphony and figures of sound also effectively produce sound and rhythm in certain passages. In the translation there is no variety of sentence length and sentence structure and few rhythmical devices. Consequently, the translation does not produce the rhythm and sound of the original, and fails to reproduce the stylistic quality of the original. 
Style as Interpretation. In a work of literature style is ultimately inseparable from the context of the work, and in a translation the style should be adapted to the characters and the theme of the original work. In the original, Huck Finn is the narrator and the book is written in his language. His American vernacular and misspellings reveal him to be a young, uneducated Southwestern boy, and his language and expression are suited to his humble character. In the translation he writes and speaks good standard Japanese like a well-educated boy. Therefore, his language does not agree with his humble character in the story.

Another major character, Nigger Jim, speaks his Missouri Negro dialect and expresses himself like an illiterate man. But his language, though one of the lowest, is flexible enough to express not only his humble folk mind but also his true dignity with vitality and streingth. In the translation his language does not reveal him really to be illiterate. He speaks a standard Japanese nearly as good as Huck Finn does, and only slight variations in his verb inflections and vulgar pronouns make his language a little lower than that of others. His language, therefore, is not really suited to his character at all, and his personality as expressed by the vitality of his language is lost. Other minor characters also 
speak standard Japanese, and their individuality is lost in the translation.

In the original the style also is adapted to the context of the book. In the descriptive passages of landscape the style is elevated to the poetic level, and in the passages of action it moves rapidly, in order to produce the actual feeling in each situation. The style of the translation, however, neither elevates nor moves rapidly as the original does according to the context. Italics often used in the original emphasize words and phrases in statement and dialogue and contribute to the conversational quality and vitality. In writing, italics convey word emphasis and make the meaning of the original clear and vivid. In the translation no italic is used, and the word emphasis is utterly lost.

\section{Suggestions for the Improvement of Japanese}

Translation. The Japanese translation of Huckleberry Finn succeeds in translating literally almost every word and sentence of the original. Very few additions to and deletions from the language and thought of the original are seen in the translation, and misinterpretations are also of small number. The main defect of the translation, however, lies in the failure to reproduce the quality of the language and style of the original as a literary work. 
The majority of the informal, colloquial English words of the original are represented by formal, standard Japanese. The straightforwardness, concreteness, vitality, and the rich, local connotations of the language of the original are, as a result, greatly diminished in the translation. In addition, the conversational quality, readability, and the variety and vitality of the style of the original are not successfully reproduced in the translation. The failure of the Japanese translation in reproducing the quality of the language and style of the original comes from (1) the method of literal translation; (2) the difficulty of reproducing dialect writing; and (3) the limitation of the translator's talent.

In order to improve the Japanese translation of Huckleberry Finn, the method of literal translation must be abandoned. Understanding every word of the original correctly is a basic requirement for a translator, but translation is much more than simply understanding the language of the original. He must reproduce the quality of the language and style of the original in Japanese with the same force and effect as the original. Translating the original word for word is merely to replace it with another language, and the quality of the original language cannot be spontaneously reproduced in another language by a mere replacement of words. In order to reproduce the 
quality of the language and style of the original successfully, a translator must create the exact quality in Japanese. He must perfectly adapt the language of the original to the peculiar nature of the Japanese language, and without troubling over the verbal difficulty he must transmute the quality of the original into Japanese. Although fidelity to the meaning of the original is important, he must use his freedom to amplify or omit the original, if necessary, so that the quality of translation may be improved. Translation, in other words, is a creative work. Especially in translating Huckleberry Finn into Japanese, a rigid literal translation results in a clumsy work, and the method of idiomatic translation must be used.

Since the notable characteristic of Huckleberry Finn is an excellent use of the American vernacular, the Japanese vernacular must be used in order to produce the quality of the language and style of the original successfully. Although there are seven major dialects and countless deviations in each major dialect, the reproduction of the American vernacular in the Japanese vernacular is one of the most difficult problems. It is, without doubt, impossible to find a Japanese dialect exactly corresponding to the original. Therefore, it would be necessary for a translator to devise some method of 
reproducing the quality of the original in the Japanese vernacular. For example, it could be possible to use the dialect spoken in a river town or in a fishing village. Probably the use of the dialect most widely spoken and frequently used in dialect literature would be advantageous. Or, a translator could make a new dialect common tc all regions by combining several dialects so that it would not call to mind one particular part of the country. He has freedom to choose any of the dialects spoken in Japan, but it would be preferable to use the dialect of the countryside rather than that of the city, because the story of Huckleberry Finn is located in the countryside along the Mississippi. Whatever his choice might be, he must be well acquainted with the dialect he is going to use in translation, and he must be able to command it on the leve1 of literary art.

Lastly, as to a translator, the ideal would be that the translator's talent be equal to the original author's. Unfortunately, excellent bilinguists tend to be scholars and professional people, whose talent is not equal to the original author's in creative writing, and good writers are very seldom excellent bilinguists. Especially in translating Huckleberry Finn, he must be an excellent bilinguist and at the same time an excellent dialect writer, to understand the American vernacular and 


\section{1}

reproduce its original quality in Japanese. Although there is at the present moment one complete translation of Huckleberry Finn, it is hoped that a translator, whose ability and seriousness are equal to the original author's, will improve the present translation and reproduce the quality of the original exactly, so that the Japanese people may enjoy and appreciate Huckleberry Finn more. 
B IBLIOGRAPHY 


\section{BIBLIOGRAPHY}

\section{PR IMARY SOURCES}

\section{A. ENGLISH}

Clemens, Samuel. The Adventures of Huckleberry Finn. New York: Harper \& Brothers, 1912.

"Fenimore Cooper's Literary Offences," How to TeIi a Story and Other Essays. New York: Harper $\frac{\text { Oo }}{\&}$ Brothers, $189 \%$.

. "How to Tell a Story," How to Tell a Story and

Other Essays. New York: Harper \& Brothers, $\frac{1897}{189}$

- Life on the Mississippi. New York: Harper

\&Bंrothers, , 19 the

- Mark Twain in Eruption, ed. Bernard De Voto.

New York: harper \& B $\overline{\text { rothers, }} 1940$.

- Mark Twain's Autobiography, ed. Albert Bigelow

Paine. $\frac{2}{2}$ vols. New York: Harper \& Brothers, 1924.

- Mark Twain's Letters, ed. Albert Bigelow Paine.

2 vols. New York: Harper \& Brothers, 1935.

- Mark Twain's Notebook, ed. Albert Bigelow Paine.

New York: Harper \& Brothers, 1935.

- Mark Twain's Speeches, ed. William Dean Howells. New York: Harper \& Brothers, 1923.

Roughing It. 2 vols. in 1 . New York: Harper

\& Brothers, 1913 .

- A Tramp Abroad. 2 vols. in 1. New York:

Harper $\&$ Brothers, I921. 


\section{B. JAPANESE*}

Fukizawa, Tadae, tr. A Connecticut Yankee in King Arthur's Court. Tokyo: Okakura Shobo, 1951.

Hamada, Masajiro, tr. The Innocents Abroad. 3 vols. Tokyo: Shingetsu Sha, 1949; Tokyo: Iwanami Shoten, 1951 .

Ishida, Eiji, tr. The Adventures of Tom Sawyer. Tokyo: Iwanami Shoten, 1946.

Ishii, Momoko, tr. The Adventures of Tom Sawyer. Tokyo: Iwanami Shoten, 1952 .

[One of the Children's Library.]

Kagatani, Rinnosuke, tr. and ed. The Humorous Stories That Made the World Laugh. Tokyo: Shoryudo, 1926.

[Concerning Chambermaid, The Jumping Frog, Aurelia's Unfortunate Man, Advice to Little Gir Is, From Mark Twain's Speeches, and others.]

Kasuya, Shinyo, tr. and ed. Mark Twain's Humorous Stories. Tokyo: Nanzando, 1928 .

[A Ghost Story and Legend of the Capitoline Venus.]

Kurume, Motoichi, tr. The Prince and the Pauper. Tokyo: Bunka Shoin, 1947.

Matsumoto, Keiko, tr. The Prince and the Pauper. Tokyo: Shincho Sha, 1954.

Muraoka, Hanako, tr. The Prince and the Pauper. Tokyo: Kaizo Sha, 1927; Tokyo Iwanami Shoten, 1934; Tokyo: Gitsugyo no Nihonsha, 1949.

Nakamura, Tameji, tr. The Adventures of Huckleberry Finn. 2 vols. Tokyo: Iwanami Shoten, I941; Tokyo: Kawade Shobo, 1950.

* This bibliography was contributed by the Japanese National Diet Library and Professor M. Hamada, and most of the translations were not accessible to the writer. 
Naotaro Takiguchi and Takashi Sugiki, tr. and ed. Adam's Diary. Tokyo: Yagumo Shoten, 1949.

[Extracts from Adam's Diary, The Loves of Alonzo Fitz Clarence and Rosannah Ethelton, The Esquimau Maiden's Romance, A Curious Experience, The Californian's Tale, The Jumping Frog, and The Echo That Didn't Answer.]

Nishikawa, Masami, tr. The 1,000,000 Pound Bank-Note. Tokyo: Chikuma Shobo, I951.

Ohashi, Eizo, ed. The Adventures of Huckleberry Finn, with notes and introduction. Tokyo: Kenkyusha, 1935.

Okubo, Yasuo, tr. The Adventures of Tom Sawyer. Tokyo: Mikasa Shobo, 1951, 1952; Tokyo: Shincho Sha, 1953.

1950. Tom Sawyer Abroad. Tokyo: Jitsugyo no Nihonsha, . Tom Sawyer Detective. Tokyo: Jitsugyo no Nihonsha, 1950; Tokyo: Shincho Sha, 1955.

Otakuro, Katsuhiko, tr. The Prince and the Pauper. Tokyo: Kodansha, 1950.

Sasaki, Kuni, tr. The Adventures of Huckleberry Finn. Tokyo: Shunju Sha, 1926; Tokyo: Kodansha, 1946.

- The Adventures of Tom Sawyer. Tokyo: Katei Yomiuri Kankokai, 1919; Tokyo: Seika Shoin, 1921; Tokyo: Kodansha, 1950.

, tr. and ed. Famous Stories of Mark Twain. Tokyo: Kaizo Sha, 1929, 1939.

[Pudd'nhead Wilson, The Adventures of Tom Sawyer, The Jumping Frog, Is He Living or Is He Dead?]

, tr. and ed. Ten Humorous Stories. Tokyo: Chimatsu Shuppansha, 1916 .

[The Esquimau Maiden's Romance, A Curious Dream, The Jumping Frog, How I Once Edited an Agricultural Paper, The Stolen White EIephant, Some Rambling Notes of an Idle Excursion, The Story of the Bad Little Boy, The Story of the Good Little Boy, and others.J 
Sato, Rikichi, tr. The Adventures of Tom Sawyer. Tokyo: Kadokawa Shoten, 1952.

Shibuzawa, Seika, tr. The Adventures of Tom Sawyer. Tokyo: Dowa Shunjusha, 1950.

Sugiki, Takashi, tr. Humorous Stories of Mark Twain. Tokyo: Shunyodo, 1918.

Takiguchi, Naotaro, tr. Eve's Diary and Five Other Stories. Tokyo: Iwanami Shoten, 1952 .

[Eve's Diary, Extracts from Adam's Diary, The Loves of Alonzo Fitz Clarence and Rosannah Ethelton, The Esquimau Maiden's Romance, A Curious Experience, The Californian's Tale.]

Terai, Yasuo, tr. The Prince and the Pauper. Tokyo: Kadokawa Shoten, 1952.

Ueno, Naozo, tr. Life on the Mississippi. Osaka: Sogensha, 1948 .

Yanagida, Izumi, tr. The Jumping Frog. Tokyo: Kindaisha, 1926 .

\section{SECONDARY SOURCES}

\section{A. ENGLISH}

Blair, Walter. Native American Humor (1800-1900). New York: American Book Company, 1937.

Bowers, Wanda Marie. "Some Aspects of Mark Twain's Style in His Three Books of Foreign Travel, "University of Missouri M.A. thesis (unpublished), 1950.

Buxbaum, Katherine. "Mark Twain and American Dialect," American Speech, II (Feb. 1927), pp. 233-236.

De Voto, Bernard. Mark Twain at Work. Cambridge, Mass.: Harvard University Press, 1942.

- Mark Twain's America. Cambridge, Mass.: Houghton Mifflin Company, 1951. 
Emberson, Frances Guthrie. Mark Twain's Vocabulary: A General Survey. Columbia, Missouri: University of Missouri, 1935.

"A Vocabulary Study of Huckleberry Finn," University of Missouri M.A. thesis (unpubiished), 1930 .

Hemminghaus, Edgar H. Mark Twain in Germany. New York: Columbia University Press, 1939.

Henderson, Archibald. Mark Twain. New York: Frederick A. Stokes Company, 1910 .

Hoben, John B. "Mark Twain: On the Writer's Use of Language," American Speech, XXXI (Oct. 1956), pp. 163-171.

Howe11s, William Dean. My Mark Twain. New York: Harper \& Brothers, 1910 .

Marx, Leo. "The Pilot and the Passenger: Landscape Conventions and the Style of Huckleberry Finn," American Literature, XXVIII (May, 1956), pp. 129-146.

Paine, Albert Bigelow. Mark Twain: A Biography. 4 vols. New York: Harper \& Brothers, I935.

Robert L. Ramsay and Frances Guthrie Emberson. A Mark Twain Lexicon. Columbia, Missouri: University of Missouri, 1938.

Trilling, Lione1. "Huckleberry Finn," The Liberal Imagination. Garden City, N. Y.: Doubleday \& Company, 1953.

Wagenknecht, Edward. Mark Twain: The Man and His Work.

New Haven, Conn.: Yale University Press, 1935. 


\section{B. JAPANESE*}

Clemens, Clara. My Father Mark Twain, tr. Okubo Tadatoshi. Tokyo: Taihei yo Shuppansha, 1950.

Akimoto, Hiroshi. "The Pike County Dialect in Huckleberry Finn," Kobe Gaikokugo University Ronso, V, no. 2 (1954).

Fujikawa, Takeo. "Reference Books on Mark Twain and Blake," Sekaibungaku, IV (1955).

Hamada, Masajiro. "Mark Twain as a Satirist," Kobe Univ. Bungakkai Kenkyu, V (1953).

- Mark Twain, His Character and Works. Tokyo: Kenkyusha, 1955 .

. "Mark Twain's Audience," Eigokenkyu, (1956).

Hamada, Masajiro. "Mark Twain's Conception of Social Justice," Eibungaku (1922).

- "Mark Twain's Literature and His National Character," Eigo Kyoiku (1922).

"A Short History of Criticism on Mark Twain," Eibungaku Kenkyu, XXII, no. 1 (1942).

Matsushita, Masao. "The Conjugations of the United States" Southern Vulgar Verbs Used by Mark Twain," Kobe Shosen Univ. Kiyo, V, no. 2 (1954).

Nagata, Toshiichi. "The Statue of Mark Twain, A True Democrat," Rikkyo Univ. Eibeibungakkaiho, IX (1951).

Ohashi, Eizo. Mark Twain. Tokyo: Kenkyusha, 1936.

Sakuma, Hara. "A Note on Mark Twain," Eigo Seinen, LIV, no. 6, (1935).

Tokunaga, Junkichi. "An Introduction to the Dialects of Huck and Jim," Hiromae Univ. Kyoikugakubu Kiyo (1956).

* This bibliography was contributed by the Japanese National Diet Library and by Professor M. Hamada, and most of them were not accessible to the writer. 
Tomita, Rin. "A Son of Age, Mark Twain," Eigo Seinen, LIV, no. 6 (1935).

Yoshida, Hiroshige. "Verbs of Mark Twain's English," Hiroshima Univ. Bungakubu Kiyo, III (1953).

\section{THEORY OF TRANSLATION}

Amos, Flora Ross. Early Theories of Translation. New York: Columbia University Press, 1920.

Belloc, Hilaire. On Translation. Oxford: Oxford University Press, $\frac{\text { Tra31. }}{1931}$

Bieber, Konrad F. "The Translator--Friend or Foe?" French Review, XXVIII (May, 1955), pp. 493-497.

Frost, William. Dryden and the Art of Translation. New Haven, Conn.: Yale University Press, 1955.

Lord, George deF. Homeric Renaissance. New Haven, Conn.: Yale University Press, 1956.

Johnson, E. D. "On Translating Thomas Wolfe," American Speech, XXXII (May, 1957), pp. 95-101.

Matthiessen, Francis otto. Translation, An Elizabethan Art. Cambridge, Mass.: Harvard University Press, 1931 .

Maymi, Protasio. "General Concepts or Laws in Translation," Modern Language Journal, XL, (Jan., 1956), pp. 13-21.

Milligan, E. E. "Some Principles and Techniques of Translation," Modern Language Journal, (Feb., 1957), pp. 66-71.

Postgate, John Percival. Translation and Translations. London: G. Bell \& Sons, 1922.

Wagner, Monica. Rufinus, the Translator; A Study of His Theory and His Practice as IIlustrated in His Version of the Apologetica of St. Gregory Naziangen. Washington, D. C.: The Catholic University Press, 1945 . 
William N. Locke and A. Donald Booth, ed. Machine Translation of Language. Cambridge, Mass.: Massachusetts Institute of Technology, 1955.

Woodhouselee, Alexander Fraser Tytler. Essay on the Principles of Translation. London: J. M. Dent \& Co., 1790 .

\section{ON LANGUAGE AND STYLE}

Browne11, W. C. The Genius of Style. New York: Charles Scribner's Sons, 1924.

Dobree, Bonamy. Modern Prose Style. Oxford: Oxford University Press, 1934.

Flesch, Rudolf F. The Art of Plain Talk. New York: Harper \& Brothers, 1946 .

Fowler, H. W. A Dictionary of Modern English Usage. Oxford: Oxford University Press, $193 \%$.

Fries, Charles Carpenter. American English Grammar. New York: D. Appleton-Century Co., 1940.

Krapp, George Philip. The English Language in America. New York: The Century Co., 1925 .

Mencken, H. L. The American Language. New York: Alfred A. Knopf, 1923.

Muriy, J. Middleton. The Problem of Style. Oxford: Oxford University Press, 1925.

Raleigh, Walter. Style. London: Edward Arnold, 1907.

Read, Herbert. English Prose Style. New York: Henry Holt and Company, 1928.

Spender, Stephen. World Within World. New York: Harcourt, Brace and Company, I951.

Wyld, Henry Cecil. A History of Modern Colloquial English. Oxford: Basil Blackwe11, 1936. 


\section{DICTIONARIES}

Bartlett, John Russe11. Dictionary of Americanisms. Boston: Little, Brown, and Co., 1889 .

Funk and Wagnalls. New Standard Dictionary of the English Language. New York: Funk and Wagnalls co., 1930.

Mathews, Mitford M., ed. A Dictionary of Americanisms on Historical Principles. 2 vols. Chicago: Universitty of Chicago Press, 1951.

Sir James A. H. Murray, Henry Bradley, W. A. Craigie, C. T. Onions, ed. A New English Dictionary on

Historical Principles. 13 vols. Oxford: Oxford University Press, 1888-1826.

Sir William Craigie and James R. Hulbert, ed. Dictionary of American English on Historical Principles. 4 vols. Chicago: University of Chicago Press, 1938-1944.

William Allan Neilson, Thomas A. Knott, Paul W. Carhart, ed. Webster's New International Dictionary, second edition. Springfield, Mass.: G. \& C. Merriam Company, 1937 .

Whitney, William Dwight, ed. The Century Dictionary and Cyclopedia. 12 vols. New York: The Century Co., 1914.

Wright, Joseph. The English Dialect Dictionary. 6 vols. Putnam's Sons, I898. 
APPENDIX 


\section{APPENDIX}

This Appendix is furnished for persons who might be interested in obtaining more information about the nature of the Japanese translation. In the Appendix three parts of Huckleberry Finn are chosen to demonstrate the various phases of the language of the original and the translation: Chapter I shows Huck's language; Chapter VI, Huck's father's language; and Chapter VIII, Nigger Jim's language. The Japanese translation is retranslated into English, but at the same time the original Japanese of the Japanese translation is used in footnotes. The retranslation is done as faithfully as possible, and every word under discussion is given a full explanation. The original is listed on the left, and the translation on the right.

The words and phrases under discussion are underlined.

\section{Abbreviations Used}

Or. - The original

OED - The Oxford English Dictionary

Tr. - The Japanese translation

W. - Webster's International Dictionary 


\section{APPENDIX}

Chapter I. I Discover Moses and the Bulrushers ${ }^{1}$

You don't know about $\underline{\text { me }}^{2}$ without $^{3}$ you have read a book by the name of The Adventures of Tom Sawyer; but that ain't no matter. ${ }^{4}$ That book was made ${ }^{5}$ by $\underline{\text { Mr. }}{ }^{6}$ Mark
Chapter I. The Discovery of Moses and the Bulrushers ${ }^{1}$

You do not know about me, ${ }^{2}$ without your having ${ }^{3}$ read a book by the name of The Adventures of Tom Sawyer. But that does not matter. ${ }^{4}$ That book was written ${ }^{5}$ by

$1_{\mathrm{Tr}}$ : The title of the chapter, while the original has a subject and a verb, is rendered in one noun phrase in the translation, which is a very suitable, common title used in Japanese books.

$2 \mathrm{Tr}$ : Although English has no other expression for the first personal pronoun than $I$, Japanese has several different personal pronouns. The personal pron., I 私 (Watakushi or watashi), used here, is a polite, formal pron., ordinarily used by well-educated, grown-up people, not by a small school boy. This use of I 私 sets the tone of the translation and Huck's character in a polite, formal way which is certainly not in the original at all.

${ }^{3}$ or: This is a solecism, making a grammatically erroneous construction. Tr: A formal and correct. (んだ :ヒがゲルイ゙". "If you have not read," or "without your having read.")

${ }^{4}$ or: Dial. or illit. Tr: Formal expression. ( ${ }^{\prime \prime} j て ゙$ t....ㅊะ." "Does not matter.")

50r: Now only as a rare archaism is make used in the sense of "make a book." "It is common to speak of 'making' a sonnet or an epigram; but it would sound odd to speak of 'making' a tragedy or a novel" (OED). Tr:

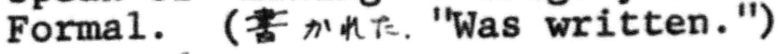

${ }^{6} \mathrm{Tr}: \mathrm{Mr}$. $氏(\mathrm{Sh} i)$ is used. Mr. could be at least translated in three different ways: 
Twain, and he told the truth, mainly. ${ }^{7}$ There was things which he stretched, ${ }^{8}$ but mainly he told the truth. That is nothing. 9 I never seen $^{10}$ anybody but lied one time or another, without ${ }^{11}$ it was Aunt Polly, or the widow, or maybe Mary. ${ }^{12}$ Aunt Polly-- or other. The exceptions ${ }^{11}$

氏(Shi), and 叚 (Dono). While 莄 (San, or sama) is the most popular usage, $区(\mathrm{Sh} i)$ and $\boldsymbol{H}^{2}$ (Dono) are much more formal and show more reverence to the person addressed. Although $民$ (Shi) is often used to call an author's name, we cannot expect a young boy like Huck to use $i$ (Shi), and 根 (San, or sama) would be more suitable to him and closer to the orig.

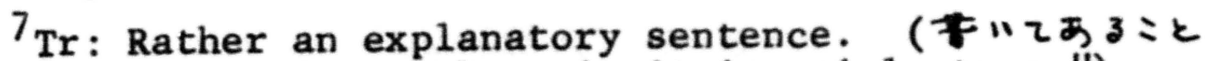
休大体本学. "What is written about in it is mainly true.")

80r: Colloq. and fig. "To strain beyond legitimate extent; to exaggerate in narrative" (OED, W). Tr: Formal and not exact. (数强挍." "To exaggerate.")

${ }^{9}$ Or: A complete denial; utter insignificance. $\mathrm{Tr}$ : A weak, partial denial, and not correct. (大したことではない. "Not important.")

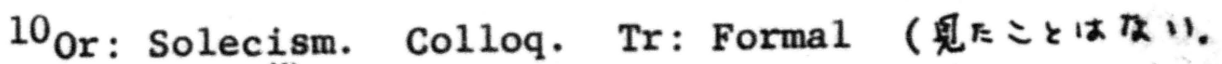
"Have never seen.")

${ }^{11}$ Or: Dial. "Unless; except" (W). Tr: Formal. Translated into a noun, and is the subject of the following sentence. (例外. "The exception.")

${ }^{12} \mathrm{Tr}$ : Miss or Mrs., $れ ん$ (San), is added to Mary. It is a common respectable title before the name, male or female. Since Mary is older than Huck, and is a respectable girl, Huck is rather expected to use it before her 
Tom's Aunt Polly, she is ${ }^{13}$-and Mary, and the Widow Douglas is $^{14}$ all told about in that book, which ${ }^{15}$ is mostly a true book, with some stretchers, ${ }^{16}$ as I said before.

Now the way that the book winds up is this: Tom and me $^{17}$ found the money are Aunt Polly, the widow, and maybe Miss Mary. ${ }^{12}$ Aunt Polly--she is ${ }^{13}$ Tom's Aunt Polly--and Miss Mary, and the Widow Douglas, all appear $^{14}$ in that book. $\underline{\mathrm{It}}^{15}$ is mostly true, with some exaggerations, ${ }^{16}$ as I said before.

Now the book ends in the following manner. Tom and $\underline{I}^{17}$ found the money that

name. Later in the book, however, $₫ ん($ San) is omitted. Cf. "Emmeline." (Chap. 17)

13 or: Inversion for the sake of emphasis. $\mathrm{Tr}$ : Japanese has no inversion of sentence structures, but there are many emphatic expressions similar to English, e.g. by omitting the subject; by using a strong, short inflection of the verb; or even by omitting any weak verb. Translation has a weak, clumsy sentence, esp. by the use of a personal pron. she, which occurs often in literal translation.

140r: Solecism. Are. Tr: Formal. (出乙来 3 . "Appear," or "are told. ")

${ }^{15} \mathrm{Tr}$ : An adj. clause becomes an independent sentence. Since Japanese has no subordinate conj. which, it is adequate to make a new sentence in this case, since no change of meaning occurs.

16or: slang. "An overstretching of the truth; 1ie" (W). $\operatorname{Tr}$ : Formal, and not precise. (新张" Exaggeration.") 170r: Solecism. Tr: Formal. ( 私は. "I") 
that the robbers $\underline{\text { hid }}^{18}$ in the cave, and $\underline{i t}^{19}$ made us rich. We got six thousand dollars apiece--all gold. It was an awful sight of $^{20}$ money when it was piled up. We11, Judge Thatcher he ${ }^{21}$ took it and put it out at interest, and $\underline{i t}^{22}$ fetched $^{23}$ us a dollar a day a piece all the year round--more than the robbers had hidden ${ }^{18}$ in the cave. Because of ${ }^{19}$ it we became rich. We got six thousand dollars a piece-all gold. When it was piled up, it became a mountain of ${ }^{20}$ money. We11, Judge Thatcher ${ }^{21}$ took charge of it and lent it out at interest. Because of it $^{22}$ both of us received ${ }^{23}$ a

${ }^{18}$ Or: Solecism. Tr: Formal. （かくに2あいルE,"Had hidden. ")

19 or: Subject. Tr: Adv. phrase. An explanatory and awkward expression. The sentence structure it made us rich cannot be literaliy translated into a proper Japane $\overline{s e}$ which has no such sentence structure. The emphasis on it,

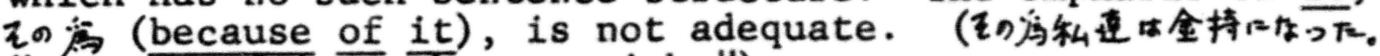
"Because of it we became rich.")

20 Or: Now colloq. slang. "A great number, quantity, or sum" (W). Tr: Colloq. (大变社金只山. "A mountain of money')

21 or: Dial. Repetition of names. Tr: Formal. No repetition.

${ }^{22}$ see n. 19.

23 or: Solecism. "To go after things and bring them back" (W). Tr: Not precise. (はい,つた. "Came in," or received.") 
a body ${ }^{24}$ could tell what to do dollar a day all through the with. The Widow Douglas she $^{25}$ year--it was more than we ${ }^{24}$ took me for her son, ${ }^{26}$ and could tell how to spend. allowed $^{27}$ she would sivilize ${ }^{28}$ The Widow Douglas ${ }^{25}$ me; but it was rough ${ }^{29}$ living adopted ${ }^{26}$ me. And she in the house all the time, considering $^{30}$ how dismal ${ }^{31} \quad$ ordinary person. ${ }^{28}$ But,

240r: Dial. "A person" (W). Tr: Omitted, as the subject is often taken for granted in Japanese: we, Tom and Huck, is naturally suggested.

${ }^{25}$ See n. 21.

26 or: colloq. "To receive into one's household for provision and care, or to adopt, as a brother's children or a father" (W). Tr: Formal. Not precise. (泰孔にする. "To adopt.")

27 or: Dial. "To have in mind as an intention; propose, intend" $(W)$. Tr: Formal. Not exact. ( $/$ T $\wedge$. "Thought," or "intended.")

28 Or: "To bring out of a condition of savagery or barbarism and instruct in the ways of an advanced society; to refine" (W). Since this is a very big word for Huck, he has a strong fear of it, saying sivilize, which is ironically misspelled. $\operatorname{Tr}$ : Very weak and not precise. (人显々の人朐. "An ordinary person.")

${ }^{29}$ Or: Colloq. "Bearing or falling hardly on a person" (OED). Tr: Formal. ("ラ י. "Hard," "painful.") $30 \mathrm{Tr}$ : Not exact. Explanatory. By cutting the sentence short and by the use of because instead of considering, the expression becomes very flat and. Loses the smooth, gentle style of the orig. (何故といい:に. "Because," "the reason is.")

31 or: Solecism. Adj. used for adv. "Woeful;

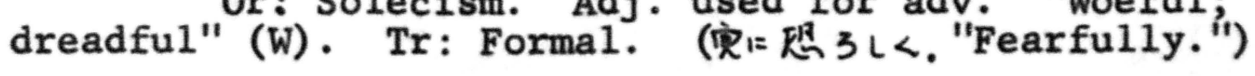


regular and decent the widow was in all her ways; and so when I couldn't stand it no longer I lit out. ${ }^{32}$ I got into my old rags and my sugar-hogshead $^{33}$ again, and was free and satisfied. But Tom Sawyer he ${ }^{35}$ hunted me up and said he was going to start a band of robbers, and I might join if I would go back to the widow and be respectable. So I went back. it was hard ${ }^{29}$ to live in the house all the time. Because $^{30}$ she was awful1y ${ }^{31}$ regular and decent in all her ways. And so when I could not stand it any longer, I lit out. ${ }^{32}$ I put on the rags again, made the sugar-hogshead a house, ${ }^{33}$ and being free, I was satisfied. 34 But Tom Sawyer $^{35}$ hunted me up, and he told me that since he was going to organize a band or robbers, I might join it if I would go back to the widow and be good. So I went back.

320r: slang. "To go away, or depart, esp. in haste" (W). Tr: Formal. (舟ひ"出す. "To go away in haste.")

${ }^{33} \mathrm{Tr}$ : Expansion, making the meaning clear. (矿糖・空 榑巨家とな⿰." "Made a sugar-hogshead my house.")

${ }^{34} \mathrm{Tr}$ : Very formal and rigid expression, contrary to the easy and colloquial expression of the original.

${ }^{35}$ See n. 21. 
The widow cried over me, and called me a poor lost lamb, and she called me a lot of

other names, too, but she never meant no ${ }^{36}$ harm by it. She put me in ${ }^{37}$ them $^{38}$ new clothes again, and I couldn't do nothing but sweat and sweat, 39 and feel all cramped up. We11, then, the old thing commenced again. The widow rung a be11 for supper, and you had ${ }^{40}$ to come to time. ${ }^{41}$ When you got
The widow cried for me. And she called me a poor lost lamb. And she called me by various other names. But she did not mean any ${ }^{36}$ harm. I was put in ${ }^{37}$ the new clothes ${ }^{38}$ again. And the sweat streamed down in me. 39 And I felt all cramped up. Then, the old thing began again. The widow rang a be11 for supper. Then

${ }^{36}$ Or: Solecism. Double negative. Tr: Formal.

${ }^{37} \mathrm{Tr}$ : The passive voice here by replacing she by me is a very proper Japanese expression, in order to avoid an awkward, clumsy expression.

${ }^{38}$ Or: Solecism. Those. $\mathrm{Tr}$ : Not translated.

${ }^{39}$ Or: Solecism. Double negative. Cf. n. 36. $\mathrm{Tr}$ :

Formal. Also emphatic sweat and sweat is well communicated by the vivid image of sweat streaming down. (だウだうと流忟. "Streamed down.")

${ }^{40} \mathrm{Tr}$ : From here down the past tense of several verbs is represented by the present tense to indicate daily routine.

41 or: Obs. "Against time" Misinterpretation. (時に危がへずに。 (W) Tr: Formal. "In time," or "on time.") 
to the table you couldn't go right to eating, but you had to wait for the widow to tuck down ${ }^{42}$ her head and grumble a little over the victuals, though there warn't $t^{43}$ really anything the matter with them--that is, nothing on $1 y^{44}$ everything was cooked by itself. In a barrel of odds and ends it is different; things get mixed up, and juice kind of $^{45}$ swaps $^{46}$ around, and the things go better. ${ }^{47}$ you have ${ }^{40}$ to go on time. ${ }^{41}$ When you get to the table, you cannot start to eat at once. You have to wait for the widow to $\underline{\text { lower }}^{42}$ her head and grumble something on the victuals. Though there was not ${ }^{43}$ really anything the matter with them-that is, nothing wrong except that ${ }^{44}$ everything was cooked by itself. In the barrel of odds and ends it is different. Things are mixed up. The juice $\underline{\text { is }}$

420r: "To thrust into a place where it is snugly held" (W. OED). This word is strange and out of place here, for bow is the normal term. Tr: Formal. Not precise. ( $\overline{\sigma^{\prime \prime} 3}$. "Lower down," "incline the head.")

43 Or: Solecism. Tr: Formal. that.")

${ }^{44}$ Or: Solecism. Tr: Formal. (ミとだけで. "Except

45 or: colloq. "In a way; somewhat" (W). Tr: Not translated.

(交换. "Ex: Colloq "To exchange" (W). Tr: Formal.

47 or: Colloq. "To outbid, surpass; to exceed" (W). Tr: Formal. ( 
After supper she got out her book $^{48}$ and learned 49 me about Moses and the Bulrushers, 50 and $I$ was in a sweat $^{51}$ to find out all about him; ${ }^{52}$ but by and by she let it out $^{53}$ that Moses had been dead a considerable long time $;^{54}$ so then I didn't care no ${ }^{55}$ more about him, exchanged. ${ }^{46}$ And it tastes better. 47

After supper she took out her $\underline{B i b l e}^{48}$ and taught $^{49}$ me about Moses and the Bulrushes. ${ }^{50}$ And I was impatient $^{51}$ to find out all about the story. ${ }^{52}$ But by and by she said ${ }^{53}$ that Moses had been dead a long, long time ago. ${ }^{54}$ So then I did not care $\underline{\text { any }}^{55}$ more about

${ }^{48} \mathrm{Tr}$ : Expansion, mentioning the name of the book. ( 耳聖 t. "Bible.")

49 Or: Now vulgarism. "To teach" (W). Tr: Formal. (数 १3. "To teach.")

50 Or: Solecism. Bulrushes. Tr: Formal. (華. "the bulrush.")

51 Or: "A state of impatience" (OED). Colloq. To undergo suffering, of anxiety (W). Tr: Formal. (嵝br "Be impatient.")

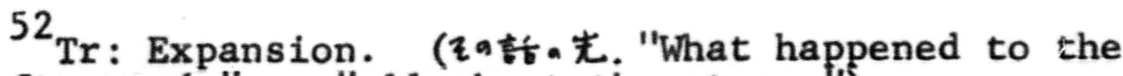
story afterward," or "all about the story.")

53 or: Colloq. "To tell something; to speak out" (W). $\operatorname{Tr}$ : Formal. ( $\mathrm{c}$. . "To tell.")

54 or: Solecism. "Considerably" (W). Tr: Colloq. A good Japanese expression. ( ${ }^{55}$ See n. 36 . 
because I don't take no stock $\underline{\text { in }}^{56}$ dead people.

Pretty soon I wanted

to smoke, and asked the widow

to let me. But she wouldn't.

She said it was a mean

practice $^{57}$ and wasn't clean,

and I must try to not do ${ }^{58}$

it any more. That is just

the way with some people.

They get down on ${ }^{59}$ a thing when $^{60}$ they don't know

nothing about it. Here she

was a-bothering ${ }^{61}$ about Moses, which was no kin to her, and him. For I have nothing to do with $^{56}$ the dead.

Very soon, I wanted

to smoke. And so I asked

the widow to let me. But

she would not allow me.

She said that it was a mean habit $^{57}$ and was not clean. And I should try not to ${ }^{58}$ smoke any more. There are often some people who behave like that. When 60 they do not know anything about it, they condemn ${ }^{59}$ it. Here this widow is

56 or: "To give faith or credence to" (W). Tr:

Misinterpretation. (用 $12 r_{2} 1$. "Nothing to do with.")

$57 \mathrm{Tr}$ : Not precise. ( Habit.")

58 or: Solecism. Split infinitive. Tr: Formal.

59 or: colloq. "To dislike and treat harshly" (W).

$\operatorname{Tr}$ : Colloq. (

60 Or: Although (W). Tr: Misinterpretation. (... 時 $1:$. "At the time when.")

${ }^{61}$ or: Colloq. \& Dial. Tr: Formal. 
no use to anybody, being gone, bothering $^{61}$ about Moses who you see, ${ }^{62}$ yet finding a power was not kin to her and, of $^{63}$ fault with me for doing a being dead, no use to anything $^{64}$ that had some good in body, and she blames ${ }^{63}$ me it. And she took snuff, too; for the smoking ${ }^{64}$ which has of course that was all right, some good in it. Moreover because she done ${ }^{65}$ it herself. she takes snuff. Of course it is all right. Because she does ${ }^{65}$ it herself.

Her sister, Miss Watson, a tolerable ${ }^{66} \mathrm{slim}$ old maid, with goggles on, had just come to live with her, and took a set $\underline{\text { at }}^{67}$ me The Widow's sister, Miss Watson, who was a very $^{66}$ slim, old maid with goggles on, had just come to live with her, and she

62 Or: Conventional speech without any meaning. $\operatorname{Tr}$ : Not translated.

63 or: Colloq. \& Dial. "A great number of; abundance" (W). Tr: Formal. ( ${ }^{64} \mathrm{Tr}$ : Expansion. It is also a very formal word. ( 喓煌. "Smoking.")

${ }^{65}$ Or: Solecism. Tr: Formal.

66 or: Dial. of tolerably. "Moderately agreeable; merely acceptable" (W) Tr: Formal. Not precise. (传分气. "Very.")

${ }^{67}$ Or: obs. "Wager, a pointed attack" (W) $\operatorname{Tr}$ :

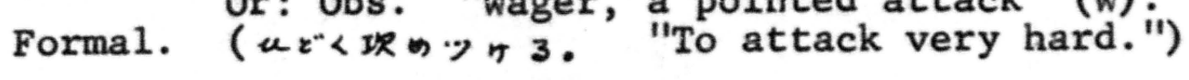


now with a spelling-book.

She worked me middling 68

hard for about an hour, and

then the widow made her ease

up. I couldn't stood ${ }^{69}$ it

much longer. Then for an

hour it was deadly ${ }^{70}$ dull,

and I was fidgety. Miss

Watson would say, "Don't put

your feet up there Huckle-

berry;" and 'Don't scrunch up

like that, Huckleberry--set

up straight;" and pretty soon

she would say, "Don't gap and

stretch like that, Huckle-

berry--why don't you try to

behave?" Then she told me all

about the bad place, ${ }^{71}$ and I attacked $^{67}$ me very hard with a spelling-book. She worked me pretty ${ }^{68}$ hard for an hour. And then the widow made her ease up. I could not stand ${ }^{69}$ it any longer. Then for an hour it was very $^{70}$ dull. And I was fidgety. Miss Watson would say, "Don't put your feet up there, Huckleberry.' "Don't scrunch up like that, Huckleberry--sit up straight." And pretty soon she would say again, "Don't gap and stretch like that, Huckleberry--why don't you try to behave?" Then she

68 Or: Dial. "Moderately, rather" (W). Tr: Formal. Not precise. (相賞 $u$ 七" $<$. "pretty hard.")

${ }^{69}$ Or: Solecism. Could not stand. Tr: Formal.

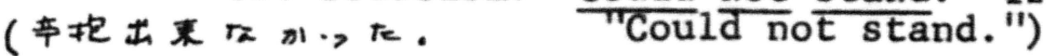

70 or: "Extremely; excessively; terribly" (W). Tr: Not strong enough. ( $u \in "<$. "Very")

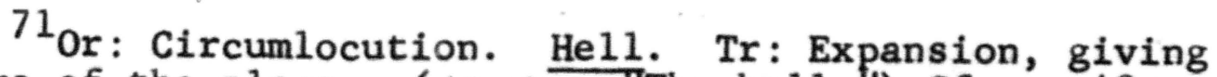
the name of the place. ( te 独, "The hell.") Cf. n. 48 . 
said I wishes I was ${ }^{72}$ there. She got mad then, but I didn't mean no harm. Al1 I wanted $^{73}$ was to go somewheres ; ${ }^{74}$ all I wanted was a change, I warn't particular. ${ }^{75}$ She said it was wicked ${ }^{76}$ to say what I said; and said she wouldn't say it for the whole world; $\underline{\underline{\text { she }}}^{78}$ was going to live so as to go to the good place. ${ }^{79}$ Well, I couldn't see no advantage in going where she was going, told me all about the hel1. ${ }^{71}$ And I said I wished I were ${ }^{72}$ there. Then she got mad. Though I did not mean any harm. What I wanted $^{73}$ was merely to go somewhere. ${ }^{74}$ Al1 I wanted was only a change. ${ }^{75}$ Any place suited me if it is somewhere else. She said it was very $\underline{\text { bad }}^{76}$ to say what I said. She said she would not say it for whatever happens. She said ${ }^{77} \underline{\text { she }}^{78}$

\section{0r: Solecism. I wish I were. $\operatorname{Tr}$ : Formal.}

${ }^{73} \mathrm{Tr}$ : A literal translation makes a very clumsy, poor Japanese expression. (私a欲 $(\pi a / x$. "What I wanted.")

74 or: Dial. Somewhere. $\operatorname{Tr}$ : Formal.

${ }^{75} \mathrm{Tr}$ : Expansion. Repetition of "al1 I wanted" is

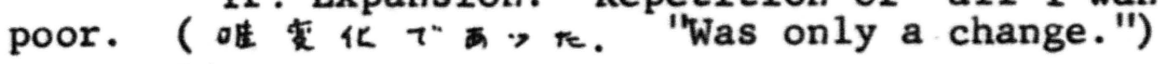

76 or: "Morally bad; evil in character, conduct, principle" (W). Tr: Not precise. ( "wrong.")

${ }^{77} \mathrm{Tr}$ : The repetition of she said because of cutting the sentence too short produces a clumsy sentence.

78 Or: Italicized to indicate the emphasis. $\mathrm{Tr}$ : Not italicized, although it is quite possible to do so.

${ }^{79} \mathrm{Tr}$ : Expansion, indicating the name of the place. (天国. "The heaven.") Cf.n. 71 . 
so I made up my mind I wouldn't try for it. But I never said so, because it would only make trouble, and wouldn't do no good.

Now she had got a start, ${ }^{80}$ and she went on ${ }^{81}$ and told me all about the good place. ${ }^{82}$ She said all a body $^{83}$ would have to do there was to go around all day long with a harp and sing, forever and ever. ${ }^{84}$ lived in order to go to the heaven. ${ }^{79}$ Well, there is no advantage in going where she was going. So I made up my mind I would not try it. But I never said so. Because it would only make trouble and would not do any good.

$$
\text { Now, opening her }
$$
mouth, 80 she told me all about the heaven. ${ }^{82}$ She said what everybody ${ }^{83}$ had to do in the heaven was to go around all day long with a harp, singing for eternity. ${ }^{84}$ So I did not

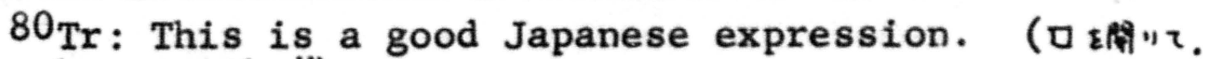
"Opening her mouth.")

${ }^{81}$ Or: Colloq. "Keep talking" (W). Tr: Omitted as an unnecessary sentence.

$$
{ }^{82} \text { See n. } 71 ; \text { n. } 79 .
$$

830r: Dial. "A person" (W). Tr: Formal. Clumsy, because of its emphasis. (几てa人ふ". "Everybody," "all the people.")

${ }^{84}$ Or: Rather conversational. Emphatic. Tr: Formal. Weak. ( $\mathrm{k}^{\mathrm{i}} \mathrm{i}$. "For eternity.") 
So I didn't think much of it. But I never said so. I asked her if she reckoned ${ }^{85}$ Tom Sawyer would go there, and she said not by a considerable sight. ${ }^{86}$ I was glad about that, because I wanted him and $\mathrm{me}^{87}$ to be together. Miss Watson she $^{88}$ kept pecking $\underline{a t}^{89} \mathrm{me}$, and it got tiresome and lonesome. By and by they fetched 90 the niggers $^{91}$ in and had prayers, think it a very good place. But I never said so. I asked her if Tom Sawyer would go there. She said he would never ${ }^{86}$ go there. I was glad to hear that. For I wanted both of us ${ }^{87}$ to be together. Miss Watson ${ }^{88}$ kept complaining to ${ }^{89} \mathrm{me}$. And then it became tiresome and lonesome. By and by they brought $^{90}$ the niggers ${ }^{91}$ in Omitted.
85 or: colloq.
"To think; suppose"
(W). $\operatorname{Tr}$ :

${ }^{86}$ Or: Now Colloq. Slang. "A great number, quantity or sum" (W). Tr: Formal. Not precise. (沠 ᄂ ?. "Never.") Cf. n. 20 .

${ }^{87} \mathrm{Tr}$ : Explanatory. ( =人て". "Both of us.")

${ }^{88}$ Or: Dial. Repetition. Tr: Formal. Cf. n. 21.

89 or: Colloq. "To criticize or find fault with constantly. Has the image of striking with a beak or with a petty, repeated blow" (W). $\operatorname{Tr}$ : Colloq. Weli reproduced.

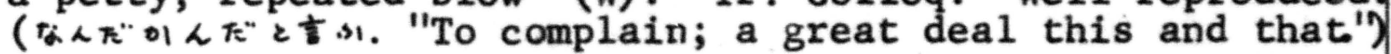
90 See p. 147, n. 23.

910r: Colloq. "Derogatory" (W). Tr: Colloq. Although there is not one Negro in Japan, there is a word pertaining to its race, but it does not have the same connotation as U.S. (黑ん坊. "Nigger.") 
and then everybody was off to bed. I went up to my room with a piece of candle, and put it on the table. Then I set $^{92}$ down in a chair by the window and tried to think of something cheerful, but it warn't no use. ${ }^{93}$ I felt so ${ }^{94}$ lonesome I most ${ }^{95}$ wished I was $^{96}$ dead. The stars were shining, and $^{97}$ the leaves rustled $^{98}$ in the woods ever so $^{99}$ mournful; ${ }^{100}$ and I and had prayers. Then everybody went to bed. I went up to my room with a candle and put it on the table. Then I sat ${ }^{92}$ down in a chair by the window and I tried to think of something cheerful. But it was no use. ${ }^{93}$ I was so lonesome that ${ }^{94}$ I almost ${ }^{95}$ wished I were dead. 96 The stars were shining. And 97 the leaves rustled zawa-

920r: Dial. Sat. Tr: Formal. ( 婹部. "Sat down.")

930r: Solecism. Double negative. $\operatorname{Tr}$ : Less formal. (吠目E"., E. "Wasn't good.") Cf. p. 150, n. 36 .

940r: Colloq. So...(that). Tr: Formal. ( $k 2 t \ldots$... i.. "So...that.)

950r: Colloq. \& Dial. Almost. Tr: Formal. ( ほそ". "Almost; as much as.")

${ }^{96}$ See n. 72.

97 Tr: From here this sentence is broken into many short sentences, greatly reducing the effect of the beautiful description of original.

98 $\mathrm{Tr}$ :ざわ゙か(Zawa-zawa) is a Japanese figurative expression of rubbing sounds, as of leaves, papers, cloth, etc., being moved about.

${ }^{99}$ Or: Very intensive and poetic. Tr: Very weak. (とても."Very.")

100 or: Solecism. Mournfully. Has a poetic quality.

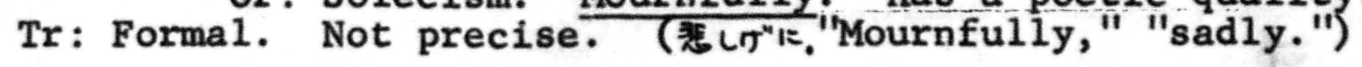


heard an owl, away off, whowhooing $^{101}$ about somebody that was dead, and a whippowill and a dog crying about somebody that was going to die; and the wind was trying to whisper scmething to me, and I couldn't make out what it was, and so it made the cold shivers run over me. ${ }^{103}$ Then away out ${ }^{104}$ in the woods I heard that kind of a sound that a ghost makes when it wants to tell about something that's on its mind ${ }^{105}$ and can't make itself understood, and so can't rest easy zawa $^{98}$ in the woods very ${ }^{99}$ mournfully. 100 And I heard an owl who-whooing far away. It was crying about somebody who was dead. And I heard ${ }^{102}$ a whippowill and a dog crying for somebody who was going to die. And the wind was trying to whisper something to me. But I could not make out what it was. It made me shiver all over zoku-zoku. 103 And then, far away from ${ }^{104}$ the wood, I heard that

$101 \mathrm{Tr}$ : Expansion. Weakens the stylistic quality. Cf. n. 97.

${ }^{102}$ See n. $97 ;$ n. 101.

${ }^{103} \operatorname{Tr}: \bar{\tau}\langle\cdot<$ (Zoku-zoku) is a Japanese figurative expression of shaking or trembling all through the body as of fear or cold. Cf. n. 98 .

${ }^{104} \mathrm{Tr}$ : Misinterpretation. (絭のずっと向いに, "Far away from the woods," or "beyond the woods.")

$105 \mathrm{Tr}$ : A clumsy expression because of its literal translation. (zas 12113 何事》 $E$. "What it is thinking; the thing in its mind.") 
in its grave, and has to go about that way every night grieving. I got so ${ }^{106}$ downhearted and scared I did 107 wish I had some company. Pretty soon a spider went crawling up ${ }^{108}$ my shoulder, and I flipped it off and it lit in the candle; and before I could budge bu $^{109}$ it was all shriveled up. 110 I didn't need anybody to tell me that that was an awful bad sign and would $\underline{\text { fetch }}^{111}$ me some kind of a sound that a ghost makes when it wants to tell about something in its mind which ${ }^{105}$ it cannot make itself understood and so it cannot rest still in its grave, and it has to go about like that, grieving every night. I was so ${ }^{106}$ downhearted and scared that I wished ${ }^{107}$ I had had somebody here. Pretty soon a spider went crawling mozo$\underline{\text { mozo }}^{108}$ up my shoulder.

${ }^{106}$ See n. 94.

${ }^{107} \mathrm{Tr}$ : Emphasis did is not translated. Cf. n. 78.

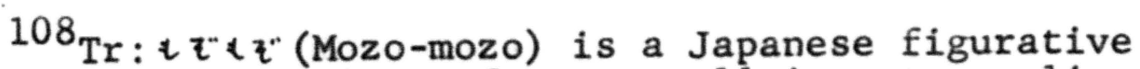
expression of the feeling of some small insect crawling up on the body. Cf. n. 98 ; n. 103 .

${ }^{109} \mathrm{Tr}$ : A good translation, expressing a very short length of time within a sound of an exclamation of surprise. (あっと思旅涪に。 "In a second.")

${ }^{110} \mathrm{Tr}$ : Adv. 5"5"3" (gi-gi-gi) is a Japanese figurative expression of the sound of being shrivelled up by the fire. Cf. n. 108.

$111_{\text {See n. } 23 .}$ 
bad luck, so I was scared and most $^{112}$ shook the clothes off of me. I got up and turned around in my tracks three times and crossed my breast every time; and then I tied up a little lock of my hair with a thread to keep witches away. But I hadn't no confidence. 113
When I flipped it, it

jumped in the candle. In a moment . $^{109}$ it was all shriveled up gi-gi-gi. 110 I did not need anybody to tell me that it was an awfully bad sign and that it would bring $^{111}$ me some bad luck. So I was scared, and shook so hard as ${ }^{112}$ the clothes would get off of me. I got up and turned around on the spot for three times and crossed my breast every time. And then, I tied up a little lock of my hair with a thread to keep witches away. But it did not seem enough. 113

\section{${ }^{112}$ See n. 95.}

$113 \mathrm{Tr}$ : Expansion. "It did not seem satisfactory.")

(大丈天とは思へなかフた。 
Chapter VI. Pap $^{1}$ Struggles with the Death Ange1 ${ }^{2}$

I got things all up to the cabin, and then it was about dark. ${ }^{3}$ While I was cooking supper the old man took a swig ${ }^{4}$ or two and got sort of ${ }^{5}$ warmed up, 6 and went to ${ }^{7}$ ripping $^{8}$ again.
Chapter VI. Pap $^{1}$ Struggles with the Death Angel ${ }^{2}$

I took everything to the cabin. Then it became dark. ${ }^{3}$ While I was cooking supper, pap took a swig ${ }^{4}$ or two, and recovered his spirit $^{6}$ a $\underline{1 i t t l e}^{5}$ and began ${ }^{7}$ to swear $^{8}$ again. Since pap

lor: Dial. "Father" (W). Tr: Dial. (攵吿 [Chan] "Pap," or "dad.")

2 Tr: Having a subject and a verb, it is an odd expression as a title of the chapter and sounds like a very literal translation. Also, the Death Angel could be improved: instead of Death Ange1, the Death God may fit better to Japanese idea.

${ }^{3} \mathrm{Tr}$ : Clumsy. This short, independent sentence destroys the smooth, conversational quality of original.

"Or: Colloq. "A long draft, or drink" (W). Tr: colloq. $(-.=$ 杯 $u$ 加 it . "One or two drink.") The verb took is rendered by colloq. Japanese. ( $u>>01$ it $\pi$. "Took.") 5 or: Colloq. "In a way; somewhat" (W). Tr:

Formal. (少し<. "A little.")

6r: Rare. "To reinvigorate; to generate enthusiasm" (M). Tr: Formal. ( $九$ 花ずく. "To reinvigorate.")

${ }^{7}$ Or: Solecism. Went ripping. Tr: Formal. (始め3. "To start.")

80r: Colloq. "To break forth into vehement, often profane, utterance" (W). Tr: Formal. ( 3 . "To swear.") 
He had been drunk over in town, and $\underline{\text { laid }}^{9}$ in the gutter all night, and he was a sight to look at. ${ }^{10}$ A body ${ }^{11}$ would ' $a$ ' thought he was Adam--he was just all mud. Whenever his 1iquor begun ${ }^{12}$ to work he most $^{13}$ always went for ${ }^{14}$ the government. This time he says: "Call this a govment! " Why, just look at it and see what it's like. Here's the had been drunken in town and slept $^{9}$ in the gutter all night, he had a very queer shape. ${ }^{10}$ People $^{11}$ would have thought that he was Adam--he was really full of mud all over. Whenever his liquor began ${ }^{12}$ to work, he almost $^{13}$ always made an attack $^{14}$ on the government. This time he says: "Call this a government: 15 Just

${ }^{9} \operatorname{Tr}$ : Expansion. (垵>でE. "Slept.")

10 or: Colloq. "Something odd, ludicrous, or the

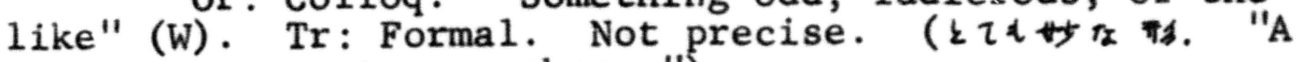
very queer or strange shape.")

11 or: Colloq. "A person"(w). Tr: Formal. (人. "People.")

120r: Solecism. Began. Tr: Formal.

130r: Colloq. \& Dial. Almost. Tr: Formal.（大抵. "Almost.")

14 or: Colloq. "To attack" (W). Tr: Formal. (㓚草む3. "To attack.") Particularly formalized as a written language by making a noun phrase. (政府攻率. "An attack on the government.")

15 Or: Solecism. Spelled according to pap's pronunciation. Tr: Formal. Characteristics of pap's pronunciation do not appear in translation. 
law a-standing ${ }^{17}$ ready to take look at it and see what a man's son away ${ }^{18}$ from him ${ }^{19}$-- it's like, without fail. ${ }^{16}$ a man's own $\underline{\text { son }}^{20}$ which $^{21}$ he has had all the trouble and all the anxiety and all the expense of raising. Yes, 22 just as that man has got that son raised at last, and ready to go to work and begin to do suthin' ${ }^{23}$ for him $^{24}$ and Here is a law ready ${ }^{17}$ to tear a man's son off ${ }^{18}$ from pap $^{19}$--his own son, 20 for whom ${ }^{21}$ he has had all the troubles and all the anxiety and all the expense of raising. Yes, ${ }^{22}$ just when his father has got

${ }^{16} \mathrm{Tr}$ : Colloq. (ち*んと. "Exactly," "without fail.")

170r: Colloq. \& Dial. Standing. Tr: A good expres-

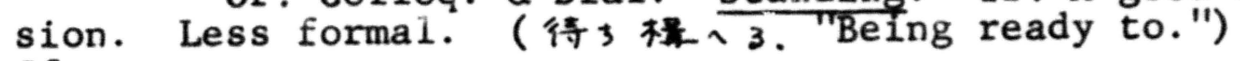
Cf.

${ }^{18} \mathrm{Tr}$ : A good, strong word. ( break off, pick off fruits, leaves, etc.")

${ }^{19} \mathrm{Tr}$ : Colloq. (竌攵 [ Oyaji]. "Dad," or "pap.") A vulgar usage of father. Though often used in conversation without any respect for father, it is seldom used in the formal writing or speech. Huck's father is very likely to use it.

${ }^{20} \mathrm{Tr}$ : Colloq. or less formal. (恔. "Son.") This is less formal usage often used by fathers, particularly when they refer to their sons.

$21_{\mathrm{Tr}}$ : Colloq. (z"). "He" or "it.") A colloquial, vulgar expression of the masculine third person pron.; sometimes for pron. it.

${ }^{22} \mathrm{Tr}$ : Emphasized. (‡うた". "Yes," or "Yes, sir.") "Be of use.")

23 or: Solecism. Something. Tr: Formal. (役に立》。 ${ }^{24}$ Or: Italicized. Tr: Not italicized. 
give him $^{25}$ a rest, the law up and goes for him. ${ }^{26}$ And they call that ${ }^{27}$ govment! ${ }^{28}$ That ain't all, nuther. ${ }^{29}$ The law backs that old ${ }^{30}$ Judge Thatcher up and helps him to keep me out o' my property. Here's what the law does: ${ }^{31}$ The law takes a man worth six thousand dollars and up'ards, and jams him into an old his son raised at last, ready to go to work, and begin to do something ${ }^{23}$ for $\underline{\text { him }}^{24}$ and give pap ${ }^{25}$ a rest, the law comes and prevents it. ${ }^{26}$ And they call it $^{27}$ government: ${ }^{28}$ But, that's not all. 29 The law backs that blamed $^{30}$ old Judge up and helps him to keep me out of my property. This

\section{${ }^{25} \operatorname{Tr}$ : See n. 19.}

26 Or: Personification. Tr: Colloq. Very precise. ( $\left.\varepsilon^{n} y=1\right)$. "A shouting loudly to prevent other's action or behavior.") Here it means that you cannot do so easily as you thought you could.

27 Or: Italicized for emphasis. Tr: Not italicized and weakened. Cf. n. 24.

${ }^{28}$ See n. 15.

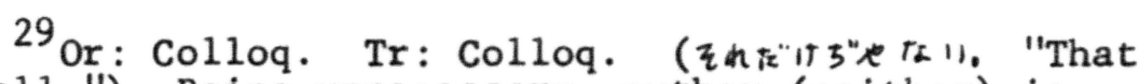
ain't all.") Being unnecessary, nuther (neither) is omitted.

${ }^{30} \mathrm{Tr}$ : Colloq. (老查 [ Oibore]. "Damned old." This is used when one is mad with some old man or woman.

$31 \operatorname{Tr}$ : Japanese has neither colon, nor semi-colon, so replaced by that is here. 
trap $^{32}$ of a cabin like this, and lets him go round in clothes that ain't fitten 33 for a hog. They call that govment! A man can't get his rights in a govment like this. Sometimes I've ${ }^{34}$ a mighty notion to just leave ${ }^{35}$ the country for good and all. ${ }^{36}$ Yes, and I told ${ }^{37}$ 'em $^{38}$ so; I told old Thatcher so to is what the law does. That is,$^{31}$ the law takes six thousand and some hundred dollars from the man, jams him into such a cabin as this trap $^{32}$ and lets him go around in such clothes that are not fitted ${ }^{33}$ even for a hog. They call it government! People can not get his rights in a government

\section{2 or: slang. "A contemptuous term applied to any-} thing old or worn out". (Wr). Tr: Incorrect. (察口よj/ . "Like a trap.")

${ }^{33}$ or: Solecism. Fit. $\operatorname{Tr}$ : Formal. (似合的", "Not fit.")

${ }^{34} \mathrm{Tr}$ : The personal pron. I 供 (Ore), in pap's speech, is a colloquial, vulgar expression, which is quite different from $x_{4}$ (Watakushi, or watashi) of Huck's. This will determine the tone of pap's speech. This is not, however, too vulgar like (Ora) as Jim uses, and 值 (Ore) is sometimes used even among well-educated people.

${ }^{35}$ Or: Solecism. Split infinitive. Tr: Formal.

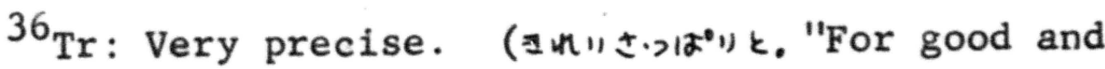
a11.")

${ }^{37}$ See n. $27 ;$ n. 24.

${ }^{38} \mathrm{Tr}$ : Colloq. Very precise. (zוl) ל. "They." A very rude, vulgar expression of the third person plural pron. they. 
his face. Lots of 'em heard me, and can tell what I said. Says $I^{39}$ for two cents I'd leave the blamed ${ }^{40}$ country and never come a'near it ag'in. Them's the very words. ${ }^{41}$ I says, look at my hat--if you call it a hat--but the lid raises up ${ }^{42}$ and the rest of it goes down till it's below my chin, and then it ain't rightly a hat at all, but more like my head was shoved up through a jint ${ }^{43} \mathrm{o}^{\prime}$ stovepipe. Look at it, says $\underline{I}^{44}$.- like this. Sometimes $\underline{I}^{34}$ have a wonderful notion to leave $^{35}$ the country for good and all. ${ }^{36}$ Yes. And I told ${ }^{37}$ 'em $^{38}$ so. I told old man, Thatcher, so to his face. A lot of them heard me. And I can tell what I said. I say. ${ }^{39}$ For two cents I would leave this hateful ${ }^{40}$ country and never come back again. $\underline{I}$ said these very words. ${ }^{41}$ I say. Look at my hat-if you can call it a hat--

${ }^{39} \mathrm{Tr}$ : Inversion of says I is impossible in Japanese. Also I say is cut off by the period, which makes its modifier very obscure and very clumsy.

40 or: colloq. Condemned; confounded (W). Tr:

Formal. Not precise. (枝 $r_{\alpha}$. "Hateful.")

${ }^{41}$ Or: Solecism. Very emphatic. Tr: Formal.

Emphatic. (そくりこム通り. "These very word.")

42 or: Solecism. Is raised up. $\operatorname{Tr}$ : Formal. (持了上供 3 . "Is raised up." )

${ }^{43}$ or: Solecism. Joint. $\mathrm{Tr}$ : Formal. ( "Joint.")

${ }^{44}$ See n. 39. 
such a hat for me to wear--one|but the lid is raised $^{42}$ of the wealthiest men in this and the rest of it goes town if I could git my rights. down below my chin. It is not a hat at all. It is just as if my head were shoved up through a joint ${ }^{43}$ of stovepipe. Look at it,

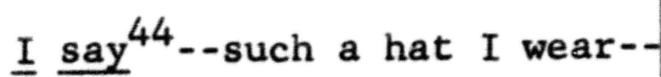
I am one of the wealthiest men in this town if I could get my rights. 
Chapter VIII. I Spare Miss

Watson's Jim.

"Well, you see, it 'uz dis $^{2}$ way. 01 e missus ${ }^{3}$--dat's Miss Watson--she pecks on me all de time, $\underline{e n}^{4}$ treats me pooty $^{5}$ rough, but she awluz ${ }^{6}$ said she wouldn' sell $\mathrm{me}^{7}$ down to Oreleans. But I noticed dey $^{8}$ wuz a nigger
Chapter VIII. I Spare Miss Watson's Jim.

"We11, my dear, it was $^{1}$ this $^{2}$ way. 01d missis ${ }^{3}$ --that is Miss Watson--pecks at me all the time. She does it very ${ }^{5}$ hard. But she always ${ }^{6}$ said she wouldn't sell me ${ }^{7}$ down to Oreleans. But very ${ }^{10}$ lately

${ }^{1}$ or: Solecism. Spelled according to Jim's pronunciation, showing his illiteracy. Was is spelled either 'uz, or wuz. Tr: Formal. Very close to the standard Japanese. Has very little variations of the inflections of verbs, and could hardly be called dialectic or colloquial. The only difference is adding da to each inflection. ( $r_{\alpha}$ a $\kappa^{\prime \prime} \alpha$. "Was this way.")

20r: Solecism. That. Th is always pronounced $\underline{d}$ by Jim. Tr: Formal. (

3 Or: Solecism. Very often the last word is not pronounced. Tr: Formal. (光 $甘$ 衣 "Old missis.")

${ }^{4}$ Or: Solecism. And. Tr: Not translated.

${ }^{5}$ Or: Solecism. Pretty. Tr: Formal. Not exact. ( オ“.”分. "Very.")

${ }^{6}$ Or: Solecism. Always. Tr: Formal. (始 "Al1 the time.") pronoun.

${ }^{7} \mathrm{Tr}$ : 俺 (Ora), I, is a very vulgar personal

${ }^{8}$ Or: Solecism. There. Tr: Formal. 
trader roun' de ${ }^{9}$ place considable $^{10}$ lately, en I begin to git $^{11}$ oneasy. 12 Well, one night I creeps ${ }^{13}$ to de do ${ }^{14}$ pooty late, en de do' warn't $t^{15}$ quite shet, 16 en I hear old missus tell de widder ${ }^{17}$ she gwyne to $^{18}$ sell me down to Orleans, but she didn' want there $^{8}$ wuz a nigger trader around $^{9}$ the place. And then I become uneasy. ${ }^{12}$ Wel1, one night, I crept $^{13}$ to the door $^{14}$ very late. The door warn't $^{15}$ quite shut. ${ }^{16}$ And I hear old missis tell the widow $^{17}$ she is going to ${ }^{18}$ sell me down to Orleans, but

${ }^{9}$ Or: Solecism. Often the ending is not pronounced. $\mathrm{Tr}$ : Formal. ( $\overline{\mathrm{T}} \mathrm{r}=$ !). "Around.")

${ }^{10}$ Or: Obs. exc. Dial. Considerably. Tr: Formal. ( > ". "Very.")

110r: Solecism. Began to get. Tr: Colloq. Became.

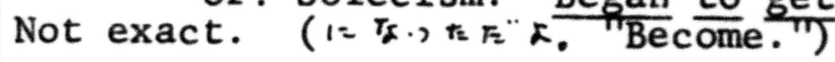

12 Or: Solecism. Uneasy. Tr: Formal. (心配次. "Uneasy.")

130r: Solecism. Crept. Tr: Formal. Not exact. ( 行, たビ." "Went.")

14 or: Solecism. The ending is omitted. Tr: Formal. ( $户$ 口. "Door; entrance.")

15 Or: Dial. Wasn't. Tr: Less formal. ( "Warn't.")

16 Or: Solecism. Shut. Tr: Formal. ( $|z \cdot\rangle\rangle$. "Shut.') "Widow.")

17 Or: Solecism. Widow. Tr: Formal. (末亡人.

${ }^{18}$ Or: Solecism. Was going to. Tr: Formal. (ふンと思〉てい3. "Is 
to, but she could git eight hund'd dollars for me, en it 'uz sich $^{19}$ a big stack ó $\underline{\text { big }}^{20}$ money she couldn' resis'. De widder she ${ }^{21}$ try $^{22}$ to git her to say she wouldn't do it, but I never waited to hear de res'. I lit out ${ }^{23}$ mighty quick, ${ }^{24}$ I tell you.

"I tuck out ${ }^{25}$ en shin $^{26}$ down de hill, en she didn't want to, but she could get eight hundred dollars for me, and it was $\underline{\text { such }}^{19} \underline{a}^{b_{i g}}{ }^{20}$ money that she couldn't resist. The widow $^{21}$ wuz trying ${ }^{22}$ to get her to say she wouldn't do it, but I ran away $^{23}$ in a great haste ${ }^{24}$ without listening to them any more.

"I jumped out ${ }^{25}$ and ran down $^{26}$ the hill. And

\section{Or: Solecism. Such. Tr: Formal. ( $<z z$.} "Such...that.")

20 Or: Colloq. "A large quantity or number" (W). Tr: Formal. ( $k$ 金. "A lot of money, "a big money.") Formal.

${ }^{21}$ Or: Solecism. Repetition of the name. $\operatorname{Tr}$ :

${ }^{22}$ Or: Solecism. Tries. Tr: Formal. Wuz is used here to indicate that all the inflections of verbs are added da, which is dialectic. (" $T=T^{\prime \prime}$. "Wuz trying.")

23 or: slang. "To depart, esp. in haste" (W). $\operatorname{Tr}$ : Formal. ( ü 5 . "To go away in haste.")

24 or: Colloq. "In a great degree; very" (W). Tr: Formal. (

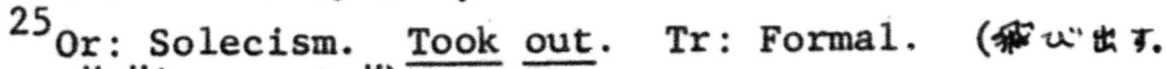
"Ran away," "jump out.") 260r: "To use one's legs; to move quickly" (OED). $\operatorname{Tr}$ : Formal. Accurate. (醉 4 F, 3. "Run down.") 
'3pec $^{27}$ to steal a $\underline{\text { skift }}^{28}$ '1ong ${ }^{29}$ de sho' som'ers ${ }^{30}$ 'bove $^{31}$ de town, but dey wuz people a-stirring 32 yit, so I hid in de ole tumbledown cooper shop on de bank to wait for everybody to go 'way. Well, I wuz dah $^{33}$ all night. Dey wuz somebody roun' all de time. 'Long 'bout six in
I'd thought ${ }^{27}$ to steal a $\underline{\text { skiff }}^{28}$ along $^{29}$ the shore somewhere $^{30}$ above $^{31}$ the town. But people in the town wuz still awake. ${ }^{32}$ so I hid in the tumbledown cooper shop on the bank, to wait for everybody to go away. We11, I wuz there ${ }^{33}$ all night. There wuz somebody around all the time.

27 Or: Solecism. Expect. Ex and $\underline{t}$ are not pro-

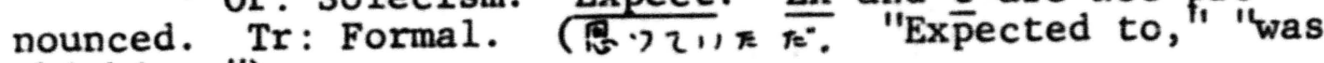
thinking. ")

${ }^{28}$ Or: Solecism. Skiff. Tr: Formal. Not exact. (小开.

${ }^{29}$ Or: Solecism. Along. A is often omitted, e.g. 'bove, 'way, 'bout. Tr: Formal.

30 or: Dial. Somewhere. $\operatorname{Tr}$ : Formal. $\left(\varepsilon^{\prime \prime}=n \neg "\right.$. "Somewhere.")

$$
31_{\text {See n. } 29 .}
$$

32 or: Colloq. \& Dial. "To be up" (W). A-stirring

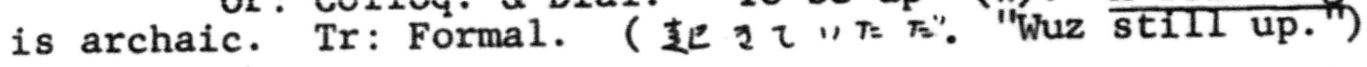
33 or: Solecism. There. Cf. dey wuz, n. 8. $\operatorname{Tr}$ : Formal. ( $(z=1$. "There."i $)$ 
de mawnin' ${ }^{34}$ skifts begin to go by, en 'bout eight er ${ }^{35}$ nine every skift dat went 'long wuz talkin' 'bout how

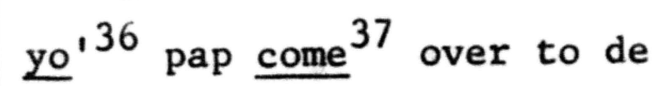
town en say you' $\underline{s}^{38}$ killed. Dese las' skifts wuz full o' ladies en genlmen a-goin' 39 over for to see de place. ${ }^{40}$ Sometimes $^{41}$ dey'd pull up at de sho' en take a res' $\underline{b}$ 'fo $^{142}$ dey started acrost, ${ }^{43}$
About six in the morning skiff began to go by. And about eight or ${ }^{35}$ nine every skiff that passed wuz talking about how your ${ }^{36}$ pap came $^{37}$ over to the town and said you were ${ }^{38}$ killed. These last few skiffs wuz full of women and men going $^{39}$ over to see the actual place. ${ }^{40}$ For a while $^{41}$ they pulled up at

${ }^{34}$ Or: Solecism. Morning. Tr: Formal. ( $\mathbf{T l}$. "Morning.")

${ }^{35}$ Or: Solecism. Or. Tr: Formal. (

${ }^{36}$ Or: Solecism. Your. $\operatorname{Tr}$ : Formal. あんた (Anta) you is a colloquial expression of $\frac{1}{\lambda}$ (Anata) you which is a respectable personal pron.

${ }^{37}$ Or: Solecism. Came. Tr: Formal. ( killed.")

38 or: Solecism. Tr: Formal. ( 积 I た. "Were

${ }^{39}$ See n. 32.

${ }^{40} \mathrm{Tr}$ : Formal. Explanatory. (现 场. "The actual place.")

$41_{\mathrm{Tr}}$ : Incorrect. (レボくく. "For a while.")

${ }^{42} \mathrm{Tr}$ : Expansion. (それか子. "Then.")

${ }^{43}$ or: Solecism. Across. Tr: Formal. 
so by de talk I got to know all 'bout de killin', I 'uz powerful $^{44}$ sorry you's killed Huck, but I ain't $\underline{n o}^{45} \mathrm{mo}^{\prime}$ now.

"I laid dah under de shavin's ${ }^{46}$ all day. I 'uz hungry, but I warn't afeard $^{47}$ bekase $^{48}$ I knowed $^{49}$ ole missus en de widder wuz goin' to start to de camp-meet'n right the shore and taken a rest, and then $^{42}$ they started across. ${ }^{43}$ So by the talk I got to know all about the killing. I was very ${ }^{44}$ sorry you were killed, Master Huck. But I ain't ${ }^{45}$ so sorry any more.

"I laid there under the shavings ${ }^{46}$ all day. I wuz hungry, but warn't afraid. $^{47}$ The reason ${ }^{48}$ wuz that the old missis and the widow were going to the camp-meeting soon

( $\iota^{44}$ "Or: Chiefly Illit. "Mighty" (W). Tr: Formal. ( $飞 て も$ "Very.")

45 Or: Solecism. Double negative. Tr: Formal.

46 Or: Solecism. Ing is often abbreviated into in', 'n'. Tr: Formal.

47 Or: Archaic \& Dial. "Afraid" (W). Tr: Formal. ( 怖くは. "Afraid.")

48 Or: Solecism. Tr: Formal. (そのかルル゙. "The reason was.")

${ }^{49}$ Or: Solecism. Tr: Formal. This is omitted. 
$\operatorname{arter}^{50}$ breakfas' en be gone all day, en dey knows $^{51}$ I goes $^{52}$ off wid de cattle 'bout daylight, so dey wouldn' 'spec ${ }^{53}$ to see me roun' de $^{54}$ place, en so dey wouldn' miss me tel1 ${ }^{55}$ after dark in de evenin'. De yuther $^{56}$ servants wouldn' miss me, kase $^{57}$ dey'd shin out en take holiday soon as de ole folks ${ }^{58}$ 'uz out'n de way. after $^{50}$ the breakfast, and they knew $^{51}$ I go ${ }^{52}$ out with the cattle about daylight. So they wouldn't expect ${ }^{53}$ to see me around the ${ }^{54}$ house. So they wouldn't notice my absence till ${ }^{55}$ after the dark in the evening. The other ${ }^{56}$ servants wouldn't notice it either. Because $^{57}$ they go out and take holiday as soon as their $^{\text {masters }}{ }^{58}$ was out of sight.

50 Or: Solecism. After. Tr: Formal.

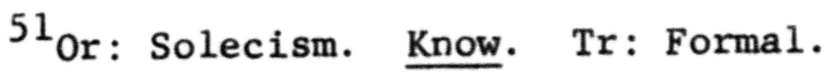

52 Or: Solecism. Go. $\operatorname{Tr}$ : Formal. Cf. n. 38.

53 see n. 27.

${ }^{54}$ See n. 9.

550r: Solecism. Till. Tr: Formal. (までは."Till.")

56 Or: Solecism. Other. Tr: Formal. (他,."Other.")

57 Or: Solecism. Because. Tr: Formal. (そのわり. "The reason.")

$58 \mathrm{Tr}$ : Not exact and explanatory. (主人 $t 5$. "Masters," or "hostesses.") 
University Libraries

University of Missouri

Digitization Information for Theses and Dissertations project. Scanned from microfilm; no subsequent editing done.

Local identifier

Source information

Identifier

Format

Content type

Notes

Capture information

Date captured

Scanner manufacturer/model ScanPro 3000 /e-ImageData

Scanning software

Optical resolution

Compression

Color settings

File types

Notes

Derivatives - Access copy

Editing software

Resolution

Color

File types

Notes
Nakada1958

Microfilm reel\# T1958-52-T1958-58

Microfilm

Text

2019

PowerScan $3000(\mathrm{TM})$ v5.341

$600 \mathrm{dpi}$

LZW

bitonal

tiff

Scanned from microfilm; no editing done.

Photoshop

600 dpi

grayscale

pdf

Converted from tiff to pdf using Adobe Acrobat Pro DC. 